\title{
ENERGY USE IN POLAND, 1970-1991: SECTORAL ANALYSIS AND INTERNATIONAL COMPARISON
}

\author{
Stephen Meyers, Lee Schipper, Jürgen Salay \\ Energy Analysis Program \\ Energy and Environment Division \\ Lawrence Berkeley Laboratory \\ University of California \\ Berkeley, CA 94720
}

With

A. Gromadzinski, E. Hille, P. Kaleta, * M. Kumanowski, **

J. Maron, J. Norwisz,* S. Pasierb

Polish Foundation for Energy Efficiency (FEWE)

*Polish Academy of Sciences

**Energy Information Center, Ministry of Industry and Trade

July 1993

This work was supported by the Office of Environmental Analysis, Office of Policy, Planning, and Program Evaluation, U.S. Department of Energy, through the U.S. Departrnent of Energy Contract No. DE-AC03-76SF00098. 


\begin{abstract}
This report provides an analysis of how and why energy use has changed in Poland since the 1970s, with particular emphasis on changes since the country began its transition from a centrally planned to a market economy in 1989. The most important factors behind the large decline in Polish energy use in 1990 were a sharp fall in industrial output and a huge drop in residential coal use driven by higher prices. The structural shift away from heavy industry was slight. Key factors that worked to increase energy use were the rise in energy intensity in many heavy industries and the shift toward more energy-intensive modes of transport. The growth in private activities in 1991 was nearly sufficient to balance out continued decline in industrial energy use in that year.

We compared energy use in Poland and the factors that shape it with similar elements in the West. We made a number of modifications to the Polish energy data to bring it closer to a Western energy accounting framework, and augmented these with a variety of estimates in order to construct a sufficiently detailed portrait of Polish energy use to allow comparison with Western data. Per capita energy use in Poland was not much below W. European levels despite Poland's much lower GDP per capita. Poland has comparatively high energy intensities in manufacturing and residential space heating, and a large share of heavy industries in manufacturing output, all factors that contribute to higher energy use per capita. The structure of passenger and freight transportation and the energy intensity of automobiles contribute to lower energy use per capita in Poland than in Western Europe, but the patterns in Poland are moving closer to those that prevail in the West.
\end{abstract}




\section{Table of Contents}

Page

INTRODUCTION .............................................................................................................. $1-1$

OVERVIEW OF TRENDS ................................................................................................. $\quad 2-1$

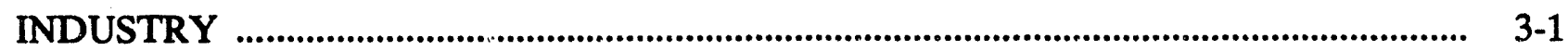

TRANSPORT …..........................................................................................................

OTHER CONSUMERS ....................................................................................... $5-1$

ENERGY TRANSFORMATION .......................................................................................... 6-1

INTERNATIONAL COMPARISON ................................................................................ 7-1

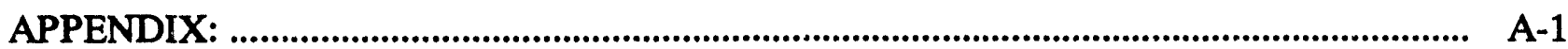




\section{ACKNOWLEDGEMENTS}

Adam Gula of FEWE provided comments and insight in the course of the study. Mieczyslaw Kwiatkowski of the Polish Power Grid Company kindly provided data and clarified issues regarding electricity use. We also ackowledge comments received from Stanislaw Chyrczakowski of the Institute of Fundamental Technological Research of the Polish Academy of Sciences, Paul Komor of the U.S. Congress Office of Technology Assessment, Kevin Fitzgerald of the Wharton School of Economics, and from Ruth Steiner and Steve Greenberg of LBL. Charles Campbell of LBL prepared the graphs for this report. 


\section{INTRODUCTION}

Poland has been in the midst of a profound transformation since the end of the communist era in 1989. Along with Hungary and the Czech Republic, Poland is the furthest along in political and economic reform among the countries in Eastern Europe. The largest of these three countries, Poland adopted a more radical economic reform program than Hungary and began earlier than Czechoslovakia.

The changes in the economy have already had an important impact on energy use in Poland, which primarily relies on coal. One of the characteristics of the Polish energy economy under communist rule was the great inefficiency with which energy was used in many areas. While improvement in energy efficiency is not the main factor determining how well the Polish transformation will succeed, it is certainly an important element in increasing industrial productivity and reversing the degradation of the environment. Reducing air pollution from energy production and use is an importast part of the government's energy policy.

This report provides an analysis of how and why energy use has changed in Poland since the 1970s, with particular emphasis on changes since the country began its transition from a centrally planned to a market economy in 1989. In order to better understand Polish patterns, we also compare energy use in Poland and the factors that shape it with similar elements in the West. This comparison highlights where the most important differences exist, and also provides insight in how energy use in Poland might look as the country evolves toward Western economic and lifestyle patterns.

This report fulfills several purposes. As an analysis of changes in energy use in Poland during the process of economic reform, it provides a guide to what might be expected in other countries in Central and Eastern Europe that started later on a somewhat similar path. As the first detailed comparison of Poland with countries in the $O E C D$, it provides some perspective on how efficient or inefficient energy use in Poland really is. Viewing the changes in energy use in Poland during the past few years with this comparative perspective in mind permits analysts to estimate where energy efficiencies in Poland might converge with those in the OECD, and where gaps may remain. These gaps have become important goals for public policies in both Poland and in countries aiding Poland with economic recovery. In this sense, this analysis helps both Polish authorities and outsiders to focus efforts to promote energy efficiency on those sectors and uses that need the most help.

Various Polish studies of energy consumption, including forecasts of future consumption, have been published in recent years. As part of the background material for the energy policy program prepared by the Ministry of Industry and Trade and presented to the parliament in 1992, a team of the Polish Academy of Sciences (PAN) utilized a multi-sector model of the energy-economy to assess future demand and the environmental effects of changes in energy consumption. ${ }^{1}$ The team made use of a number of specific studies on energy use in different economic sectors carried out by Polish researchers, including evaluations of the potential for energy conservation. Contributing to the policy program effort, the government's Energy Information Centre conducted a comparison of Poland's energy use with that in OECD countries. ${ }^{2}$ They have also prepared energy balances for Poland according to the methodology of

\footnotetext{
${ }^{1}$ Energy Policy of Poland and the Draft Programme to the year 2010, Ministry of Industry and Trade, Warsaw, November 1992.

2 M. Kumanowski et al, Analiza strukturalna gospodarki narodowej $i$ zuzycie paliw $i$ energii w krajach ronswinietyuch oraz kierunkowe prognozy dla Polski [Structural Analysis of the Economy and Fuel and Energy Use in Developed Countries and Outlook for Poland], Centrum Informatyki Energetyki [Energy Information Centre], Warszawa, 1991; and by the same authors, Energetyka polska na tle krajow wysokorozwinientych [Polish Energy on the Background of Highly Developed Countries], Centrum Informatyki Energetyki, Warszawa, 1992.
} 
the International Energy Agency. ${ }^{3}$

In addition to the above work, the Polish Foundation for Energy Efficiency (FEWE) recently conducted an inventory of greenhouse gas emissions in Poland in $1988 .{ }^{4}$ Another study on energy use and carbon dioxide emissions in Poland was sponsored by the Stockholm Environment Institute in 1990.5

While the above studies (not all of which are available in English) provide much insight into the nature of Polish energy use, they are partially limited by the way in which Polish authorities have traditionally kept energy use statistics (see below). In this study we made a number of modifications to Polish statistics to present a picture of energy use that is as close as possible to the framework employed in our analyses of energy use in Western countries and the Soviet Union. ${ }^{6}$ In this and other studies, we use a combination of data and judicious estimates to allocate energy use to various sectors. For each major sector, we analyze energy use by relating it to appropriate indicators of activity, structure, and energy intensity.

Given the nature of the Polish statistics and the difficulty of making reliable estimates in some cases, we were not able to present as complete a disaggregation and analysis as we would have liked. But the data and analysis are sufficient to illuminate the key trends in Polish energy use as well as the differences between Poland and Western countries. The main focus of our study is final energy use in each of the main sectors: industry, transport, and residential/commercial. We cover the energy transformation sector more briefly. We do not discuss state agriculture and state construction, as these are minor energy users.

\subsection{Data Issues and Sources}

Statistics on energy use in Poland have historically been organized according to the structure of the national economy, not according to the purpose of use. The national economy (and final energy use) is divided into four main sectors: industry (which includes the energy sector and mining), agriculture, construction, and transport. Official statistics include only state and collective enterprises; small-scale private activities are not counted. Some slight shifts in apparent energy use may result from changes in economic classification over time.

The difference between total national consumption of the various energy carriers and the consumption of the four basic economy sectors is counted in "Other Consumers." (Beginning with 1988, there are separate data on energy use by municipal enterprises.) "Other Consumers" include homes and other buildings, private farms, forestry, private personal transportation, and small private enterprises engaged in industrial operations, construction, and transport. It appears that the military's energy use is also included under "Other Consumers."

In the course of this study, we made a number of adjustments to the Polish data, as well as estimates that seemed reasonably well-founded. The adjustments are briefly described at the beginning of each section, and are discussed in detail in the Appendix. The most important adjustments involved moving certain transport uses that are included in "Other Consumers" in Polish statistics to the transport sector.

\footnotetext{
3 M. Kumanowski et al, Bilans energetyczny Polski w ukladzic statystyki OECD, EUROSTAT i ONZ [Poland's Energy Balance in the System of OECD, EUROSTAT, and the UN], Centrum Informatyki Energetyki, Warsawa, 1992.

4 The Greenhouse Gas Emissions Inventory for 1988 in Poland: Final Report, FEWE, Warsaw, 1992.

5 G. Leach and Z. Nowak, Cutting Carbon Dioxide Emissions from Poland and the United Kingdom, The Stockholm Environment Institute, 1990.

6 For an overview of these studies and our analytical approach, sec: L. Schipper and S. Meyers, with R. Howarth and R. Steincr, Energy Efficiency and Human Activity: Past Trends, Future Prospects, Cambridge, UK: Cambridge University Press, 1992.
} 
Compared to the Polish statistics, our revisions result in a small increase in energy consumption for industry, a large increase for transport (especially in recent years), and a decline for "Other Consumers." The differences in 1991 are shown in Table 1-1.

\begin{tabular}{|c|c|c|}
\hline \multicolumn{3}{|c|}{$\begin{array}{l}\text { Table 1-1. Polish Final Energy Consumption in 1991: } \\
\text { Polish Statistics and LBL Revisions (PJ) }\end{array}$} \\
\hline Sector & $\begin{array}{l}\text { Polish } \\
\text { Statistics }\end{array}$ & $\begin{array}{c}\text { LBL } \\
\text { Revised Data }\end{array}$ \\
\hline Industry ${ }^{b}$ & 1123 & 1187 \\
\hline Transport & 137 & 429 \\
\hline Other Consumers & 1424 & 1141 \\
\hline Construction (State) & 33 & 33 \\
\hline Agriculture (State) & 59 & 59 \\
\hline Total & 2777 & 2849 \\
\hline
\end{tabular}

a. For both we excluded feedstocks and non-energy petroleum products.

b. Industry includes the energy sector and mining.

Within each of the three main sectors, we further disaggregated energy use, as described in Sections 3-5 and the Appendix. Apart from the industrial sector, these disaggregations required various estimates and should be considered as approximate only.

The Polish energy data used in this study were assembled by staff of FEWE, the Energy Information Center, and the Polish Academy of Sciences. These data come from official Polish energy statistics, which are based in part on reports that all enterprises above a certain size and some government offices are required to submit. We also used data from recent publications of the Energy Information Center.

Data on economic output, activity, and other structural factors in each sector were provided by FEWE, J. Norwisz of the Polish Academy of Sciences, and also taken from the Polish Statistical Yearbook and the Polish transport statistics publication, both prepared by the Central Statistical Office (GUS).

\subsection{Report Organization}

Section 2 provides an overview of the historic trends in energy use in Poland, with special attention on the period since 1989. Sections 3 through 5 cover industry, transport, and other consumers, while Section 6 briefly covers the energy transformation sector. Section 7 presents a comparison of energy use and related factors between Poland, Western countries, and the former Soviet Union. 


\section{OVERVIEW OF TRENDS}

\subsection{The 1970-1991 Period: Overview}

Total energy consumption in Poland rosc at an average annual rate of 3.2\% per year in the 1970-79 period as the economy expanded. Energy use fell sharply in 1981 as a result of the political turmoil that led to imposition of martial law, however, and then rose only slowly in the following years as the economy stagnated (Figure 2-1). It fell in 1989 as the planned economy began to break down, and then plummeted sharply in 1990 as the economic situation deteriorated. The decline in use was much more modest in 1991, for reasons we discuss below.

Coal (hard coal and lignite) has dominated the energy picture in Poland for the past two decades (and before as well). Its share in total primary energy consumption declined slightly in the 1970s and 1980s, however, as oil and natural gas took on larger roles. The share of total Polish energy use going into intermediate transformation processes such as electricity and district heat has risen from two-thirds in 1970 to three-fourths in 1991.

Trends in the composition of Polish final energy use - after our adjustments - are shown in Figure 2-2. ${ }^{1}$ The share of coal/coke fell from $54 \%$ in 1970 to $44 \%$ in 1988 , and then dropped sharply to $36 \%$ in 1991. The share of electricity rose from $8 \%$ to $14 \%$ in the same period. Use of district heat, an important energy product in Poland, was relatively constant over the 1980s as well as in the 1989-91 period. The use of liquid fuels and gases, whose roles are much smaller than in W. Europe, rose considerably in the 1970 s, but increased relatively little in the 1980 s.

Industry (including the energy industries) has historically been the largest consumer of final energy, but its share has gradually fallen: from $51 \%$ in 1970 to $42 \%$ in 1991 (Figure 2-3). The share of "other consumers" rose from $35 \%$ in 1970 to $40 \%$ in 1991 . Transport accounted for $15 \%$ of the total in 1991 , while state agriculture and construction accounted for very small shares.

In order to gain a better sense of the role of the various sectors in total energy use, we distributed the losses in production, transmission, and distribution of electricity and district heat among the sectors according to each sector's share of total use of those two products. (The losses in other energy transformation sectors are relatively small.) In this presentation (Figure 2-4), the share of industry is slightly higher than if one counts final energy only, while the share of transport is lower.

\subsection{Trends Since 1989}

The period since the fall of the communist government in 1989 has seen dramatic change in the Polish ecenomy. The macro-economic stabilization program that was introduced in 1990 managed to reduce inflation from $50-60 \%$ to $2-4 \%$ per month. The budget deficit was cut by reducing subsidies to state enterprises. With a few exceptions, prices were freed from regulation and import restrictions abolished. As a result, economic activity in state-owned industry dropped markedly. Private activity rose, but not enough to prevent considerable decline in GDP and in the standard of living of most Poles.

Total final energy use, which had declined somewhat in 1989 , fell by $19 \%$ in 1990 , much more than the drop in GDP (according to official statistics) of about $12 \%$. The main reason is that the output decline

1 The series we constructed excludes non-energy use of energy products (primarily chemical industry feedstocks but also coke for steelmaking) from industrial energy use. Annual non-energy use, amounted to 3-4\% of total final energy use over the $1970-90$ period. We also excluded non-energy petroleum products such as bitumen, lubricants, and pyrolysis gasoline from final energy use. (These are included in "other" consumers in Polish statistics.) 
in industry, the most energy-intensive sector of the economy, was much greater than the fall in GDP. Output in agriculture and the so-called "sphere outside inaterial production" (comparable to the service sector) was about the same in 1990 as in 1989. Similar to 1990, the decline in final energy use in 1991 of only $2 \%$ was less than the fall in GDP of $8 \%$. In this case as well, the decrease in industrial production was larger than the decline in GDP. In addition, there was growth in various private activities (especially in transport) that pushed energy use upward.

Below we summarize the trends with respect to activity, structure, and energy intensities in each sector. These trends are described in detail in Sections 3-5. Before discussing energy intensities, we present data on energy prices in 1989-91. As we discuss more fully in later sections, the rise in prices has played a role in shaping energy use, but not a decisive one in most cases.

\subsubsection{Activity}

The economic "shock therapy" implemented by Poland's new government in 1989 and early 1990 brought on a severe contraction of economic activity. The impact varied among economic sectors, with industry suffering the greatest effects. Industrial output fell by $24 \%$ in 1990 and by an additional $12 \%$ in 1991. Whereas the 1990 decline was broad-based, reflecting the generalized reduction of domestic demand, the collapse of trade with Eastern Europe in 1991 hit the economy unevenly. The drop in production was particularly marked in the heavy sectors that relied on trade with the Eastern countries, or produced intermediate and capital goods. Smaller declines were registered in sectors that could expand their exports to the West, or that were the beneficiary of the increase in private consumption.

In the transport sector, the drop in industrial output and in coal consumption resulted in a large decline in public-sector freight tonne-km in 1990 and (somewhat less) in 1991. There was much growth in freight transport by private trucks, however. Passenger travel fell less than freight transport in 1990, and was steady in 1991 as growth in automobile travel made up for decline in use of public-sector transport.

In the residential sector, total living area continued to rise, but at a slower rate than in the past. In the service sector, there was continued addition of new floor area in the private sector. Output in private agriculture rose in both 1990 and 1991.

\subsubsection{Structure}

The composition of value added in Polish manufacturing shifted somewhat away from heavy industry in the 1990-91 period. The value added of chemicals and especially of metallurgy fell sharply. Value added in food \& other light industries declined considerably in 1990 but decreased only slightly in 1991. There was also a sharp drop in the output of the fuel \& power industry, which contributed to lower industrial energy intensity.

In transport, structural change contributed to higher sectoral energy intensity. For freight transport, the decline of heavy industry led to a decrease in the share of rail in total tonne-km. The role of trucks grew, especially if one counts private trucks. For passenger travel, the rise in the role of automobiles and the decline in that of intercity rail (both of which were especially marked in 1991) contributed to higher energy intensity.

In the residential sector, there has been some movement toward more central heating (especiaily based on gas), and the ownership of freezers and color TVs rose strongly. In the service sector, the increase in private activity brought more use of electrical equipment. 


\subsubsection{Energy prices}

In Poland and other former centrally-planned economies (CPEs), energy prices were set in accord with the output goals of the central plan. Technological and allocative efficiency considerations, as well as rates of return to energy producers, were largely ignored. ${ }^{2}$ Most energy prices were subsidized, in particular prices paid by households for electricity and heat. While prices of energy carriers and other products were adjusted from time to time in the communist era, there was little change in energy prices relative to other prices.

When Poland's new government took office in the fall of 1989, it increased most energy prices by up to several hundred percent as part of a general price increase on state-produced goods and services designed to reduce the budget deficit. Following an agreement with the World Bank, a new pricing system for energy was introduced in the beginning of 1990 . Subsidies on energy prices were to be diminished regularly over a period of four years, with the ultimate goal of eliminating them completely.

Accounting for general price inflation, ${ }^{3}$ which was very high in Poland in 1989 and especially in 1990, the (real) price increases since 1989 varied considerably among different energy carriers and types of customers. In general, household prices increased more than prices paid by industry, which reflects the fact that household prices were more highly subsidized. The price of steam coal for electricity generation, which approximates the price paid by large industrial users, increased three-fold in early 1990 relative to the 1989 average price, and then rose by an additional 50\% in the first half of 1991 (Figure 2-5). ${ }^{4}$ Prices for other users rose by roughly similar amounts, depending on coal quality and transport distance.

The industrial price of natural gas rose much less in 1990 than the price of coal, as natural gas was less subsidized (since around two-thirds of the gas supply came from imports) (Figure 2-6). The household price of gas also rose relatively little in 1990, remaining far below the industrial price, but it was increased proportionally much more than the industrial price in 1991. The industrial price of electricity increased by some $75 \%$ in early 1990, but did not change very much thereafter (Figure 2-7). The residential electricity price rose three-fold (from a low base) in 1990, and then increased sharply again in 1991.

For district heat for buildings, the price of which is based on dwelling floor area, not actual consumption (which most occupants are unable to control), the major price rise occurred later in 1990 than was the case for residential gas and electricity. After further increase in mid-1991, the price was about three times higher than at end-1989, but subsidies for household heat were still substantial in much of the country. 5

\footnotetext{
2 Prices were set differently for wholesale and retail consumers based on production costs reported to the planning ministries. Wholesale prices were the sum of import or domestic producer prices, marketing cost margins, and net taxes. Retail prices were charged to particular service enterprises and individual consumers. These prices were usually determined by adding turnover taxes to -- or subtracting subsidies from -- wholesale prices. (P. Marer, et al, Historically Planned Economies: A Guide to the Data, The World Bank, Washington, D.C., 1992.)

3 We converted actual prices of energy products into constant 1985 zlotys by deflating them with either the producer or consumer price index, depending on the product in question. While there is some uncertainty in the price indices, this method is preferable to converting current prices to U.S. dollars because the exchange rate adjustments in 1991 did not keep up with inflation. (Producer prices increased by $148 \%$ in 1991, and consumer prices increased by $170 \%$, but the exchange rate of zlotys to U.S. dollars rose by only 111\%.) Data on most energy prices are from material provided by FEWE. Prices on gasoline and diesel fuel are from Energy Prices and Taxes, which is published by the International Energy Agency every quarter. Polish producer and consumer price indexes are from International Financial Statistics, June 1992, Intemational Monetary Fund.

4 The new price regulations introduced in 1990 set the price of coal at the mine, and also abolished the state monopoly on wholesale and distribution of coal. The only form of price control left was on the rate of price increases. Rail transport costs rose, which further increased the delivered price of coal.

5 Gazeta Bankowa, No. 4, 1992. There are great variations in heating charges among municipalities.
} 
In contrast to the trends for most energy products, the prices for gasoline and diesel rose only slightly in early 1990 (Figure 2-8). They were at roughly the same level a year later, but then fell through 1991. Unlike other products, these fuels (derived from imported oil) were historically taxed (though not as much as in most of W. Europe). The fuel component is about half the retail price.

\subsubsection{Fnergy intensities}

In most sectors, factors other than energy prices played the main role in shaping trends in energy intensities. In industry, energy use per unit of value added (constant zloty) increased considerably in most of the heavy industrial subsectors in 1990-91 despite the rise in prices. The rise in metallurgy and in the fuel \& power subsector was especially strong. There was also some increase in most light industry subsectors. The rise in intensities appears to be related to the drop in output and the resulting low utilization of production capacity, as well as the need to maintain various fixed energy uses.

The trends in energy use per ton of various industrial products show a mixed picture: increase in some cases (e.g., rolled steel), decline in some (e.g., cement production by wet process), and little change in others. The response of factory managers requires more systematic research. There were apparently some efforts to rationalize production in the face of higher costs and decreased demand, and perhaps improvement in energy management in some cases, but very little investment in new equipment that might have increased energy efficiency.

In transport, one would expect less effort to conserve than in other sectors since fuel prices rose relatively little. For automobiles, there may have been some increase in the average energy intensity due to the substantial import of cars from the West, many of which were larger and more powerful than aver-

age Polish models. In rail transport, there was an increase for electric and diesel trains in 1991, probably related to lower utilization of capacity. Public buses and trucks had a small increase in energy intensity in 1991, as did public trucks.

In the residential sector, the energy intensity of space heating fell considerably in 1990 in response to higher coal prices. The size of the decline is somewhat uncertain, since an unknown quantity of wood substituted for coal to some extent, and there had been hoarding of coal in 1989. In contrast to the situation with coal, there was no change in energy intensity for district heating. The lack of change is hardly surprising since occupants have neither the incentive nor the opportunity to cut back on heat uss.

\subsubsection{Recent changes: summary}

The most important factors behind the large decline in Polish energy use in 1990 were the sharp fall in industrial production and the huge drop in residential coal use. Only the latter was driven primarily by rising energy prices. Factors that pushed energy use upward were an increase in energy intensity in many heavy industries and a shift toward more energy-intensive modes in transport. The growth in private activities (especially transport) in 1991 was nearly sufficient to balance out continued decline in industrial energy use in that year.

Apart from residential coal use, it is difficult to see very much effect from higher energy prices. To some extent, nominal price increases after the strong initial adjustments in early 1990 were blunted by inflation. Moreover, even after the increases, energy costs still accounted for a relatively small share of total costs for most industrial enterprises. The attention of industrial managers has been focused on issues of survival, and few had money to invest in improving energy efficiency even had it been considered a priority. 


\section{Poland Primary Energy Inputs 1970-1991 (Polish Data)}

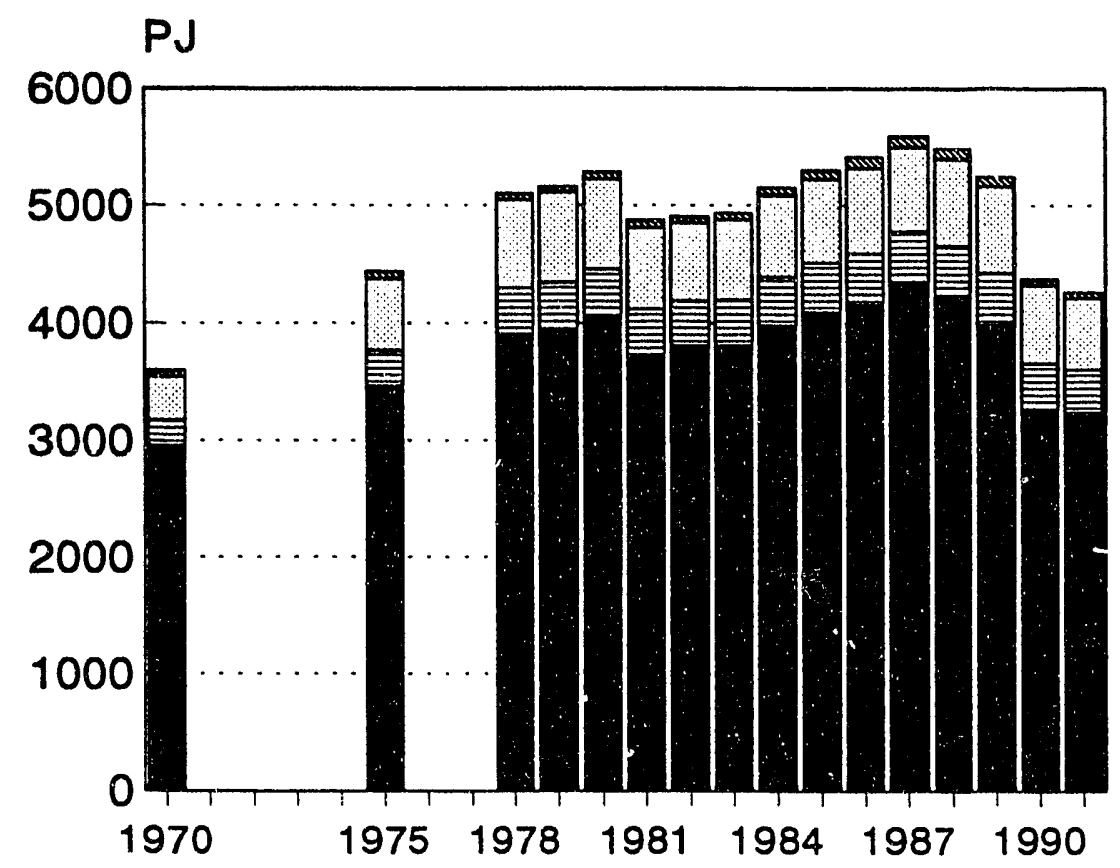

$\mathbb{N}$ Other Solids

$\square$ Oil

Natural Gas

Coal

Includes non-energy uses.

Figure 2-1

\section{Poland Final Energy Use By Type, 1970-1991}

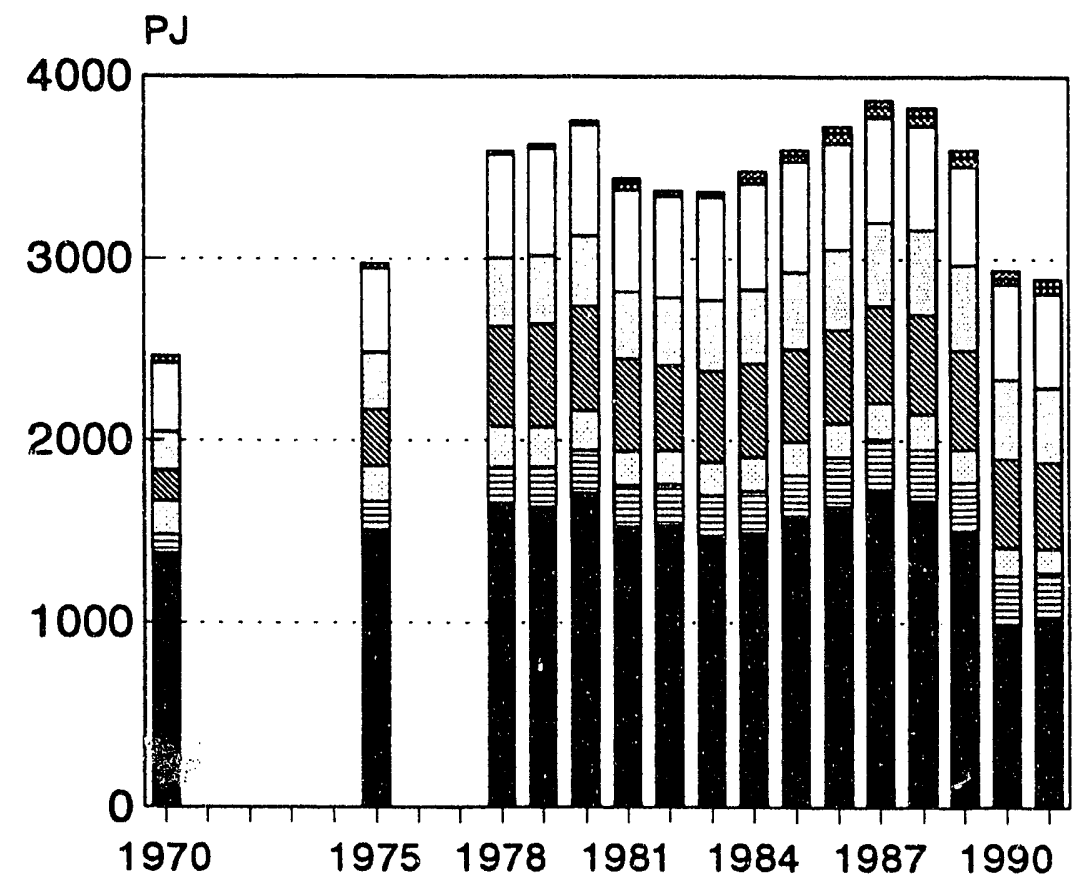

Other

$\square$ Heat

$\square$ Electricity

$\mathbb{N}$ Liquid Fuels

$\square$ Derived Gases

Natural Gas

Coal/Coke

Figure 2-2 


\section{Poland Final Energy Use By Sector, 1970-1991}

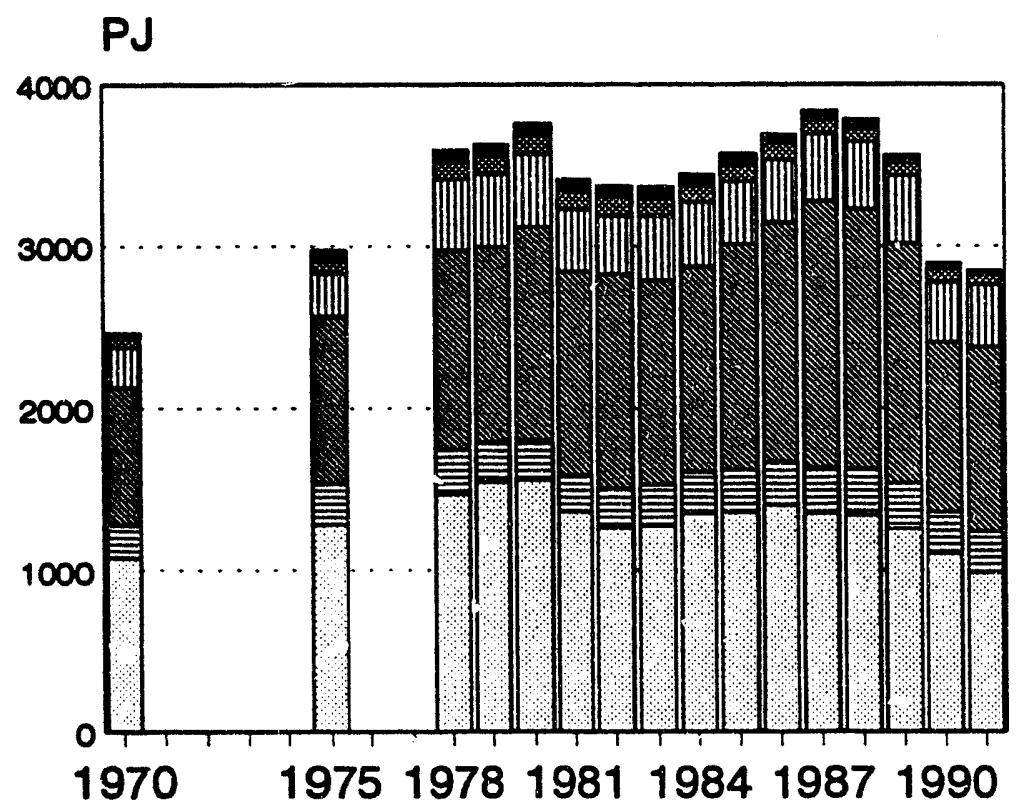

Construction

Agriculture

血 Transport

Other Consumers

Energy

Manufacturing

Agriculture \& construction are state-owned enterprises only.

Energy includes coal mining. All other mining is in manufacturing.

Figure 2-3

\section{Poland Primary Energy Use By Sector, 1970-1991}

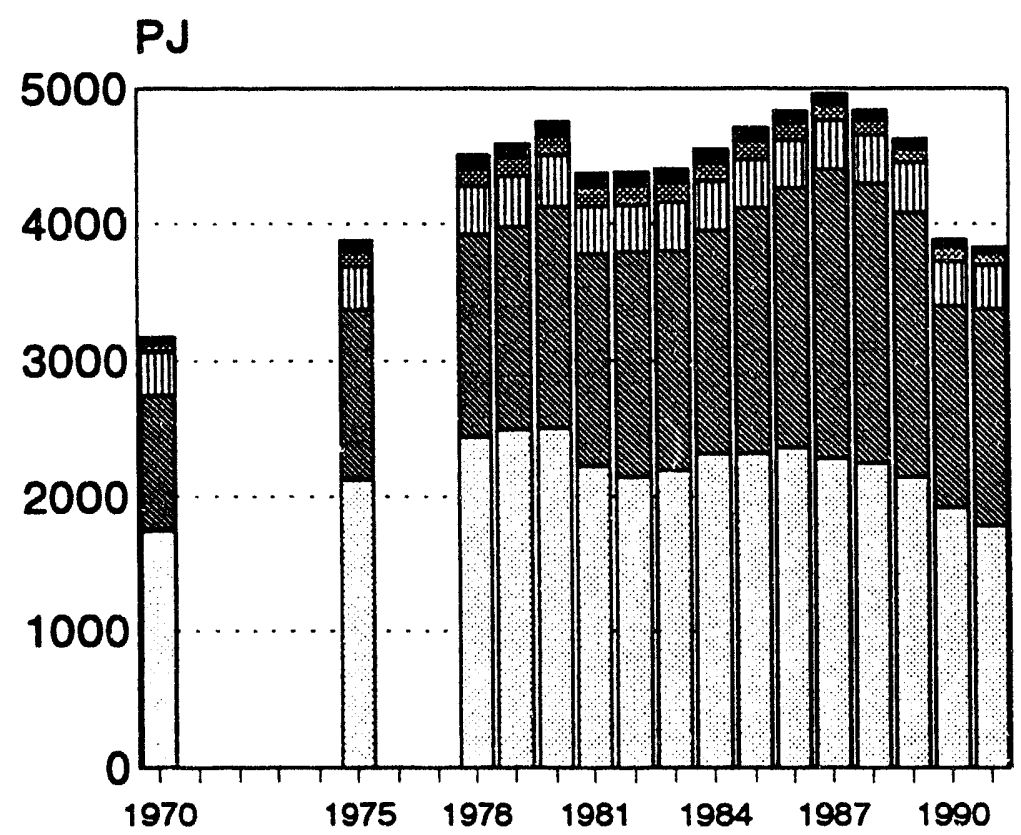

Construction

Agriculture

血 Transport

Other Consumers

Industry

Fuel inputs to electricity and heat production are distributed among sectors. Industry includes onergy and manufacturing. See notes to figure 2-3.

Figure 2-4 


\section{Poland Coal Price (for Elect. Gen) 1989-1992}

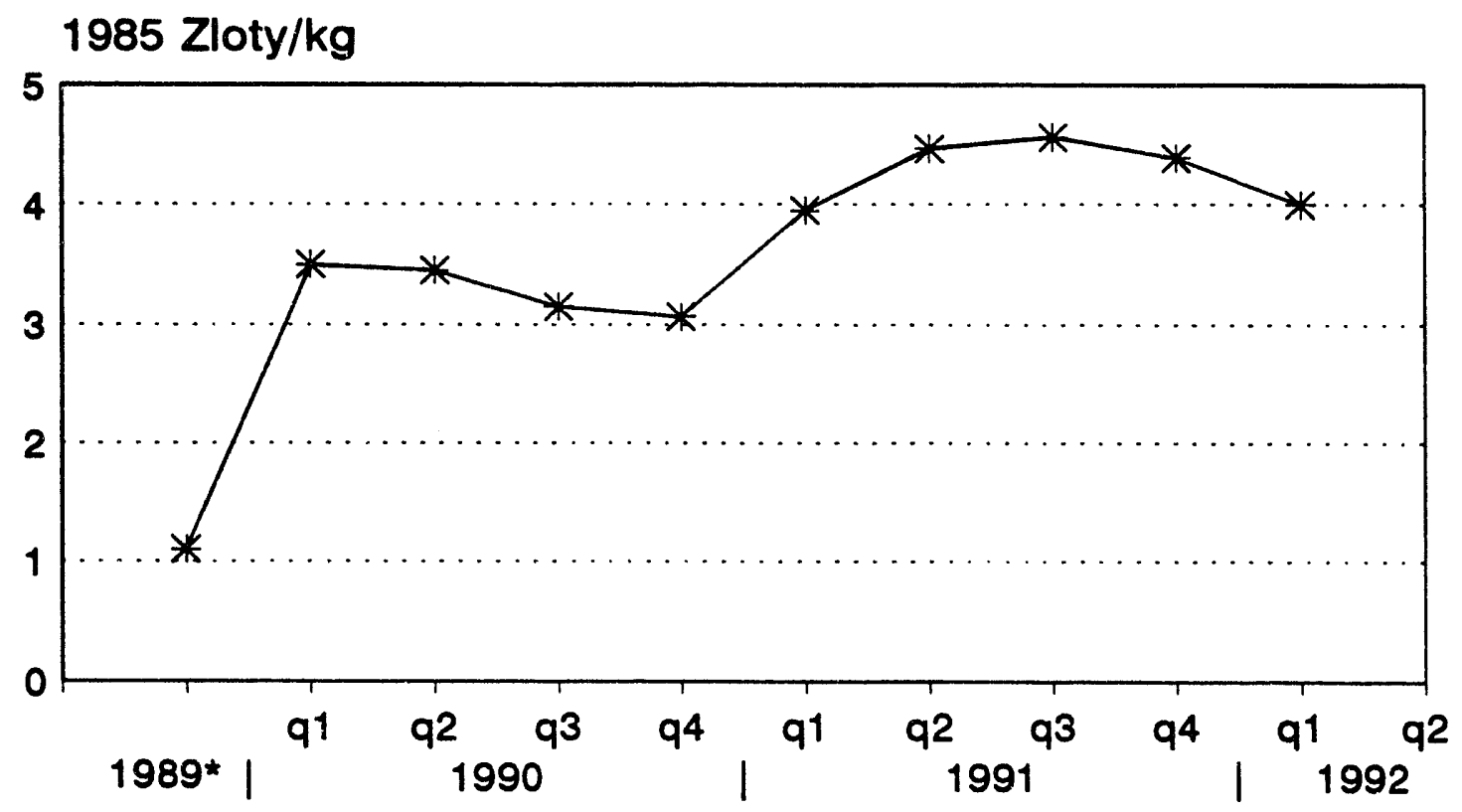

Note: All datapoints are quarterly averages except 1989, which is whole year average.

Figure 2-5

\section{Poland Natural Gas Prices 1989-1992}

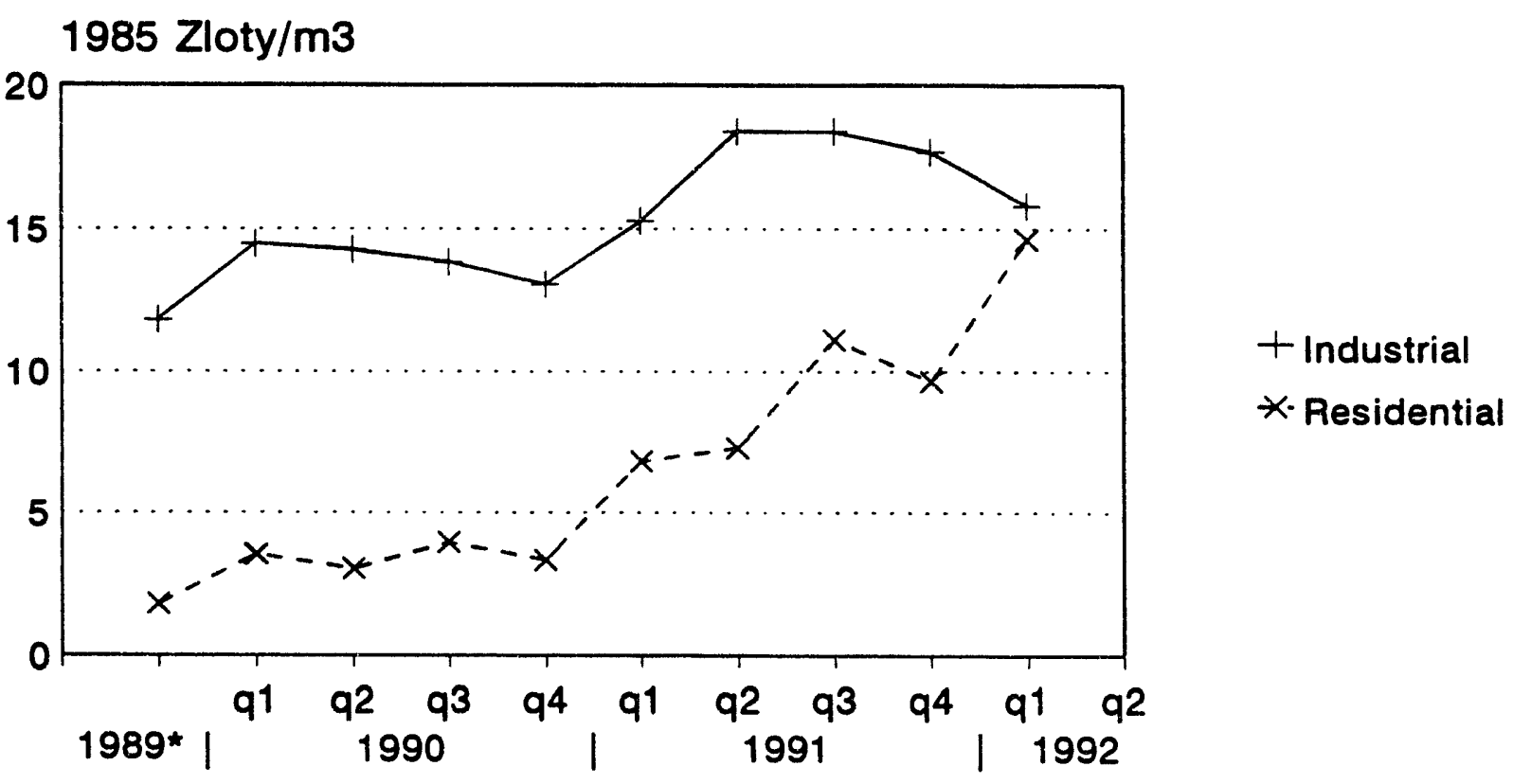

Note: All datapoints are quarterly averages except 1989, which is whole year average.

Figure 2-6 


\section{Poland Electricity Prices 1989-1992}

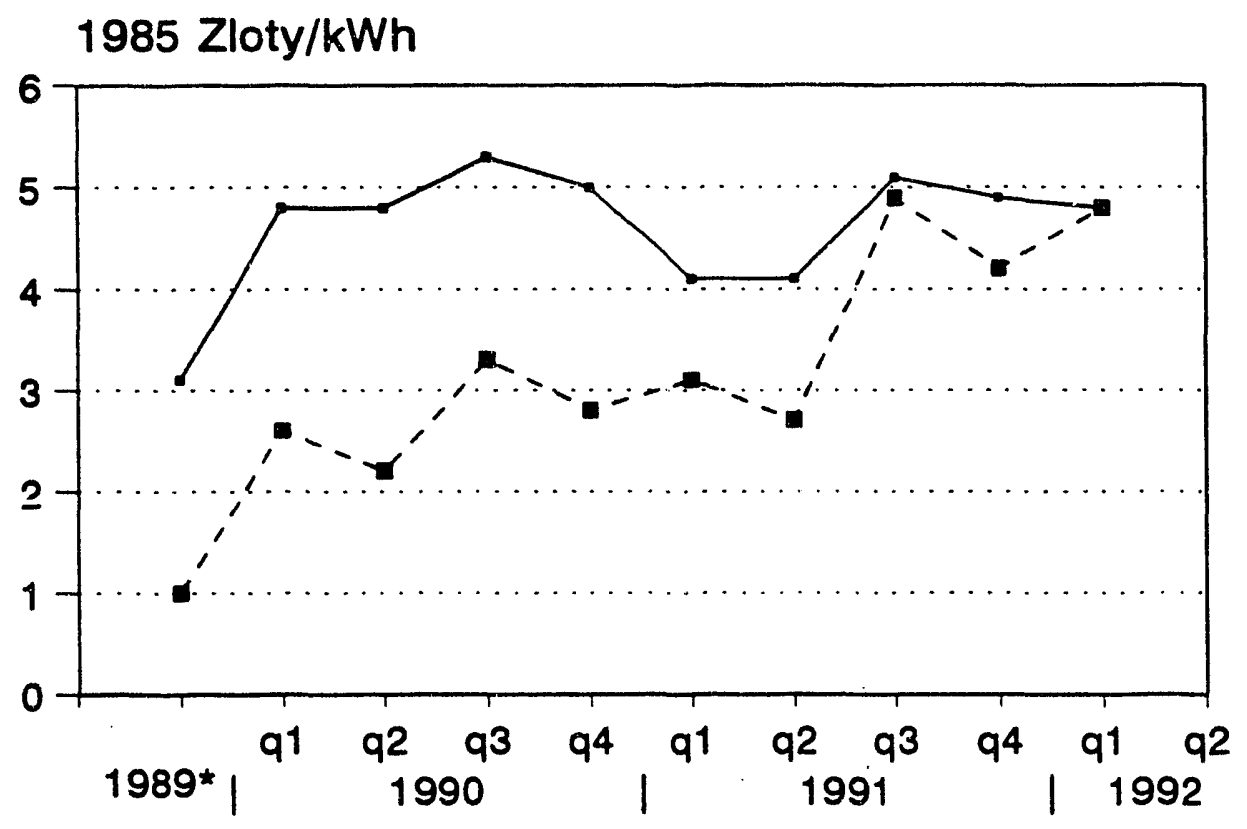

- Industrial

- Residential

Note: All datapoints are quarterly averages except 1989, which is whole year average.

Figure 2-7

\section{Poland Transport Fuel Prices 1989-1992}

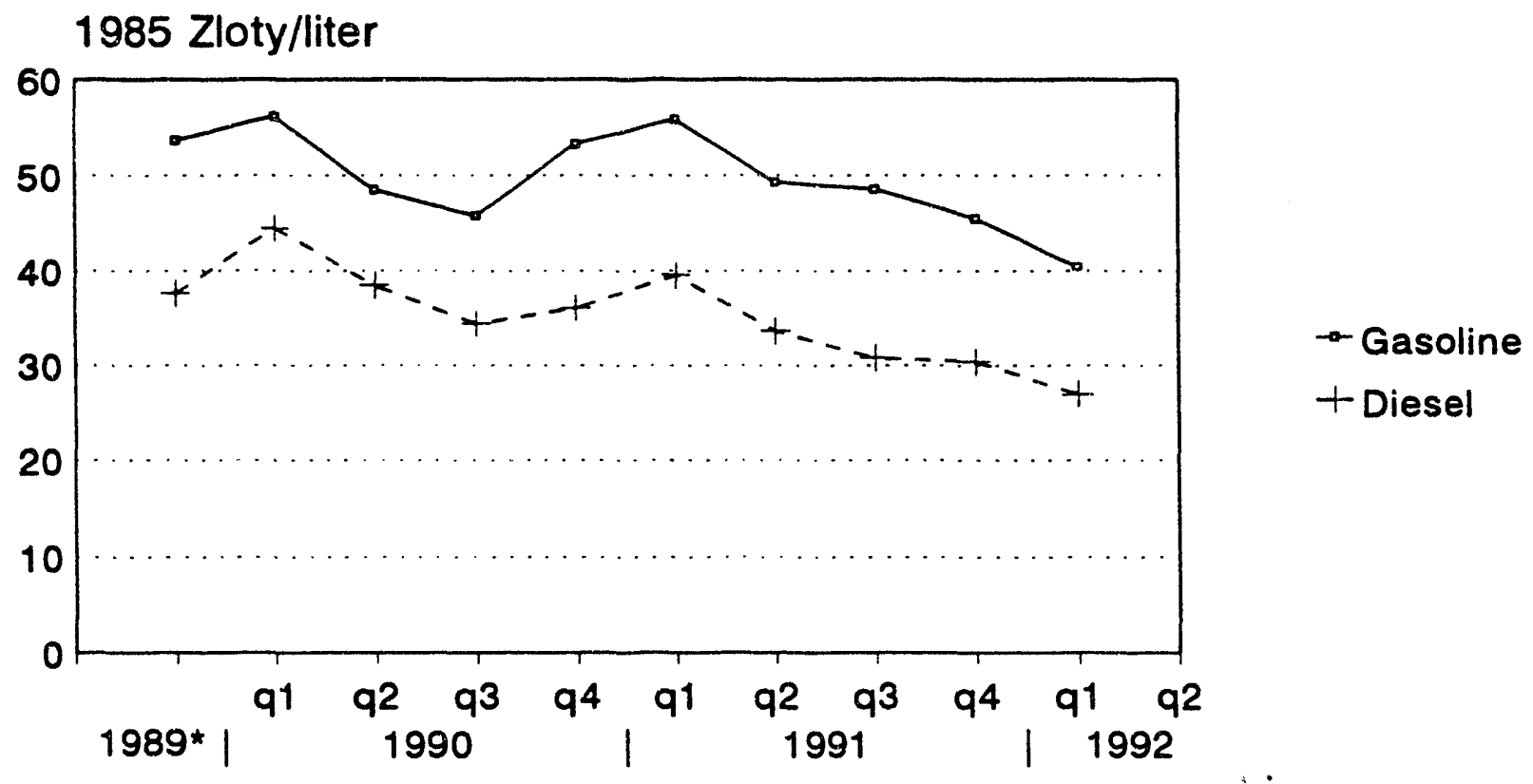

Note: Figures are retail price quarterly averages, except 1989 which is whole year àverage.

Figure 2-8 


\section{INDUSTRY}

As in other centrally-planned economies, industry was the most dominant sector of the national economy in Poland. In the period 1970-1989 it accounted for about half of total net material production (NMP). ${ }^{1}$ In NMP terms, industrial output rose by an average of $8 \%$ per year between 1970 and 1978 , when it peaked. It dropped significantly in 1980 and 1981 because of political unrest, and then recovered slowly in the subsequent years. Cutput in 1988 was only $95 \%$ of the level in $1978 .^{2}$

Of all economic sectors in Poland, industry has been hit hardest by the economic reform program that was introduced in 1990. Exposed to competition and free prices and deprived of direct subsidies from the state, the production by state industry fell dramatically. In 1991 state industry's production was less than half of the 1988 level. Another reason for the downturn is the collapse of trade with the former Soviet Union and other East European countries. This trade provided the Polish industry with raw materials and also offered important export markets. ${ }^{3}$. As domestic consumption and trade with Eastern Europe fell, the role of exports to the West increased. The share of gross industrial output (value of goods sold) that went for export increased from $13 \%$ in 1985 to $21 \%$ in 1990.4

Until the end of the 1980s, most of Poland's industrial firms were owned by the state. After the fall of the communist regime, new private industrial operations sprang up. The share of private firms in total industrial production increased from $16 \%$ in 1989 to $26 \%$ in the first quarter of 1992.5 Privatization of state companies has proven to be a slow and difficult process, however. Most of the large enterprises in fuels \& power, metallurgical, and chemical industry are still under state ownership. Although the condition of most state-owned enterprises deteriorated substantially in the 1989-91 period, they continue to provide a significant part of industrial output.

\subsection{Energy Data Issues}

The Polish data on industrial energy use include all enterprises with more than a certain number of employees (which varies among branches). Consumption by state-owned enterprises that have been privatized have continued to be counted under industry. Mining is not counted as a separate activity but rather is included within particular industrial subsectors. Marine fishing is included in the food industry.

Unlike most industrial concerns in the West, state-owned industrial enterprises in Poland were (and to a lesser extent still are) responsible for more than simply production. Many enterprises owned and managed housing for workers ${ }^{6}$ as well as recreational and other buildings. Larger enterprises and industry-wide associations managed much of their own goods transport, and also transport of employees

1 The CPEs developed their own system for national accounts, the material product system (MPS). According to this system the measure of aggregate output and income, called net material product (NMP), excluded so-called nonproductive services (such as administration, the military, education, and health) and depreciation.

2 P. Marer, J. Arvay, J. O'Connor, M. Schrenk and D. Swanson, Historically Planned Economies: A Guide to the Data, World Bank, Washington D.C., 1992, pp. 188-189.

3 While almost 50\% of Poland's total exports went to the USSR and Eastem Europe in 1985, the share had fallen to 17\% in 1991. According to World Bank data, these exports amounted to almost US\$ 6.5 billion in 1985 , but only an estimated US\$2-3 billion in 1991.

4 The metallurgical subsector especiaily became much more export-reliant: it exported $13 \%$ of its production in 1985, 27\% in 1990 , and $37 \%$ in 1991 . The machinery subsector exported $22 \%$ in $1985,28 \%$ in 1990 and $22 \%$ in 1991 , while the chemical subsector exported 17\% in 1985, 29\% in 1990 and $26 \%$ in 1991. (Rocznik Statystyczny 1992, p. 365.)

5 Central Statistical Office of Poland, as quoted in Poland: Private Sector Assessment, World Bank, 1992, p. 10.

6 The total number of enterprise-owned dwellings in 1988 (including those owned by non-industrial enterprises) was around 1.3 million (about $13 \%$ of the total housing stock). 
to/from work. The data on industrial energy consumption include the energy used in vehicles, but in the case of district heat most residential and recreational buildings that belong to industrial enterprises are connected to the municipal heating network.

An important difference between Polish and Western energy accounting practices involves the definition of final energy use in industry. In Polish statistics, the energy input to large, non-powerproducing boilers is not counted as final energy; rather, final energy refers to the heat output of the boiler. These so-called "autoproducing heat plants" are treated as an energy transformation sector, in part because some of the heat from these boilers goes into the district heat network. ${ }^{7}$ It appears that much of the heat produced by these autoproducing heat plants is used on-site. ${ }^{8}$ Thus, we have included the fuel input to the autoproducing heat plants under final energy, and subtracted their heat production from the values given under industry heat consumption in the Polish statistics (so as not to double-count). Our revision yields total industrial final energy use roughly $10 \%$ higher than the Polish method.

Another difference is that in Polish statistics the final energy use of the fuels \& power industry subsector includes plant use of most energy transformation facilities. In the Western method, this "energy sector" consumption would be excluded from final energy. This subsector also includes energy use in coal mining and oil and gas production, as well as energy used for various purposes by the energy industries. We include this subsector when speaking about industry, but exclude it when speaking about manufacturing.

\subsection{Industrial Energy Consumption ${ }^{9}$}

Industrial final energy use rose at an average annual rate of $3.6 \%$ between 1970 and 1980 , then declined sharply in the 1981-82 recession. It grew in the 1984-86 period, but then stagnated before falling considerably in 1990 and 1991.

The share of coal/coke in industrial final energy use declined slightly from $45 \%$ in 1970 to $40 \%$ in 1991 (Figure 3-1). In contrast to Western industry, liquid fuels and natural gas have continued to play relatively small roles. Heat (mostly from cogeneration) is significant. The share of electricity rose from $12 \%$ in 1970 to $18 \%$ in 1991.

The metallurgical industry has historically been the largest energy-using subsector (Figure 3-2), but its share declined from $29 \%$ in 1980 to $23 \%$ in 1991 (Table 3-1). ${ }^{10}$ The next largest subsectors are fuels \& power (much of whose energy use is plant use in energy transformation industries) and chemicals.

\footnotetext{
7 The same is true of autoproducing power plants. In principle (if not always in practice), autoproducing power plants are treated as an energy transformation sector in Westem statistics also.

8 The total amount of heat used by industry is much greater than the heat production from the autoproducing heat plants, as industry uses some of the output from its CHP plants and also purchases some heat from the network.

9 Feedstocks are not included in the energy figures reported in this and the following sections. Own use by the energy transformation subsector is included. The statistics do not include small private industries, whose energy use is counted in Other Consumers.

10 Since we did not have precise data, we made a rough adjustment to the subsectoral energy use data to include fuel inputs to autoproducing heat plants (as described above). We removed feedstock use of coke and natural gas from the metallurgical and chemical subsectors.
} 


\begin{tabular}{lcc}
\hline $\begin{array}{c}\text { Table 3-1. Polish Industrial Final Energy Use: } \\
\text { Subsectoral }\end{array}$ \\
$\begin{array}{lcc}\text { Shares (percent) } \\
\text { Subsector }\end{array}$ & 1980 & 1991 \\
\hline Metallurgical* & 29.4 & 22.8 \\
Fuels \& power* $^{*}$ & 13.6 & 19.8 \\
Chemicals* $_{\text {Building materials* }}^{*}$ & 15.2 & 16.4 \\
Machinery & 14.1 & 11.8 \\
Food & 11.5 & 11.1 \\
Paper & 7.6 & 9.8 \\
Textiles, etc. & 3.0 & 4.0 \\
Other & 4.2 & 3.4 \\
TOTAL & 3.3 & 2.8 \\
\hline
\end{tabular}

Does not include small-scale private activity.

* Includes energy use for various mining activities.

\subsection{Industrial Structure}

Since some industrial subsectors are more energy-intensive than others, changes in industrial structure often affect industrial energy use. Analysis of long-term trends in the structure of Polish industry is difficult due to lack of reliable measures of net economic output. The common Western measure of "value added" was not traditionally used in the CPEs. Moreover, prices were set administratively, so the reported output (value of goods sold) by the various subsectors does not reflect the value that the market would have placed on the production. ${ }^{11}$ Recently, M. Kumanowski of the Energy Information Center of the Ministry of Industry and Trade constructed a time-series (beginning in 1987) of value added by industrial subsector in constant 1990 prices. Since prices of industrial inputs and outputs were freed from controls in most areas during 1990, these data are an improvement on previous measures of industrial output. Given that Poland experienced very high inflation in 1989 and 1990 (averaging 250\% and 585\%, respectively), the reliability of extrapolating backwards to 1987 using 1990 prices is open to question. In addition, the Kumanowski data do not include small-scale private activity, which began to grow in 1990 .

As the comparison in Table 3-2 indicates, the Kumanowski data are different in some sectors from similar statistics published by the Central Statistical Office (GUS), which are only for 1990 and 1991. The reason is that the GUS data do include estimates of small-scale private activity. Total value added in 1990 as estimated by GUS is $25 \%$ higher than given by Kumanowski.

11 Indeed, some industrial sectors would have had negative value added if their inputs and outputs had been priced at market levels. 


\begin{tabular}{|c|c|c|}
\hline Subsector & $\begin{array}{c}\text { Kumanowski } \\
\text { data }\end{array}$ & $\begin{array}{l}\text { GUS } \\
\text { data }\end{array}$ \\
\hline Fuels \& power & 18.7 & 15.2 \\
\hline Metallurgical & 14.1 & 11.5 \\
\hline Chemicals & 9.4 & 9.2 \\
\hline Building materials* & 3.9 & 4.6 \\
\hline Paper & 1.4 & 1.3 \\
\hline Machinery & 24.2 & 26.7 \\
\hline Textiles, etc. & 7.2 & 8.7 \\
\hline Food & 17.3 & 17.4 \\
\hline Other & 3.6 & 5.4 \\
\hline Total & 100.0 & 100.0 \\
\hline $\operatorname{Total}\left(10^{12} \mathrm{Zl}\right)$ & 203 & 251 \\
\hline
\end{tabular}

* Includes cement, glass products, pottery, etc.

The changes in value added in the Kumanowski series are shown in Figure 3-3. Value added in the fuels \& power subsector fell greatly in 1990 , in part because energy prices were freed more slowly than other prices, so the value of the output of this subsector fell relative to that of its inputs. Another factor was the sharp decline in domestic coal consumption. Value added in the metallurgical subsector (which includes ferrous and non-ferrous metals) also dropped considerably (over 50\% from 1988 to 1991). Most subsectors saw a decline in 1990, but a few stayed level or even rose (food) in 1991. Machinery was the largest subsector in 1991, followed by food (Figure 3-4).

The data indicate a considerable amount of structural change-by which we mean change in the relative importance of different subsectors-in the 1987-91 period. The biggest change was a decline in the share of the fuels \& power subsector from $28 \%$ to $19 \%$. The metallurgical subsector declined considerably in importance (mainly in 1991). The largest increase in share was registered by machinery.

\subsection{Energy Intensity in Manufacturing}

In order to analyze the manufacturing sector alone, we removed the fuels $\&$ power subsector. The resulting manufacturing sector includes some mining activities (as described in Section 3.6), but not coal mining. These mining activities accounted for $8 \%$ of total manufacturing energy use in 1991.

Using value added from the Kumanowski series (which are subject to some uncertainty), we find that aggregate final energy use for manufacturing per unit value added (1990 zloty) was relatively unchanged in 1988 and 1989, but rose by $13 \%$ in 1990 and by an additional $2 \%$ in 1991 (Figure 3-5). ${ }^{12}$ Overall, the 1991 level was 13\% above the 1987 level.

Changes in aggregate energy intensity are shaped by structural change (shifts among subsectors in total output) and by changes in subsectoral energy intensities. We have estimated the independent impact of each of these forces using an approach based on Laspeyres (fixed-weight) indices. ${ }^{13}$

12 The value-added data should match reasonably well with the energy use statistics, which also do not include small-scale private activity.

${ }^{13}$ See: R. Howarth, L. Schipper, P. Duerr, and S. Strøm, "Manufacturing energy use in eight OECD countries: Decomposing 
The results show that by themselves, shifts in the structure of manufacturing pushed upward on aggregate energy intensity in 1990 (mainly due to an increase in the value-added share of the iron and steel industry), but then had a strong downward effect in 1991 (Figure 3-6). All told, the analysis indicates that structural change reduced aggregate energy intensity by only $4 \%$ between 1987 an $11991 .^{14}$

In contrast, change in subsectoral energy intensities pushed upward on aggregate energy intensity in 1989, 1990, and 1991 (Figure 3-6). By itself, it would have increased aggregate energy intensity by 20\% in the 1987-91 period.

The net outcome of the two effects was the $13 \%$ increase in aggregate energy intensity between 1987 and 1991.15 The analysis indicates that the effect of rising intensities was equally as strong in 1991 as in 1990, but the effect in 1991 was partially balanced by structural change toward less energy-intensive subsectors.

The energy intensity effect described above is the result of intensity changes in the various subsectors. ${ }^{16}$ As shown in Figure 3-7, there was not a great deal of change in 1988 and 1989, although there was some decline in building materials. In 1990, however, energy intensity rose considerably in the metallurgical and paper subsectors, and continued to increase in chemicals. (The large increase in paper, which is due to a big decline in the subsector's value added, is somewhat suspect.) There was a further large increase in the metallurgical subsector in 1991, and also a small increase in chemicals and building materials.

Given the uncertainty with respect to the data on value added, one must use caution in interpreting the above trends. The fact that increases in intensity occurred at the same time as energy prices rose significantly may at first glance seem surprising. Upon closer consideration of the Polish situation, however, it is not. Anecdotal evidence suggests that improving energy efficiency has not been a high priority for Polish industrial managers. ${ }^{17}$ Few firms have had capital to invest in modernization or in energy conservation equipment, and even low-cost measures are too expensive for the many firms in the state-owned sector struggling to survive.

The rise in intensity in several of the subsectors is probably associated with the sharp decline in production that occured in 1990-91. This resulted in low utilization of capacity in facilities, which often leads to inefficiency. Indeed, the net increase in energy intensity in 1987-91 of the various subsectors was inversely proportional to their change in output. A sudden decline in capacity utilization tends to raise the energy intensity of production for two main reasons. One is that various "fixed" energy uses have to be maintained even as production slides. In Poland this effect is particularly strong because of the large number of overhead activities in manufacturing enterprises not directly related to production. The other is that when production is down nouch equipment is operated at a level where its efficiency is low. This factor has undoubtedly been significant in Poland, where most factories cut back on production but few actually ceased operation.

We did not analyze the impact of change in product mix within subsectors on their energy intensity. Data are available to do such analysis, however, and the topic deserves further research.

the impacts of changes in output, industry structure, and energy intensity, "Energy Economics, Vol. 13:135-42 (1991). For this analysis, we separated the metallurgical subsector into its ferrous and non-ferrous branches.

14 The share of the four most energy-intensive subsectors in total manufacturing value added fell from $29.6 \%$ in 1987 to $26.1 \%$ in 1991 . The net impact on aggregate intensity was smaller than this would suggest because non-ferrous metals and paper \& pulp registered both large declines in value added and large increases in energy intensity.

15 The product does not exactly equal the $13 \%$ increase due to cross-term effects in the calculation.

16 As mentioned earlier, the data on value added (and thus the energy intensities) are subject to some uncertainty.

17 Intemational Resources Group, "Poland: Policy and Institutional Analysis," Washington, D.C., May 1992. 
In contrast to overall energy intensity, aggregate electricity intensity was roughly constant in the 1987-89 period and rose only slightly in 1990 and 1991 (Figure 3-5).

As Figure 3-7 indicates, the building materials subsector has been the most energy-intensive. Paper, metallurgical, ${ }^{18}$ and chemicals had been roughly similar in intensity until the sharp rise in paper in 1990 (which may reflect erroneous data). The other subsectors are fairly close in intensity; all are well below the values of the four energy-intensive subsectors.

\subsection{Physical Energy Intensities for Specific Products}

It is difficult to assess changes in the energy efficiency of particular industrial processes by examining energy intensity at the subsector level. Measuring energy use per unit of physical rather than economic output yields a more precise indication of energy efficiency because one can eliminate much of the impact of changes in the product mix of subsectors. In contrast to Western statistics, Polish statistics give long time-series on energy use per unit of physical output for dozens of industrial products. ${ }^{19} \mathrm{We}$ describe change in physical energy intensities for a number of key energy-intensive products below.

\subsubsection{Iron and steel}

Poland's production of crude steel increased considerably in the 1970s, then dropped in 1981 and 1982 before increasing again in the subsequent years to a peak of $17.1 \mathrm{Mt}$ in 1986 and 1987. It then decreased sharply to $13.6 \mathrm{Mt}$ in 1990 and $10.4 \mathrm{Mt}$ in 1991 . It was difficult to construct a trend in the overall energy intensity of crude steel production from the data available to us. However, Polish statistics do give data on the energy intensity of particular processes (Figure 3-8).

The energy intensity of pig iron, whose production is the most energy-intensive stage in steelmaking, declined greatly in the 1975-78 period, and then fell slightly through 1990 . It decreased sharply in 1991 as steel mills limited production at the least efficient blast furnaces and implemented other measures to control costs.

The energy intensity of rolled steel (including energy for production of crude steel) declined in the 1980 s, reflecting changes in steel-making technology. The share of steel produced by the more energyintensive open-hearth method decreased from $64 \%$ in 1975 to $36 \%$ in 1989 , while the share of steel produced in basic oxygen furnaces (BOF) increased from $26 \%$ to $48 \% .{ }^{20}$ The share of electric furnaces grew from $9 \%$ in 1975 to $16 \%$ in 1989 . The cause of the slight increase in intensity in 1990-91 is not fully clear. The share of steel produced in open-hearth furnaces decreased from $36 \%$ in 1989 to $25 \%$ in 1991 , which would lead one to expect a decline in the average energy intensity of steel production.

Looking at each type of steelmaking technology, the data show that the energy intensity of openhearth furnaces was relatively unchanged in the 1980-88 period. It increased in 1989, but then was stable despite the decline in utilization of capacity. It appears that there was some rationalization of production by steel mills. The energy intensity of steel from BOF (called "converted steel" in Polish statistics) also rose in the late 1980s. There has been little change in the intensity of electric furnaces since 1978.

\footnotetext{
18 Metallurgical energy intensity is lower than it might be because the energy output from blast fumaces rather than the input is counted as final energy (that is, they are considered an energy transformation sector).

19 A problem with using measures of physical energy intensity is that issues of product quality may be hidden. Change in product quality was generally slow ir. communist economies, however, and not likely to have much impact on the trends described.

20 The open hearth method is much more energy consuming than the BOF process. It requires lower pig iron input, but the BOF has a higher steel yield. The net energy intensity of the BOF process can be zero or even negative by recovery of the BOF converter gas.
} 


\subsubsection{Cement}

In 1989 cement production used about $6 \%$ of total final energy consumption by industry in Poland. ${ }^{21}$ The overall energy use per ton of cement (apparently) declined by around $15 \%$ in the first half of the 1980s (Figure 3-9). This trend seems surprising, since the energy intensity of both the wet and dry processes for making clinker (the intermediate product from which cement is made) rose in the same period, and there was no evident increase in the share of the (less energy-demanding) dry process in total clinker production. The dry process accounted for $37 \%$ of clinker in 1980 and for $38 \%$ in 1985 . A possible explanation is that cement producers lowered the ratio of clinker to gypsum and "sludge".

Although we did not have data on cement energy intensity in 1990-91, it may have declined, as the share of the wet process decreased slightly in 1990 and fell further in 1991, suggesting that enterprises sought to rely more on the less energy-demanding plants to meet the reduced demand for cement. The energy intensity of the wet process declined in 1990, while that of the dry process rose slightly in 1991.

\subsubsection{Other industries}

In the chemical industry, the data show little change in the energy intensity of chlorine, soda, and yrea, but some decline in that of carbide, especially in 1991 (Figure 3-10). We have not included products for which the energy input is primarily feedstock (such as ammonia and methanol).

In the wood \& paper industry, there was also little net change in energy intensities (Figure 3-11). There was a slight decline in 1991 in some areas, however, perhaps reflecting efforts to conserve energy.

\subsection{Mining}

For various years, we found data on energy use for coal mining (hard coal and lignite); copper, zinc and lead ore extraction and processing; and sulfur extraction. ${ }^{22}$ We did not have data on energy use for quarrying of building materials such as gravel, clay for bricks, marble, and the like.

For the mining activities for which we had data, final energy use declined from $107 \mathrm{PJ}$ in 1987 to 96 $\mathrm{PJ}$ in 1990 and $90 \mathrm{PJ}$ in 1991 . These mining activities accounted for $8 \%$ of total industrial energy use in 1991.

Ove half of the 1991 total was for coal mining. The energy intensity of hard coal production, most of which comes from underground mines, rose considerably in 1990 and 1991 (Figure 3-12). This trend reflects both fixed uses in the face of declining demand and also the need to lift coal from deeper in the mines. For lignite, there was apparently a large increase in intensity in the mid-1980s, but a gradual decline since then.

\subsection{Conclusion}

After a decade of relative stagnation, industrial energy use in Poland declined considerably in the 1989-91 period due to a sharp fall in industrial production. Aggregate manufacturing energy use per unit of value added rose sharply in 1990, however. Although the data on value added are subject to some uncertainty, our analysis indicates that structural change in the manufacturing sector contributed slightly to higher aggregate energy intensity in 1990, but then pushed aggregate energy intensity downward in

21 Cement is an intermediate building material product. When mixed with water, sand, gravel and the like it forms concrete. To make cement the quarried raw materials are ground and blended together and then burnt at a ternperature of about 1500 degrees. The burnt product is called clinker. The clinker is cooled and ground with gypsum to make cement.

22 In the Polish statistics, coal mining falls in the fuels \& power subsector; copper, zinc and lead ore extraction and processing in metallurgical; and sulfur extraction in chemicals. 
1991. On balance, change in subsectoral energy intensities in manufacturing pushed significantly upward on aggregate energy intensity in 1989, 1990, and 1991.

Low utilization of capacity in the depressed economic environment is a plausible explanation for the rise in energy use per value added seen in many subsectors. The data on energy use per ton for a number of energy-intensive products are not entirely consistent with the value-added-based series, however. They show an increase in 1990-91 in some cases, but little change in others. The data on physical energy intensities suggest that the actual increase in subsectoral energy intensities may be less than indicated by the value-added-based series.

Evaluation of the response of factories to the changed economic conditions in Poland requires further investigation. Anecdotal evidence suggests that some managers have undertaken various measures to rationalize operations in the face of reduced demand and rising energy cosis, but that dealing with issues of marketing and simple survival have generally taken precedence over energy saving. So far, few enterprises have had the resources to make the type of investments that would bring the significant improvement in energy efficiency that all observers agree is possible. 


\section{Poland Industry Final Energy Use By Type, 1970-1991}

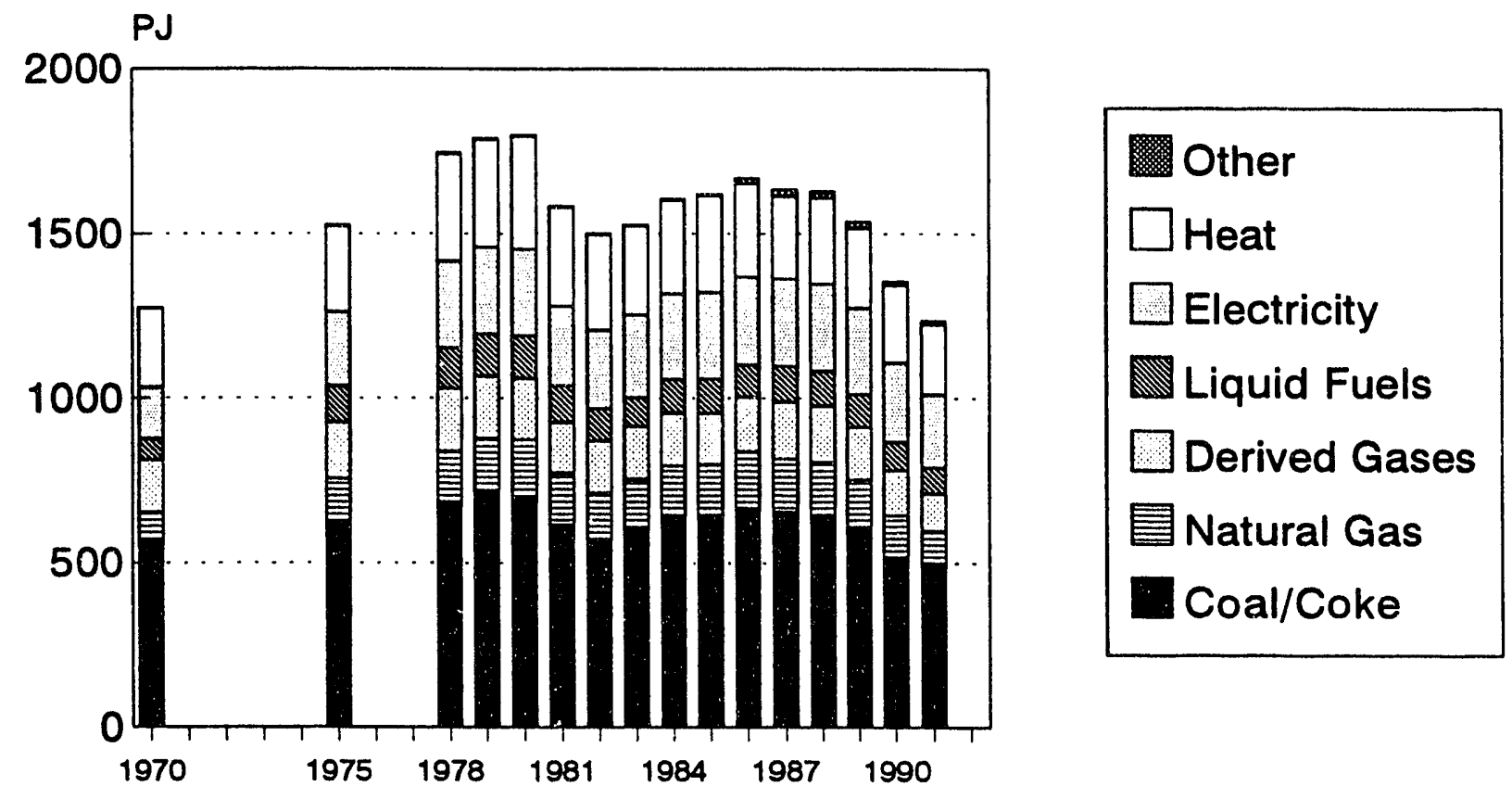

Figure 3-1

\section{Poland Industry Final Energy Use By Sub-Sector, 1970-1991}

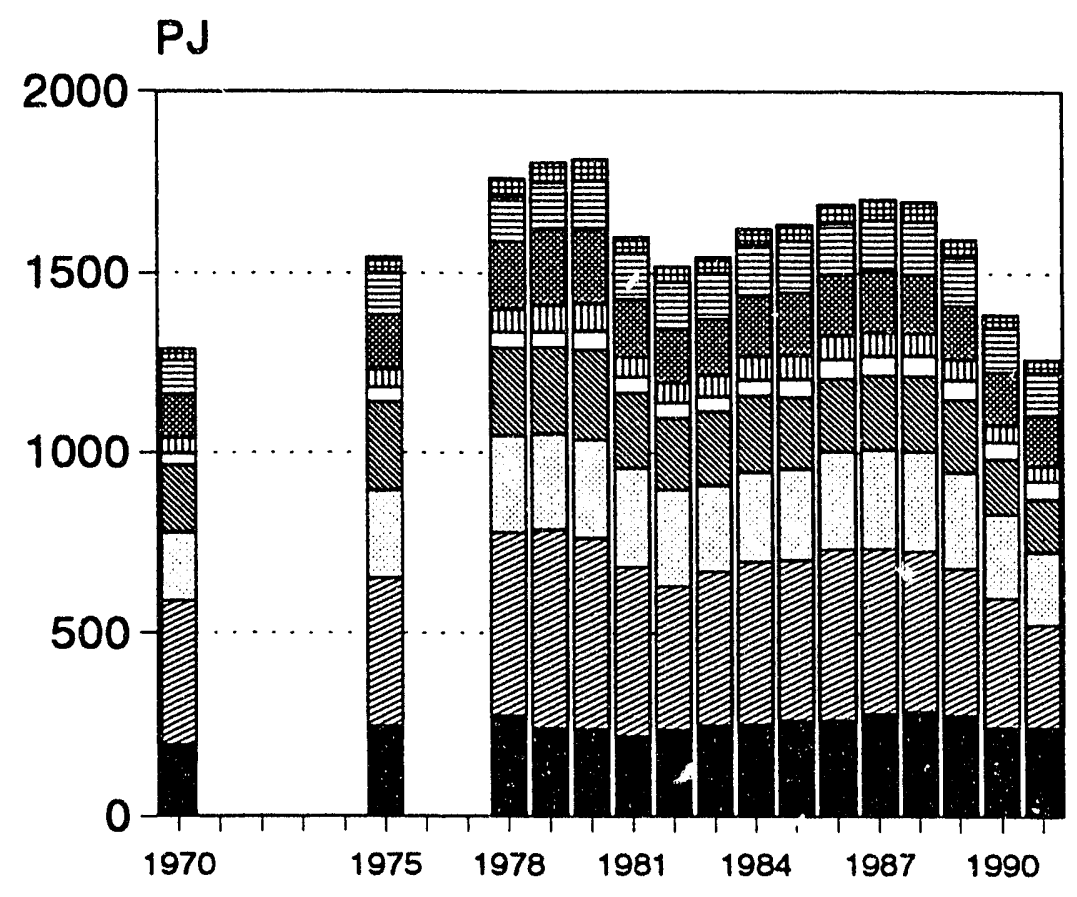

Others

篔 Food

Machinery

血 Textiles

$\square$ Paper

$\mathbb{N}$ Bldg. Materials

$\square$ Chemical

Metallurgical

Fuel \& Power

Figure 3-2 


\section{Poland Industrial Value-Added By Sub-Sector, 1987-1991}

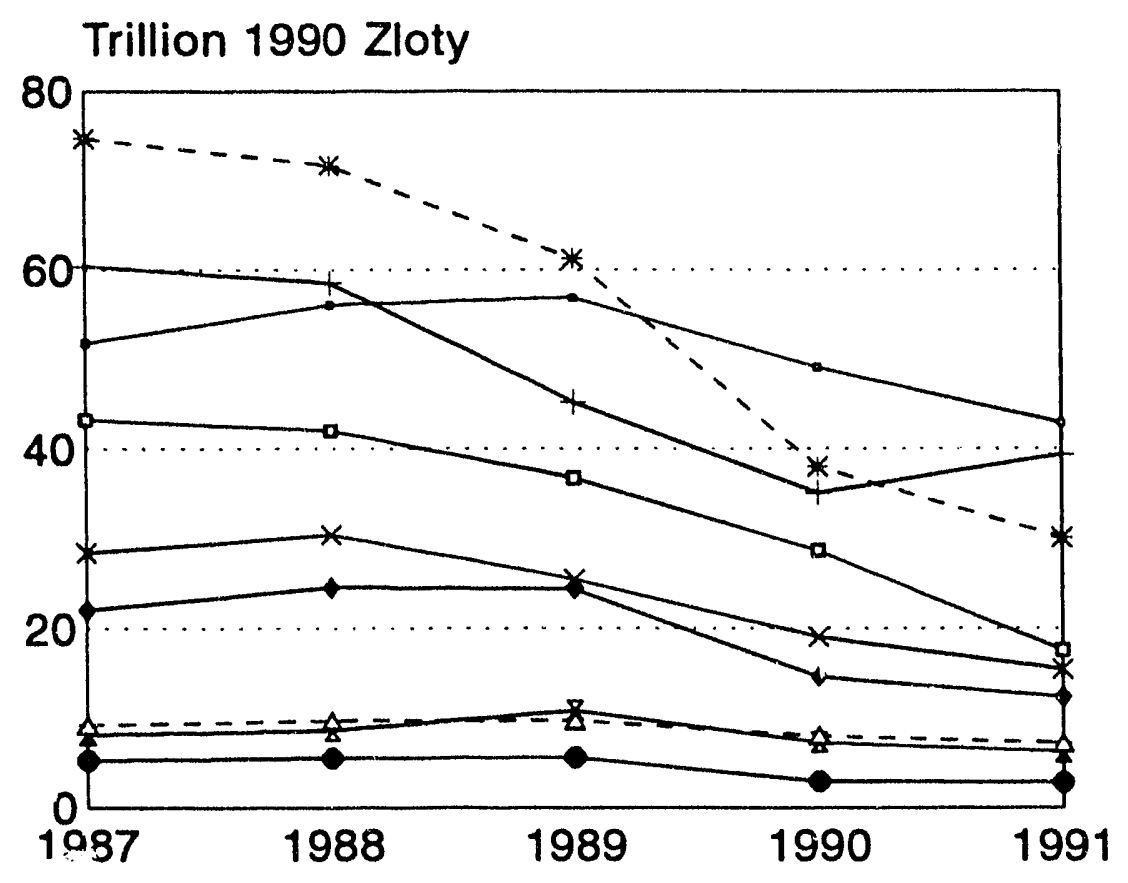

- Machinery

+ Food.

* Fuel \& Power

$\rightarrow$ Metallurgical

* Chemical

$\rightarrow$ Textiles

$\triangle$ Bldg. Materials

\& Others

- Paper

Figure 3-3

\section{Poland Industrial Value-Added By Sub-Sector, 1987-1991}

Trillion 1990 Zloty

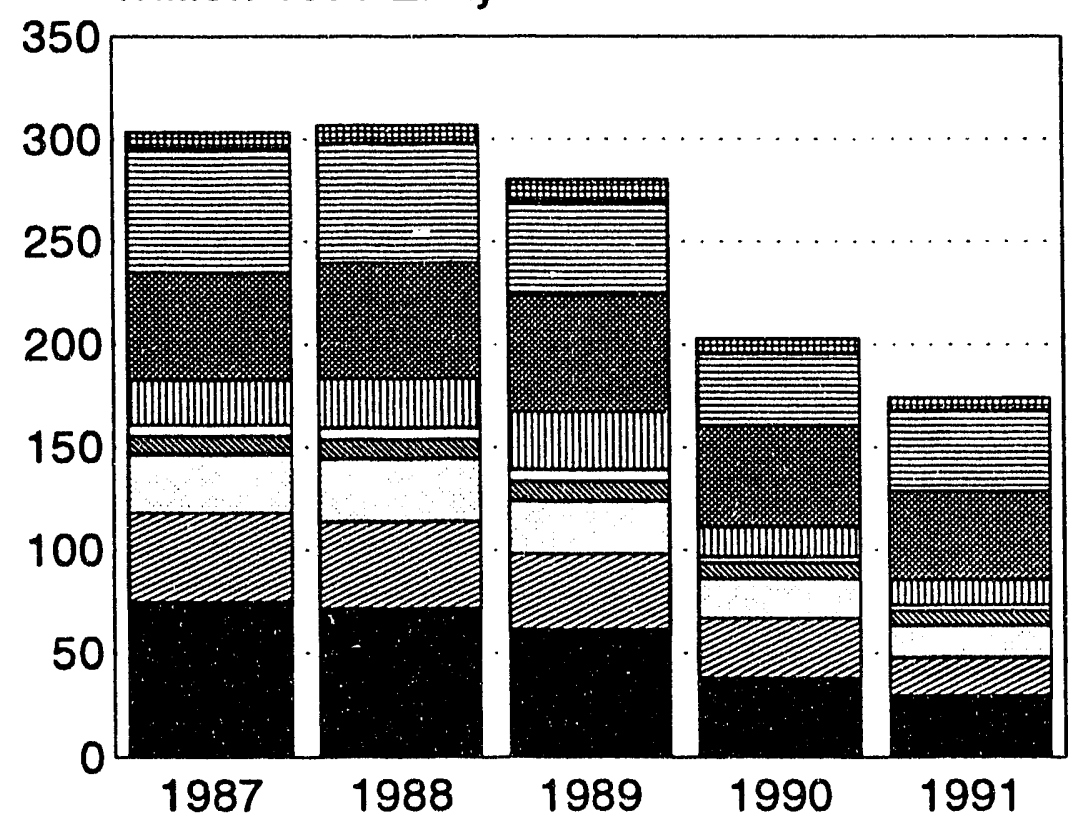

Figure 3-4

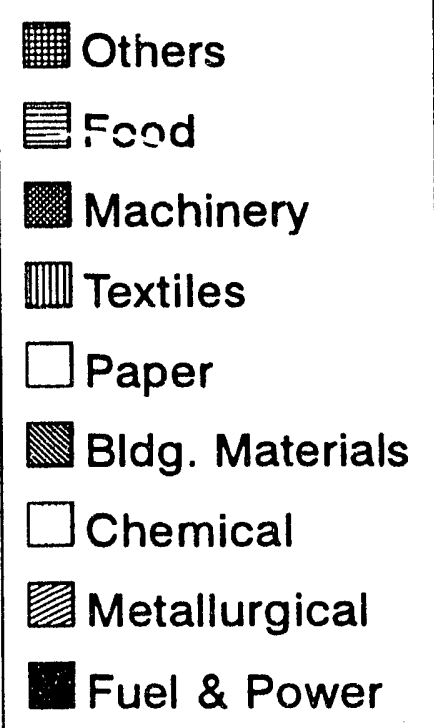




\section{Poland Manufacturing Aggregate Energy Intensity 1987-1991}

MJ value-added ('000 $1990 \mathrm{ZI})$

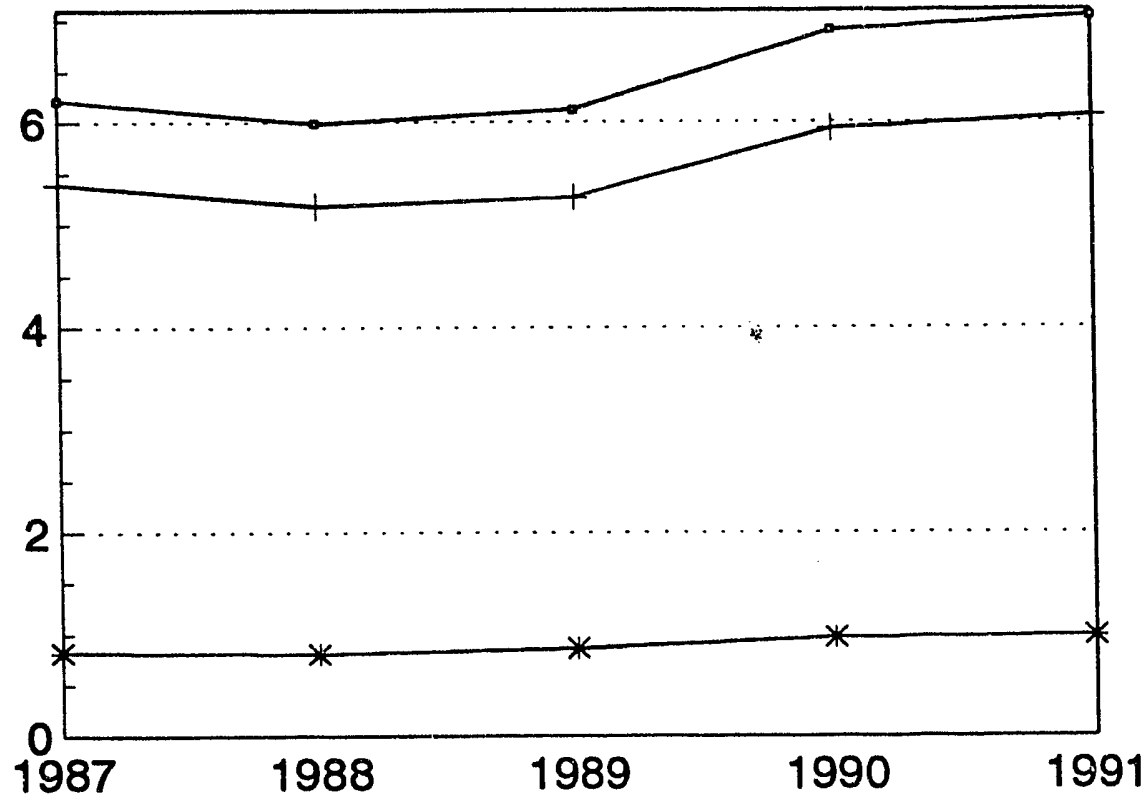

$\rightarrow$ Energy.

+ Non-Elect.

* Electricity

Figure 3-5

Poland Manufacturing Energy Use Effects of Output, Structure and Intensity

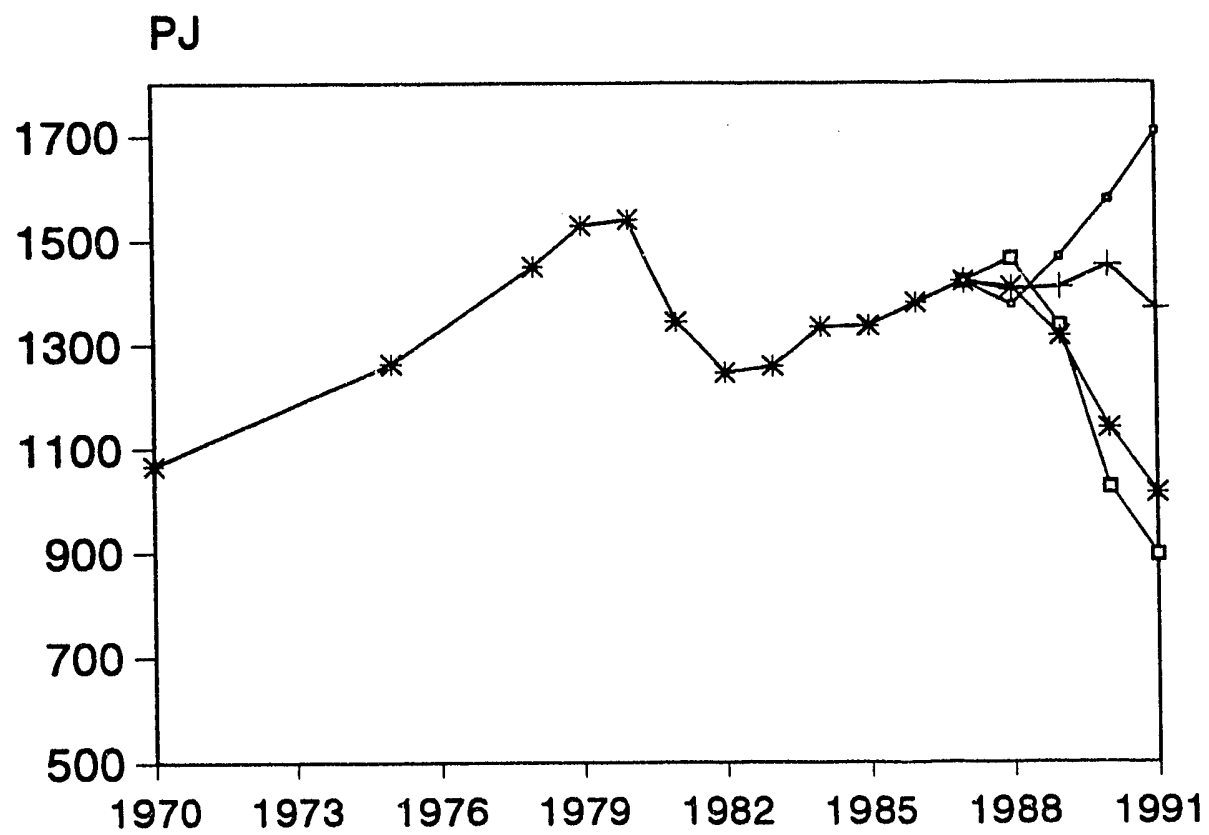

$\rightarrow$ Intensity

+ Structure

* Actual

$\rightarrow$ Output

Shows impact on energy use of changing only one parameter.

Figure 3-6 

By Sub-Sector, 1987-1991

MJ/000 $1990 \mathrm{ZI}$.

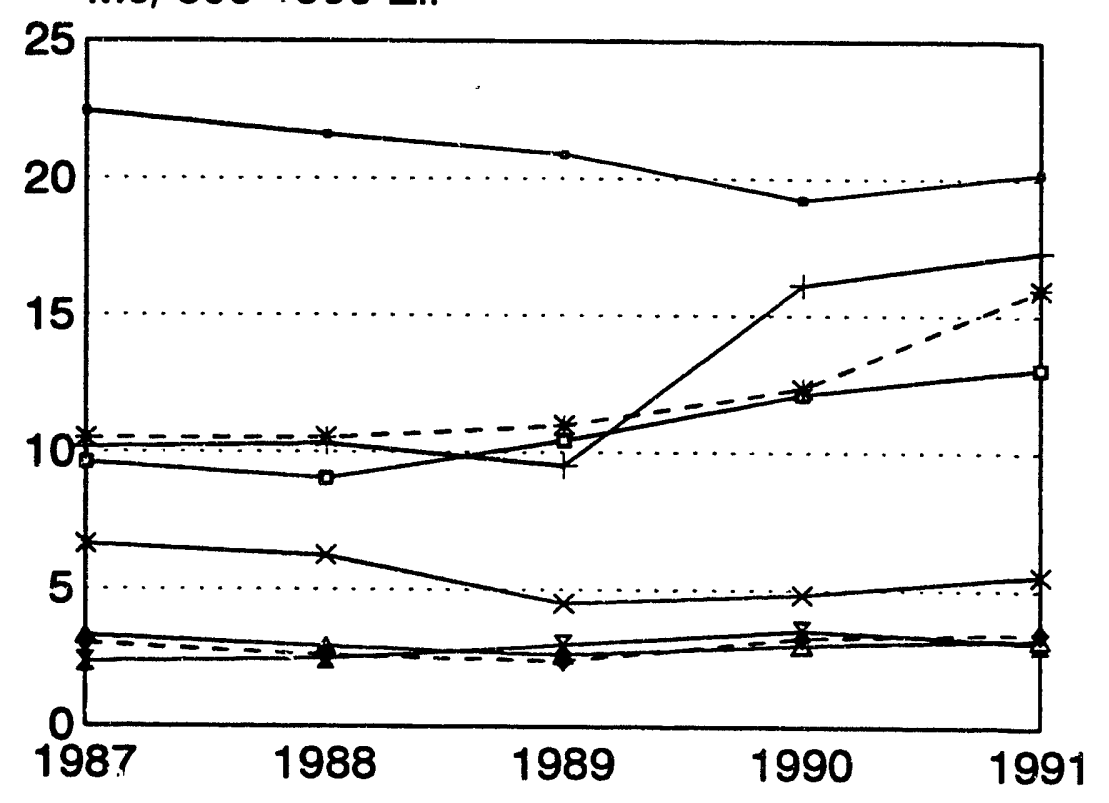

- Bldg. Materials*
+ Paper
* Metallurgical*
$\rightarrow$ Chemical*
* Others
$\rightarrow$ Textiles
- Machinery
\& Food

Figure 3-7

* Includes mining

\section{Poland Industry Energy Intensities Iron \& Steel, 1970-1991}

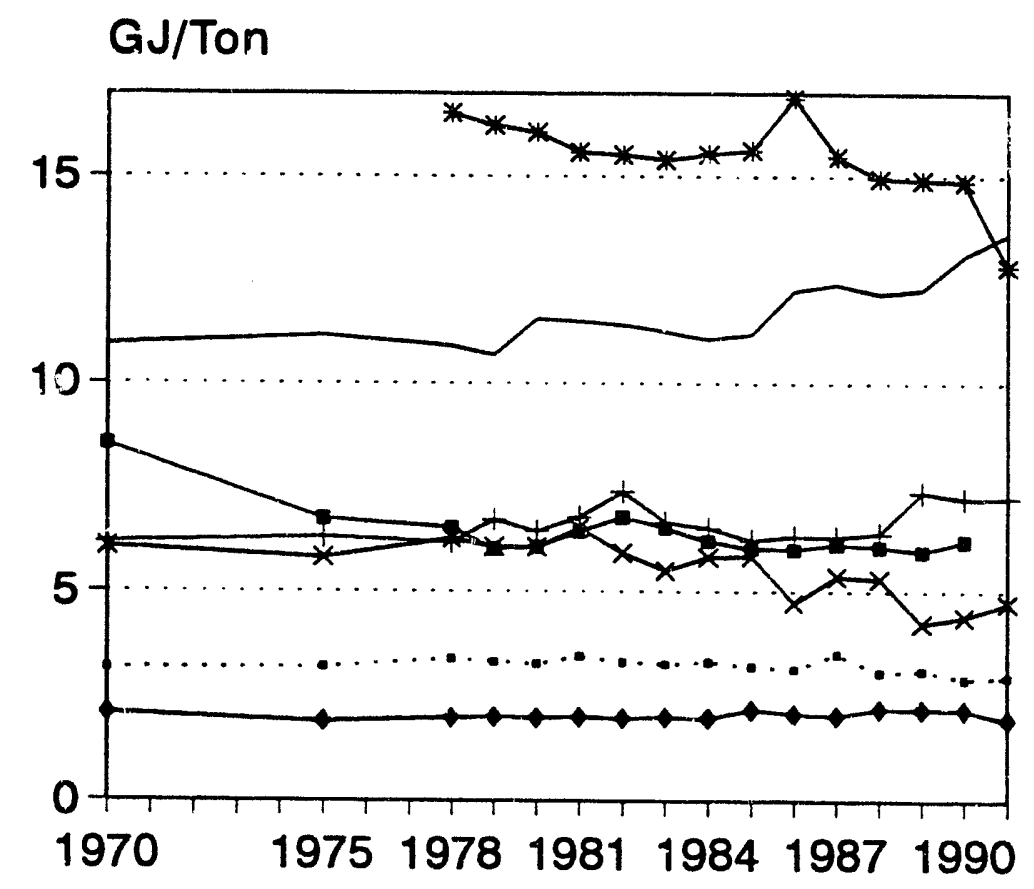
- Cast Iron Products * Pig Iron
+ Steel, Open Hearth
- Steel Pipes
* Rolling Steel
- Steel, Elect. Furnace
$\sim$ Iron Sinter

Figure 3-8 


\section{Poland Industry Energy Intensities Cement, 1970-1991}

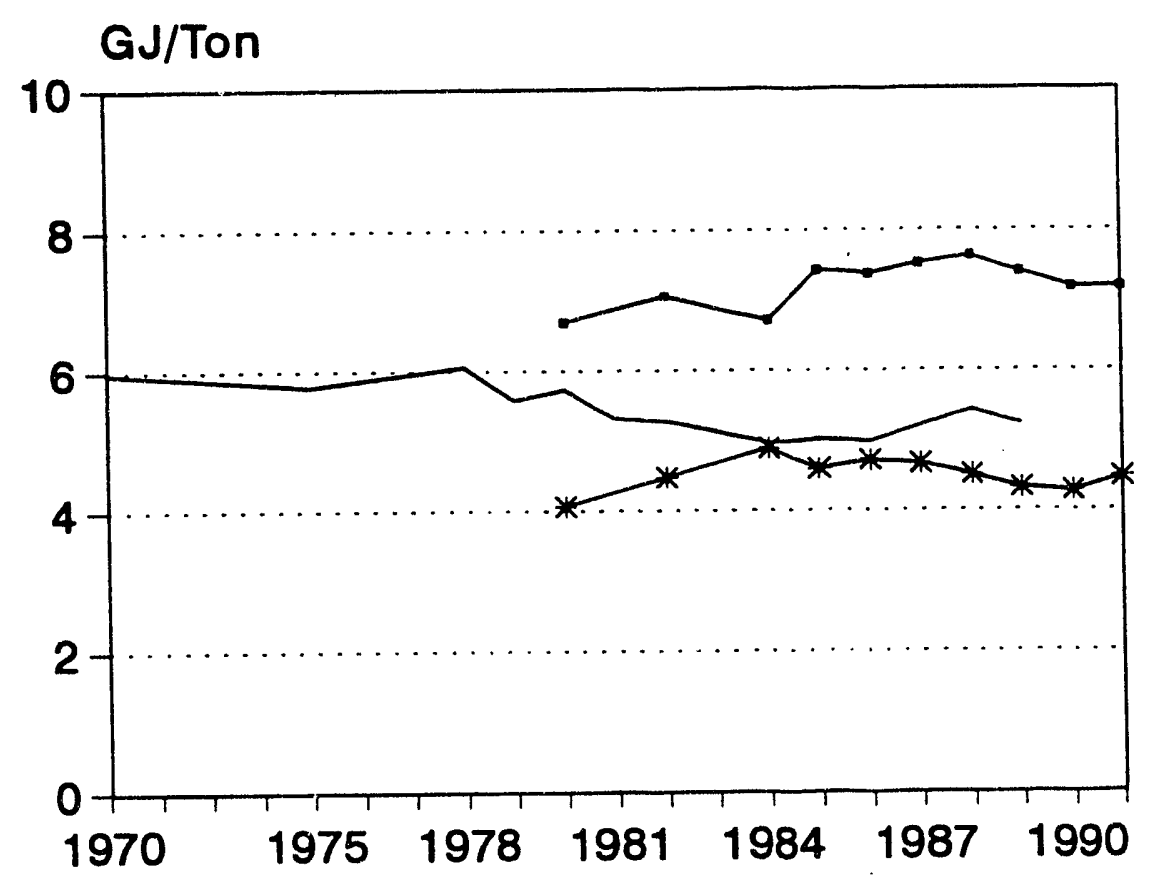

- Clinker Wet

- Cement

* Clinker Dry

Figure 3-9

\section{Poland Industry Energy Intensities Chemicals, 1970-1991}

GJ/Ton

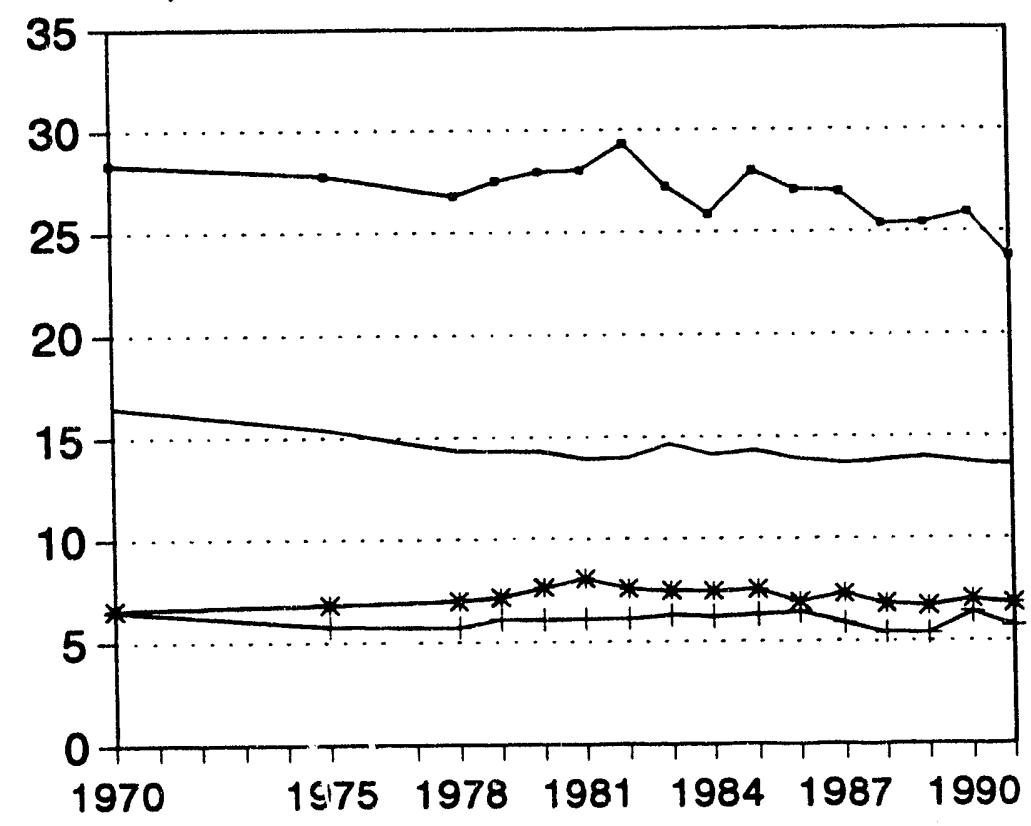

Carbide

- Chlorine (Mercury)

* Soda

+Urea

Figure 3-10 


\section{Poland Industry Energy Intensities Wood \& Paper, 1970-1991}

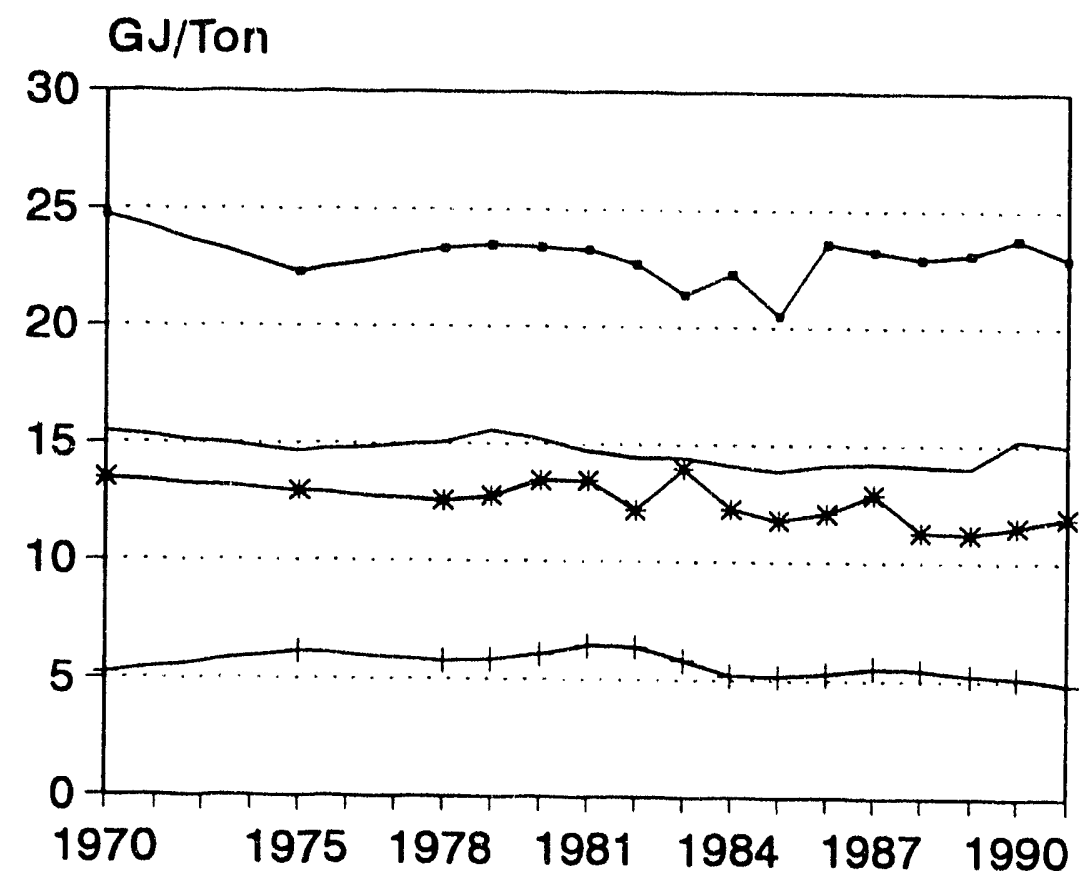

- Chemical Pulp

- Paper

* Fiberboard

+ Chipboard

Figure 3-11

\section{Poland Industry Energy Intensities Coal Mining, 1970-1991}

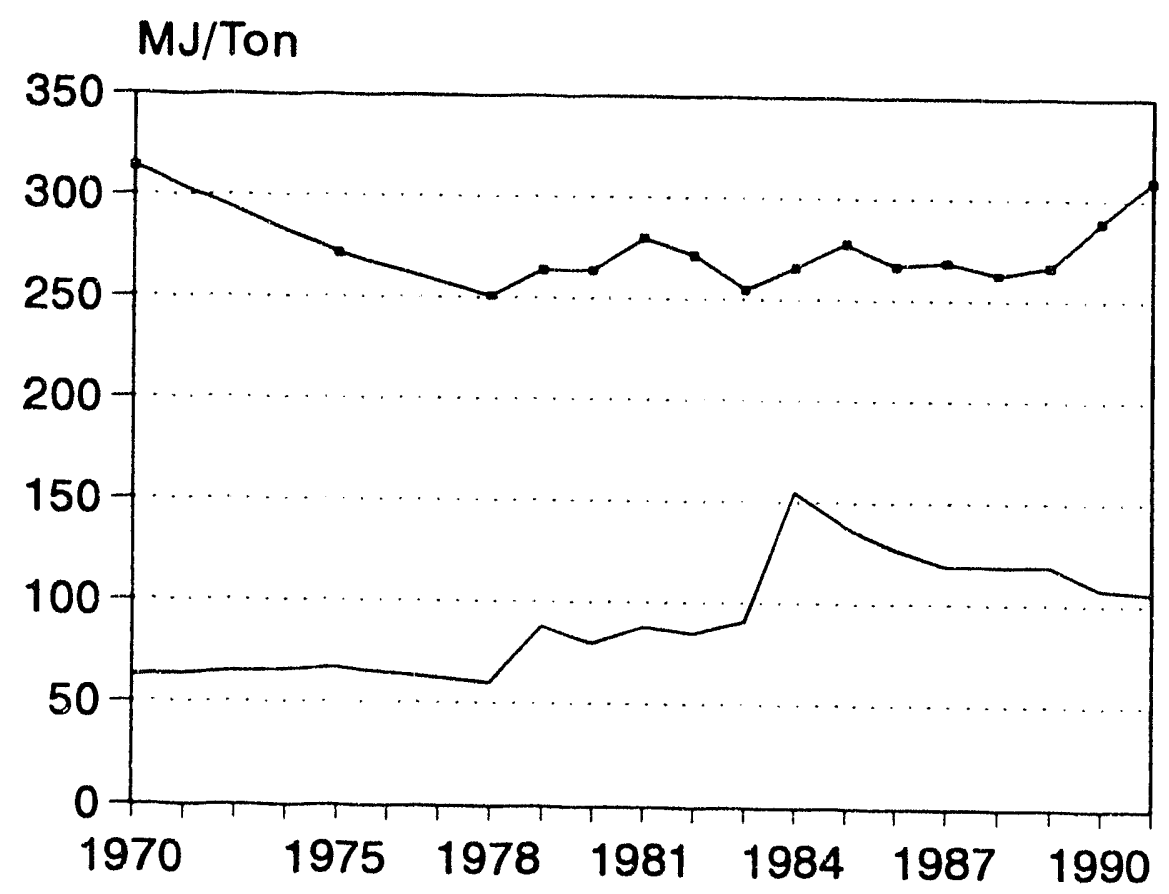

- Hard Coal

- Lignite

Figure 3-12 


\section{TRANSPORT}

\subsection{Energy Data Issues}

Polish energy statistics on transport include only state enterprises engaged in passenger and freight transport and thus greatly undercount actual energy use for transportation in recent years. In order to gain a more complete picture of transportation energy use, we made the following adjustments to the Polish data:

- Moved use of gasoline from Other Consumers (for cars, motorcycles, and small trucks) to Transport. ${ }^{1}$

- Moved liquid fuels use by municipal buses and electricity use by municipal light rail (both counted in municipal enterprises under Other Consumers in Polish statistics) to Transport; ${ }^{2}$

- Moved diesel use from Other Consumers (for private diesel trucks and tractors, private buses, military vehicles, and private construction) to Transport. Some of this consumption is for private agricultural purposes (tractors), but the amount is uncertain.

- Moved estimated fuel use by vehicles owned by state industrial enterprises and industry associations from Industry.

- Removed consumption of heat and estimated non-traction use of coal/coke and electricity (all of which are included in Polish statistics under Transport), since these are properly considered building energy uses (e.g. train stations), not for transport per se.

We have left marine use of fuels in the data even though most of this is for international shipping. ${ }^{3}$

\subsection{Overview of Transport Energy Use}

Combining Polish official statistics with our additions and revisions, we find that transport of people and goods accounted for around 15\% of Polish final energy use in 1991. Transport energy use rose in the 1970 s as private and public consumption of liquid fuels grew, but was stagnant in the 1980s (Figure 4-1). It fell sharply in 1990 with the recession, but rose slightly in 1991 as rising use of private gasoline compensated for decline in state transport enterprises.

The transport sector has seen considerable change in its fuel mix. In 1970 coal use in rail transport (mainly steam locomotives) accounted for over half of transport final energy use. Gradually coal became insignificant as inefficient steam locomotives gave way to diesel and electric ones, and liquid fuels became the dominant source. The increase in private use of gasoline was considerable (from an estimated $25 \mathrm{PJ}$ in 1970 to $87 \mathrm{PJ}$ in 1980 to $144 \mathrm{PJ}$ in 1991).

Separating out the energy used for freight and passenger transport is not easily accomplished with the Polish statistics. The statistics present a disaggregation of energy use by state enterprises engaged in intercity rail and road, marine, air, ${ }^{4}$ and other transport (including pipeline); but this split is available only from 1986 onwards. To these data we have added (or removed) energy use in the categories listed above.

\footnotetext{
1 Due to missing data, we estimated gasoline consumption for 1970 and 1975 using statistics on number of cars and motorcycles.

2 In the case of municipal buses, we had data only for 1986-91; we estimated energy use for earlier years by assuming a constant value for energy use per passenger-km (which we also estimated, as described below).

3 We had energy use data for 1986-91, and estimated earlier years using the 1986 ratio of fuel to tons carried. Marine fuel use amounted to $41 \mathrm{PJ}$ in 1991.

4 Data on jet fuel consumption include fuel purchased by non-Polish air carriers. Total use in 1991 was only 10 PJ, and was
} 
The resulting energy use by mode is shown in Figure 4-2. Private cars, motorcycles and gasoline-fueled trucks accounted for $23 \%$ of the total in 1986 , but for $32 \%$ in 1991 . The private use of diesel grew considerably in 1991, and it is the next largest mode. This consumption includes private agricultural use as well as private trucks, private buses, and military vehicles; disaggregation of the data is difficult to estimate reliably. The share of rail was considerably lower in 1991 than in 1986. A somewhat more detailed disaggregation (based on various estimates) is presented in the Appendix.

\subsection{Activity and Structure}

\subsection{Passenger transport (travel)}

Polish statistics on passenger travel are incomplete. The data on rail and bus passenger-km (pass$\mathrm{km}$ ) refer to intercity travel only. There are various statistics on municipal bus and light rail transport, but pass-km are not given. Counts of passenger car traffic are only conducted in Poland on intercity roads.

The Polish statistics show that reported intercity pass-km rose at an average rate of $4 \%$ per year in the 1970 s, and at $2 \%$ per year in the 1980 s. There was a decline of $15 \%$ in 1990 and a further $15 \%$ in 1991. If intercity travel in private cars and buses were counted, however, the decline in 1990-91 would be much less. Anecdotal evidence indicates that many people in private business use cars for intercity travel rather than trains and buses, which have traditionally been the dominant modes for such travel. There has also been considerable increase since 1989 in transport by private buses. Domestic air travel has grown since the 1970 s but is still relatively insignificant.

In order to construct a more complete picture of (motorized) passenger travel, we estimated a plausible range for pass-km in cars, motorcycles, and municipal bus and light rail for 1978 and 1988-91 (Table 4-1). (We are not aware of any data on bicycle and pedestrian pass-km.) The estimates are based on statistics on the number of vehicles and various assumptions as to average distance travelled and passengers carried, as described in the table notes. The official statistics account for $51-60 \%$ of estimated total pass-km in 1978, but for only $33-42 \%$ in 1991 . This change mainly reflects the three-fold increase in estimated car pass-km.

mainly for international travel. 
Table 4-1. Poland: Passenger-Kilometers of Motorized Domestic Travel, Reported and Estimated (billion)

\begin{tabular}{lcccc}
\hline Mode & 1978 & 1988 & 1989 & 1991 \\
\hline Official statistics & & & & \\
Intercity rail & 47 & 52 & 56 & 40 \\
Interciiy bus & 49 & 57 & 58 & 42 \\
Air & 2.5 & 3.5 & 4.9 & 3.6 \\
Inland water & 0.1 & 0.1 & 0.1 & - \\
$\quad$ Subtotal & 99 & 113 & 119 & 86 \\
LBL estimates & & & & \\
Car & $31-46$ & $64-97$ & $75-112$ & $84-126$ \\
M'cycle & 10 & 8.1 & 7.8 & $21-36$ \\
City bus & $16-26$ & $24-39$ & $23-37$ & $7.2-11.5$ \\
Light rail & $9.6-15$ & $7.8-12$ & $7.7-12$ & $204-263$ \\
Total & $165-196$ & $217-268$ & $232-287$ & \\
\hline
\end{tabular}

For cars, LBL estimates were derived from vehicle stock data and assumptions regarding average annual distance traveled (see Appendix). We assumed an average of 2 persons/car.

The ranges are $+20 \%$ and $-20 \%$ around the central estimate. For motorcycles, we assumed $5000 \mathrm{~km} / \mathrm{year}$. For city bus \& light rail, we used: (vehicles in service) $x$ (average km/day) $x$ (seats/vehicle) $x$ (estimated load factor, 25-40\%). Light rail includes trolley buses.

Combining the official and estimated data, we see that the share of the various modes in total pass$\mathrm{km}$ has changed considerably (Figure 4-3). (The figure uses the midpoint in the estimated range for cars and municipal transport.) The estimated share of cars rose from around $22 \%$ in 1978 to around $50 \%$ in 1991. It is likely that the average annual distance traveled per car has risen since 1989. Prior to that, gasoline was rationed, thus limiting car travel somewhat. There has also been rising use of cars for private business. In contrast, passenger travel in municipal public transport (bus and light rail) apparently declined slightly in 1989-91. This trend could reflect less travelling to find goods that had been scarce in the last years of the communist period.

The number of registered passenger cars in Poland rose at a very rapid rate (from a low base) in the 1970 s (an average of $18 \%$ per year). The rate of growth was much slower (9\%/year) in the $1980 \mathrm{~s}$, but enough to bring a more than two-fold increase in the fleet. With the opening of the economy, however, there was a surge in purchase of used cars imported from Western Europe. In 1991, the number of registered passenger cars rose by 0.85 million, or $16 \%$. In order to protect the domestic car industry (and gain revenues), the Polish government raised duties on imported cars in 1992, which has greatly reduced such imports.

Motorcycles were relatively important in 1970 when car ownership was very low. Their number was roughly equal that of cars in 1978 , but it has declined since then.

\subsubsection{Freight transf ort}

The Polish statistics on freight transport activity are more complete than for passenger transport, as there is less private activity. ${ }^{5}$ The importance of coal transport in the economy (for both domestic use and

5 The statistics include freight transport by state transport companies (mainly rail and road) as well as by industry-wide and individual companies in other economic sectors. The official statistics on road freight activity in 1990-91 include estimates of 
export) is reflected in the high share of rail in total freight tonne-km (t-km) (Figure 4-4). Although that share has declined from $76 \%$ in 1970 to $60 \%$ in 1990, it remains much higher than in Western Europe.

Public road transport (which includes own-transport by industrial and agricultural state enterprises) doubled its share of total $\mathrm{t}-\mathrm{km}$ from $12 \%$ in 1970 to $23 \%$ in 1989 . Road $\mathrm{t}-\mathrm{km}$ declined in 1990-91, but somewhat less than rail t-km. Freight transport by private trucks has increased considerably sinci 1989; if estimated t-km by private trucks are included, the total freight t-km in $1991 \mathrm{w}$ as only slightly less than in $1990 .^{6}$

The number of trucks in Poland (including "specialty vehicles" such as fuel tank-trucks) rose at an average rate of nearly $9 \%$ /year in the 1970 s and at $5.3 \%$ /year in the $1980 \mathrm{~s}$. (Not all registered trucks are in use, however.) The number of private trucks rose rapidly in the $1980 \mathrm{~s}$, and then increased even more after the end of the communist era (by 20\% in 1990 and by around 25\% in 1991). Many of the trucks owned by state trucking enterprises were sold to private operators in recent years. Whereas in 1980 around one-fourth of the truck fleet was private, by 1990 half of the fleet of about one million vehicles was privately-owned, and this percentage rose further in 1991. An important use of private trucks in recent years is transport of coal from mines for sale to small consumers in cities and villages.

Around 58\% of Polish trucks (not including tractor-trailers) were less than two ton capacity in 1991. The majority of trucks larger than two tons have diesel engines, but the exact share is uncertain.

A large share (perhaps half) of the private trucks are mainly of two types: small "flatbed" trucks that are used like "pickup" trucks in the U.S. (mainly using gasoline), and cargo vans. The older cargo vans made in Poland use gasoline, but newer (imported) vans use diesel. These vans are the common vehicle for small businesses. The "flatbed" trucks are commonly used by farmers.

The statistics on freight $\mathrm{t}-\mathrm{km}$ do not include movement of agricultural goods by tractor, which is by no means trivial. The number of tractors has been roughly the same as the number of trucks since 1980 . Private tractors accounted for around half of the total in 1980, but for nearly $80 \%$ in 1990.

\subsection{Energy Intensities}

Long-term trends in rransport energy intensities (energy use per vehicle-km, pass-km, or t-km) are difficult to estimate from the Polish data, but some observations are possible.

\subsubsection{Private cars}

Data on private consumption of gasoline include motorcycles and an unknown number of private trucks/vans, so it is difficult to isolate use by cars. Uncertainty regarding the share of diesel cars in total private cars compounds the problem. ${ }^{7}$ Considering plausible values for the uncertain variables, however, it is obvious that the average fuel use per car declined between the late 1970s and the late 1980 s.

Change in the average distance travelled by cars is uncertain, but probably not large for most of the period. Polish sources suggest that average distance per car has risen somewhat in 1991-92 due to the

private activity, but we have excluded these data from the totals to maintain consistency over time. We have subtracted marine t-km from the Polish statistics (which apparently refer to shipping by Polish enterprises) since these are not properly part of domestic freight transport.

6 Central Statistical Office (GUS), Transport -- Wyniki Dzialalnosci w 1991 R., Warsaw, May 1992.

7 We estimated (in consultation with J. Norwisz of PAN) that the share of diesels in total private cars rose from $2 \%$ in the early 1970 s up to $6 \%$ in 1988 , and then fell slightly in 1989-91 as the total number of private cars grew rapidly. We assumed an energy intensity of $3.6 \mathrm{MJ} / \mathrm{v}-\mathrm{km}$ for most of the period, with some decline after 1986, and an average distance traveled of 20,000 km per year. 
increased use of cars by private businesses. The decline in average fuel use is probably due to the marked shift in the size mix of the passenger car fleet toward smaller cars. Whereas in 1980, $44 \%$ of cars had engines above $2000 \mathrm{cc}$, by 1989 only $16 \%$ were in this category, and $24 \%$ were $1000 \mathrm{cc}$ or less (Table 4 2). The share of cars with engines of $1500 \mathrm{cc}$ or less rose from $34 \%$ to $54 \%$. This shift in composition reflects the rising production (in Poland) of the mini-compact FIAT 126p and also sub-compacts in the $1000-1500 \mathrm{cc}$ range. The trend toward smaller cars may have shifted in 1990-91, however, with the surge in used cars (many of them expensive models) from the West.

\begin{tabular}{lcc}
\hline \multicolumn{3}{c}{ Table 4-2. Polish Passenger Car Fleet (\%) } \\
\hline Engine Size & 1980 & 1989 \\
\hline $0-1000 \mathrm{cc}$ & 16 & 24 \\
$1001-1500 \mathrm{cc}$ & 18 & 30 \\
$1501-2000 \mathrm{cc}$ & 22 & 29 \\
$>2000 \mathrm{cc}$ & 44 & 16 \\
Total & 100 & 100 \\
Total (000's) & 2383 & 4846 \\
\hline
\end{tabular}

Source: Polish Ministry of Industry, in: International Energy Agency, Energy Policies, Poland, 1990 Survey, Paris, 1991.

Data prepared by the Ministry of Industry in 1990 show a decline in the average fleet fuel intensity of passenger cars from $11 \mathrm{~V} / 100 \mathrm{~km}(21 \mathrm{mpg})$ in 1980 to $9 \mathrm{l} / 100 \mathrm{~km}(26 \mathrm{mpg})$ in $1989 .{ }^{8}$ We do not know how these values were derived, but they are roughly consistent with our own estimates. The same report shows an increase in average distance driven from $10,000 \mathrm{~km}$ in 1980 to $11,000 \mathrm{~km}$ in 1989 . We estimate that the value in 1989 was below $10,000 \mathrm{~km}$.

\subsubsection{Rail transport}

Although we did not have data over a long time period, it is evident that the energy intensity of rail transport (expressed in final energy) has declined considerably over the years. The reason is that steam and diesel locomotives have given way to electric locomotives, which use far less final energy to provide the same traction power. ${ }^{9}$ If the electricity use were expressed in terms of primary energy, the picture would be somewhat different, but the overall intensity would still see a decline. Even though the primary energy intensity of electric locomotives is roughly three times higher than the final energy intensity, they are still far more efficient than steam locomotives, and are slightly more efficient than diesel locomotives (assuming similar operating conditions).

\footnotetext{
8 International Energy Agency. Energy Policies, Poland, 1990 Survey. Paris, 1991.

9 The share of total rail $\mathrm{t}-\mathrm{km}$ and pass-km in steam locomotives fell from $11 \%$ and $18 \%$ respectively in 1978 to near zero in 1991. The share of diesel locomotives, which had risen in the 1970 s, also declined (from $32 \%$ to $9 \%$ of $\mathrm{t}-\mathrm{km}$ and from $35 \%$ to $22 \%$ of pass-km).
} 


\subsubsection{Transport energy intensities since 1987}

Polish statistics report average energy intensities of various transport modes in recent years (Table 4-3). For rail transport, there was some increase in intensity for electric and diesel locomotives in 1990 and 1991, reflecting lower utilization of the system (i.e., more empty wagons). ${ }^{10}$ There was an increase for most other modes as well, probably also related to utilization. The higher intensities of "professional" bus and truck transport relative to public transport refiect the use of larger vehicles by the latter.

\begin{tabular}{|c|c|c|c|c|c|}
\hline Mode & Unit & 1987 & 1989 & 1990 & 1991 \\
\hline \multicolumn{6}{|l|}{ RAIL* } \\
\hline Electric & $\mathrm{MJ} / 10^{3} \mathrm{t}-\mathrm{km}$ & 77 & 74 & 79 & 85 \\
\hline Diesel & $\mathrm{MJ} / 10^{3} \mathrm{t}-\mathrm{km}$ & 376 & 402 & 462 & 518 \\
\hline \multicolumn{6}{|l|}{ BUS** } \\
\hline Public (Intercity) & $\mathrm{MJ} / 10^{3} \mathrm{p}-\mathrm{km}$ & 294 & 249 & 265 & 273 \\
\hline Professional & $\mathrm{MJ} / 10^{3} \mathrm{p}-\mathrm{km}$ & 324 & 341 & 358 & 379 \\
\hline Municipal & $\mathrm{GJ} / 10^{3} \mathrm{~km}$ & 9.3 & -- & 12.5 & 11.8 \\
\hline \multicolumn{6}{|l|}{ TRUCKS** } \\
\hline Public & $\mathrm{MJ} / 10^{3} \mathrm{t}-\mathrm{km}$ & 1485 & 1415 & 1502 & 1588 \\
\hline Professional & $\mathrm{MJ} / 10^{3} \mathrm{t}-\mathrm{km}$ & -- & 2275 & 2267 & 2390 \\
\hline Own & $\mathrm{MJ} / 10^{3} \mathrm{~km}$ & -- & 7225 & 7502 & 7694 \\
\hline
\end{tabular}

Source: Fuels and Energy Statistics

* Standard gauge. Diesel locomotives are mainly used for intervillage connections, for heavy work in mountain regions, and for work at rail stations.

** Public refers to state transport companies, professional to industry-wide transport companies, and own to individual state enterprises.

\subsection{Conclusion}

Total final energy use for transport in Poland changed very little between 1970 and 1989, as rising use of liquid fuels made up for declining use of coal in steam trains. Energy use fell in 1990 but not in 1991, as increased energy use by private cars balanced further decline in the state transport sector. Private cars (and gasoline trucks) accounted for an estimated 57\% of total energy use for transport in 1991 , up from $38 \%$ in 1986.

Passenger travel grew steadily during the 1980 s as car ownership increased. There was a strong surge in car ownership in 1991 as Poles purchased cars imported from the West. In contrast, freight transport $(\mathrm{t}-\mathrm{km})$ was stagnant in the 1980s. Public-sector freight transport de slined considerably in 1990 and 1991, mainly due to greatly decreased rail transport resulting from the economic recession and reduced shipment of coal. The considerable growth in use of private trucks in 1990-91 was nearly enough to make up for the decline in public-sector freight transport.

10 The data are in terms of gross $\mathrm{t}-\mathrm{km}$, which refers to the gross weight carried by freight and passenger trains, including the weight of the train itself. 
The average energy intensity of passenger cars declined during the 1980 s as smaller cars came to play a greater role in the fleet. This trend may have reversed in the recent past, however, as larger cars from the West have entered the fleet in great number. The overall final energy intensity of rail transport also decreased as electric locomotives became dominant. Change in the energy intensity of trucks and buses is uncertain, but probably minimal. 


\section{Poland Transport Final Energy Use* State, Municipal, \& Private}
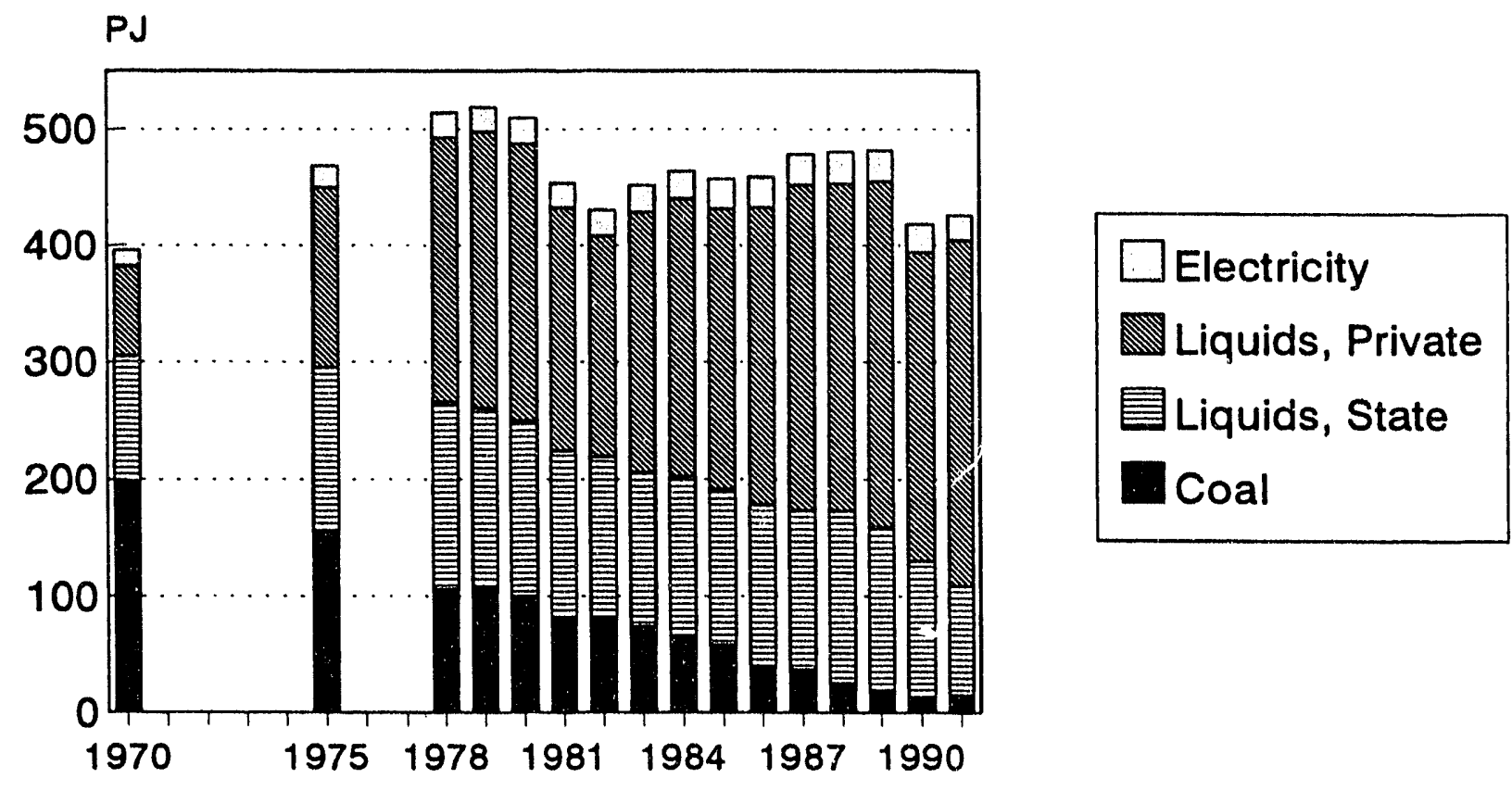

Figure 4-1

\section{Poland Transport Energy Use By Mode, 1986-1991}

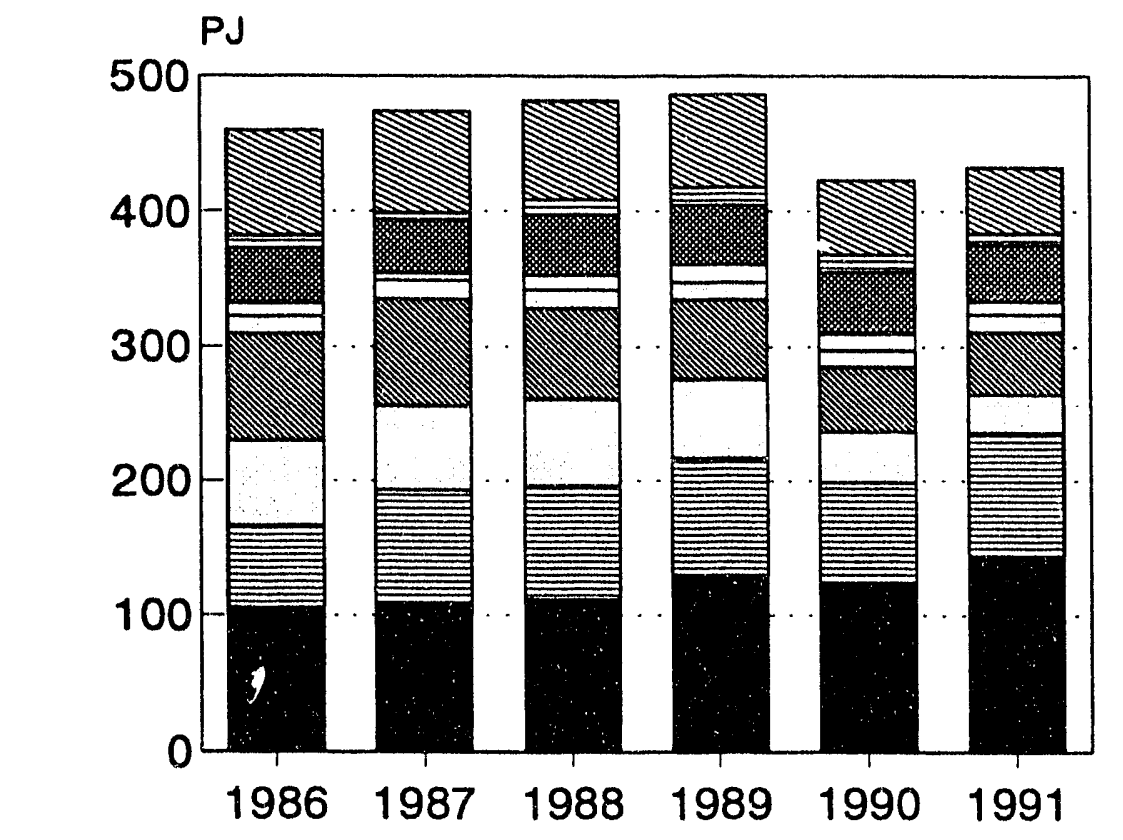

Industry Vehicles

Other

Marine

$\square$ Air

$\square$ City bus/Light rail

$\mathbb{R a i l}_{\text {, Intercity }}$

$\square$ Road, Intercity*

Private Diesel**

Private Gasoline ${ }^{\star \star *}$

\footnotetext{
* State transport enterprises only. "*Includes tractors and military. "*Mainly cars.
}

Figure 4-2 


\section{Polish Passenger Transport Passenger-km By Mode*}

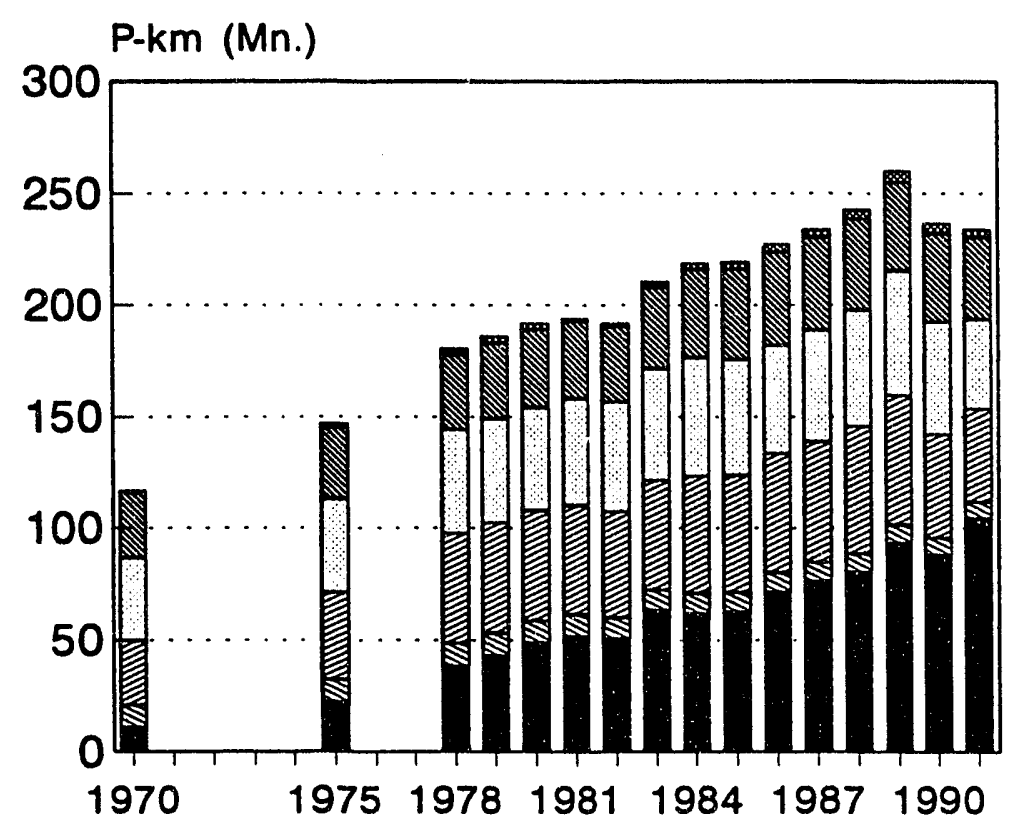

Air
City bus/Light Rail
$\square$ Rail, Intercity
Bus, Intercity
Motorcycles**
Cars**

* Official data and LBL estimates

* LBL estimates

Figure 4-3

\section{Polish Freight Transport Ton-km By Mode}

T-km (Bn.)

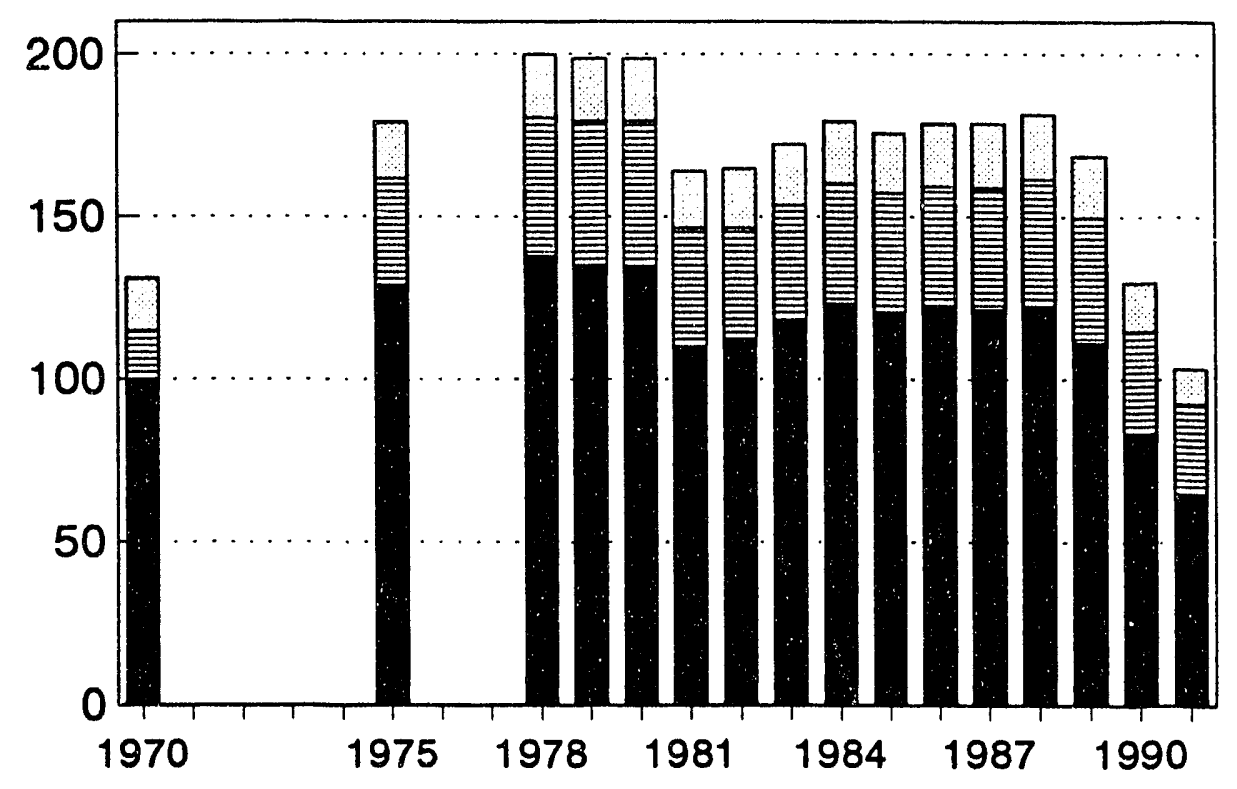

$\square$ Other

点Road*

Rail

*Not including private trucks

Figure 4-4 


\section{OTHER CONSUMERS (RESIDENTIAL/SERVICES)}

\subsection{Energy Data Issues}

Polish energy statistics have a large residual category for energy use not reported by state enterprises (as discussed in Section 1). In terms of the purpose of energy use, some of this consumption belongs to other sectors, although the amounts are often difficult to quantify with precision. As described in Section 4, we moved gasoline and diesel fuel from the "other consumers" category to Transport, and also moved coal/coke, heat, and electricity used in transport-related buildings to "other consumers", since this category includes most other buildings. We also removed estimated district heat transmission losses from "other consumers" heat consumption, since these losses are counted as consumption in this sector in Polish statistics. ${ }^{1}$ After these modifications, this category includes homes and most other non-industrial buildings, private farm electricity use, forestry, non-transport municipal activities (including street lighting), and electricity use by small private enterprises engaged in industrial operations. Military energy use for buildings is probably included in this category.

\subsection{Overview of Energy Use}

After our revisions, "other consumers" accounted for around 40\% of Polish final energy use in 1991, up from $33 \%$ in 1970 . Final energy use by this category rose considerably in the 1970 s, but increased only slightly in the first part of the 1980 s (Figure 5-1). The rise in $1985-87$ is partly attributable to colder-than-normal weather. (The years since then have been much warmer than normal.) Energy use fell by $30 \%$ in 1990 due to a huge drop in coal use, and then rose somewhat in 1991 . The decline in 1990 is somewhat misleading, as wood (not fully counted in the statistics) was substituted for coal by many rural households in response to higher coal prices. Moreover, users stockpiled coal in 1989 in anticipation of price increase, thus reducing the need to purchase coal in 1990. It may also be possible that the statistics undercounted actual coal deliveries in 1990 . Even with these caveats, it is clear that coal users greatly cut back on consumption (by closing off rooms and related bevahior). The rise in energy use in 1991 mainly reflects some rebound in coal use.

Coal/coke historically accounted for the bulk of "other consumers" energy use, but its share has fallen considerably since 1989. Most of coal/coke consumption is undoubtedily accounted for by households, but the exact share is uncertain.

District heat is the next most important energy carrier in this sector. Its use rose at a rapid rate (8\%/year) in the 1970 s as the network was expanded and more buildings were connected, but growth was much slower in the 1980 s. In marked contrast to coal, there has been little change in use of district heat since 1989. This is hardly surprising, since district heat prices are based on floor area rather than usage, and most building occupants are not able to control the heat flow anyway. Polish experts estimate that $75-85 \%$ of total district heat for buildings is used by households.

Use of piped gas in this sector rose at an average rate of $11 \% / y e a r$ in the 1970 s, as the number of homes using gas nearly doubled, but at only $5.4 \% /$ year in the $1980 \mathrm{~s}$, as the growth in customers slowed. ${ }^{2}$ About $85-90 \%$ of total "other consumers" gas is used by households.

Where piped gas is not available, many households (mainly rural) use LPG for cooking. Total "other consumers" use of LPG was fairly steady between 1978 and 1988, but fell greatly from 1988 to

1 Polish sources estimate losses at around 15\% of heat sent out (see discussion of district heat in Section 6).

2 Piped gas is mostly methane, but the category also includes nitrified natural gas and coke-oven gas. 
1990 as the price rise made its use too expensive for households. (As with coal, stockage of LPG in 1989 was partly responsible for the decline in deliveries in 1990.) 'LPG deliveries fell further in 1991.

Electricity use in this sector rose at an average rate of $9 \% / y e a r$ in the 1970 s and at $8 \%$ /year in the 1980s. There was only a slight decline in 1990 , followed by a small increase in 1991 . The actual increase in 1991 may be larger, as the electricity statistics show a large jump in losses in that year; the increase is probably electricity that was consumed but not billed. Of total electricity use (adjusted) by "other consumers" in 1990, 47\% was residential (non-farm), $13 \%$ was private farms (home use and farm equipment), $21 \%$ was public/commercial and transport-related buildings and miscellaneous municipal uses, $3 \%$ was street lighting, and $16 \%$ was other uses.

\subsection{Residential Sector}

\subsubsection{Overview of energy us ${ }^{3}$}

The residential sector accounts for an estimated $75-80 \%$ of total final energy use by "other consumers." Residential energy use in 1970 was dominated by coal/coke. Although the amount of coal/coke used by households is uncertain, it is evident from total use by "other consumers" (most of which is for residential purposes) that residential consumption rose in the 1970s as many households shifted from wood to coal. It was relatively constant in the 1980s, and then crashed in 1990 (as discussed above). The relative importance of coal/coke in residential energy use has fallen in the 1980s (and especially in 199091) as consumption of other energy carriers has grown more rapidly.

Data on residential use of district heat show an increase in consumption from 1978 to 1985 as more homes were connected to the networks, but little change since then.

Residential electricity use. (not including farms) averaged growth of $10 \% /$ year in the 1970 s and $6.9 \% /$ year in the $1980 \mathrm{~s}$. Most of the growth in the 1970 s was due to a near-doubling in consumption per customer. Use per customer continued to rise in the $1980 \mathrm{~s}$, reaching $2000 \mathrm{kWh}$ in 1989; it rose by $8 \%$ in 1990, and apparently fell by around $8 \%$ in 1991. (The 1991 consumption is probably understated, as mentioned above.) The recent trend is difficult to interpret, as there has been a substantial rise in various "cottage" industries conducted in homes. Since this would push average use upward, the decline in 1991 may be a sign that households have cut back on electricity ise where they can. Residential electricity prices (real) roughly doubled in early 1990, but were relatively uinchanged until the third quarter of 1991 , when they doubled again. Anecdotal evidence suggests that mary households have become even more careful than before with lights (installing lower wattage bulbs in some cases), have disconnected freezers (which are less necessary now that meat is readily available in shops), and have switched off refrigerators at times.

Residential use of piped gas rose considerably during the 1980 s due to both growth in the number of connected households and in average use per customer. While most customers use gas for cooking and water heating only, the rise in average use (from $15 \mathrm{GJ}$ in 1980 to $22.5 \mathrm{GJ}$ in 1989) was evidently due to increase in the share of customers using gas for space heating (which is perhaps 10-20\% of total gas customers). In real terms, househnld gas prices did not increase much until early 1991, but they then rose further during 1991. Average gas use per customer rose in 1990 and (slightly) in 1991. Households are metered for gas, and can control use, so one might expect some conservation to have occurred in 1991 . It

3 Electricity and piped gas delivered to enterprise-owned housing is counted under "other consumers", and not industry. Some heat and coal/coke provided by industrial enterprises (the latter mainly important in the coal industry) may bu counted as industry use. 
may be that gas-conserving behavior was more than balanced by increase in the share of customers using gas for space heating. ${ }^{4}$

The rise in energy prices in recent years (see Section 2) has had a strong impact on most Polish households. While outlays for electricity and heat accounted for between $2.5 \%$ (worker households) and 4.9\% (retired) of average monthly Polish household expenditures in 1985, their s. $^{2}$ are had increased to betwien $5.9 \%$ and $10.0 \%$ in 1991.5 In West European countries this share is about 5\%. Retired people have suffered hardest from the price increases. Since energy prices rose faster than incom's in 1992, the share of energy costs undoubtedly increased further in 1992.

The higher costs of electricity and heat have met a mixed reponse. While most households seem to (grudgingly) pay their electricity, gas, and heat bills, non-paymont is significant. For district heat, some Polish observers think it may be up to a third. While the municipal heat distribution companies need these revenues to cover their fuel costs, it is difficult for them to take action against those customers who are refusing to pay because they are under political pressure to continue deliver heating to the population.

\subsubsection{Activity and structure}

The number of occupied dwellings in Poland rose at a slow pace from 8.1 million in 1970 to 9.8 million in 1980 to 11.0 million in $1990 .^{6}$ The share of urban dwellings rose substantially in the 1970 s (from 56\% to 62\%) but increased less in the 1980 s (to 66\% in 1990). Around two-thirds of the 3.5 million rural occupied dwellings in 1988 were on private farms.

The reported average indoor area of Polish homes has risen steadily from 51 square meters (sq.m.) in 1970 to $55 \mathrm{sq} . \mathrm{m}$. in 1980 to $60 \mathrm{sq} . \mathrm{m}$. in 1990 . As the average number of persons per household has fallen from 4.0 to 3.5 , the average area per person has inczeased by around $50 \%$ since 1970 . Rural homes are considerably larger than urban homes ( 70 sq.m. vs. 54 sq.m. in 1990).

The percentage of Polish homes in single-dwelling buildings (34\% in 1988) is relatively high among former communist countries due to the importance of private farms. There are relatively few single-dwelling detached units in the urban areas, although recent years have seen some growth in their number. Nearly half of all dwellings are in large (10 or more unit) apartment buildings.

In 1988, around $20 \%$ of the housing stock was owned by the state and managed by the municipalities. Around $25 \%$ was so-called cooperative housing, for which members pay a small portion of the capital costs and a fee to cover operation and maintenance costs. Many large estates of multi-story apartment blocks built in the past two decades are of this type. Around 13\% of the housing stock consisted of dwellings built and administered by the state enterprises for their own employees. Just over $40 \%$ of the housing stock was private; somewhat more than half of this consisted of farm-houses. Over the years, a small share of public and cooperative housing has been purchased by the occupants.

\subsection{End-use characteristics}

Disaggregation of energy use by the usual residential end uses (i.e., space heating, water heating, cooking, lighting, and other appliances), is rather uncertain, but some observations are nonetheless possible. An estimated disaggregation is presented in the Appendix.

\footnotetext{
4 During the communist period, permits to use gas for heating were restricted: After 1989, there were no such restrictions, leading many private homeowners to install gas boilers.

5 Rocznik Sta ystyczny 1992, p. 209. The situation varies among regions.

6 One finds some differences in Polish statistics between "households" and "places for living," which are somewhat larger in number. We refer to households in our discussion.
} 
Space heating is the most important residential end use, probably accounting for $70-75 \%$ of total energy consumption in 1989 and somewhat less in 1991 . The 1988 national housing survey found that some $40 \%$ of occupied dwellings were served with district heat. Another $22 \%$ used "local" central systems; most of these are fueled with coal, but some use gas. ${ }^{7}$ The remaining $38 \%$ used stoves, most of which were fueled with coal (at least until 1990, when wood was substituted in some cases). Dwellings heated with stoves include practically all rural homes as well as older homes in central city districts and in the outskirts of cities. Heating with natural gas has become more common in recent years, but still comprises only around 5-10\% of homes. Among all homes, use of small electric heaters to supplement main heating systems has been fairly common.

While a response to higher coal prices is evident among coal-heated homes, data on use of district heat (mainly for space heating) per square meter of area show essentially no change between 1978 and 1989 , and only a slight decline in 1990 (taking annual weather fluctuations into account). The lack of change is not surprising, as discussed earlier.

Data on dwellings using so-called "local" systems show no decline in total heating energy use in 1990, and some increase in 1991. It is possible that a decrease in dwellings with coal-fired boilers was balanced by growing use of natural gas for heating in private houses. Use of energy for "local" systems doubled in the 1978-87 period as more dwellings came to be heated in this way.

Water heating. A variety of systems are used for water heating in Polish homes. A 1987 private marketing survey found that roughly equal shares were accounted for by district heat, coal boilers, gasfired "instant" water heaters, electric storage heaters, and coal stoves (Figure 5-2). Gas-fired "instant" water heaters are the most common system in older apartments. In newer apartment buildings, hot water comes from the district heat system. Many ola apartment buildings have laundry rooms where water is heated on stoves for use in older-style washers. Taking hot water from coal-fired boilers with a heat exchanger is popular in older private houses. There is little use of electric "instant" water heaters, but many rural homes have electric storage water heaters.

Cooking. According to the 1988 Housing Survey, just over half of Polish homes used piped gas for cooking. (The 1987 survey mentioned above showed a share of only 33\%.) Most of the remainder used coal stoves. LPG is used by some $10-15 \%$ of households. Electric cooking is not common.

Lighting. The average installed wattage of lamps, while not known with precision, is estimated to be in the neighborhood of $\mathbf{1 0 0 0}$ watts in a typical apartment. A fluorescent tube is common in kitchens. Poles have traditionally been careful about use of lights.

Electric appliances. Growth in the ownership of major domestic appliances in Poland since 1975 is shown in Figure 5-3. Ownership of refrigerators rose rapidly in the 1970s, ano became nearly universal by 1989.8 In the 1970 s very small (130 liter) refrigerators of Polish and Soviet manufacture were most popular. A two-door Polish refrigerator-freezer (220.240 liters) came on the market in the late 1970s, followed in the mid-1980s by a similar Soviet model. FEWE estimates that $70 \%$ of the total refrigerator stock consists of models in the larger size range. ${ }^{9}$

\footnotetext{
7 According to the survey, around two-thirds of dwellings using "local" systems were in single-dwelling buildings (heated by a boiler/radiator system). The remainder were apartment buildings, some of which are heated by "neighborhood" boilers serving more than one building. The latter pay for the heat based on dwelling floor area.

8 The data prior to 1987 are for refrigerators and freezers combined, but the ownership of freezers was relatively low prior to 1980. The data on appliance ownership are from the Central Statistical Offic:.

${ }^{9}$ Not all of the larger models are two-door refrigerator-freezers. Refrigerators of 220 -liter size with a frozen food compartment are also sold.
} 
Ownership of freezers rose during the 1980 s, and climbed further to nearly $30 \%$ of homes in 1991 . An estimated two-thirds of freezers in use are quite small (50-60 liters), as many households bought these small freezers to supplement the refrigerator they already owned. The remainder of the freezer stock is of 120-140 liter size. (In addition, there are an estimated 0.3-0.4 million freezers over 150 liters in volume used by commercial enterprises.) Upright (front-open) freezers are more common in cities, while larger chest freezers are more popular in rural areas, where they are used for storing meat.

TV sets (mostly black \& white models) were nearly universal in 1980 . The ownership of color TVs rose considerably in the second half of the 1980s, and climbed especially rapidly in 1990 and 1991, reflecting the interest in communication and entertainment in the post-communist era. About half of the total stock of around 15 million TV sets consists of color sets. Because the average black \& white set is much older than the average color set, the latter is less energy-intensive. FEWE estimates an average wattage of $200 \mathrm{~W}$ for black \& white sets, and $150 \mathrm{~W}$ for color sets. New Polish color TVs draw 90-100W, but older color TVs made in Russia use up to $400 \mathrm{~W}$. Models imported from the OECD countries require only around $60 \mathrm{~W}$.

Ownership of automatic clothes-washers rose from only around 5\% of homes in 1978 to $45 \%$ in 1991. Manual washers are still common, however. As in W. Europe, most Polish automatic clotheswashers are horizontal-axis type and heat their own water. They tend to be smaller than U.S. models, and use much less hot water due to the horizontal-axis design. They typically have a $2000 \mathrm{~W}$ heater element and a 700W motor. Clothes-dryers are relatively rare in Polish homes, as are dishwashers.

The average energy consumption in use of Polish appliances is not known with precision. Product literature from the main Polish manufacturer of refrigerators and freezers claims electricity use of 0.8 $\mathrm{kWh} /$ day for the 132 -liter refrigerators and $1.7 \mathrm{kWh} /$ day for the 240 -liter refrigerator-freezer. For both refrigerators ard freezers, the technology used is well behind Western practice.

\subsection{Service (Public/Commercial) Sector}

As in other communist countries, the service sector in Poland was historically much less developed than in the West. The total floor area is uncertain. Most newer buildings in urban areas are served by district heat. In older buildings, separate boilers for each floor are common. Schools, universities, and hospitals usually have their own heating system fueled mainly with coal or coke.

We approximated district heat consumption in the service sector by subtracting estimated residential use of district heat from total heat consumption by "other consumers." The resulting quantity fluctuated between 30 and $40 \mathrm{PJ}$ during the $1980 \mathrm{~s}$, with an apparent increasing trend in consumption in recent years. One would expect little change in usage patterns, given the lack of controls and the nature of pricing. (Some buildings now have a meter for district heat.) Although over- and under-heating of buildings was not unusual in the past, it has become less common for buildings with their own boiler (who most purchase their own fuel and have more potential to control use) in recent years.

Electricity use in the service sector (not including street lighting, but including estimated use in transport-related buildings) grew at an average rate of around $8 \%$ /year in the 1970 s, but at only $2.3 \% /$ year in the 1980 s. It fell by $12 \%$ in 1990 , but then rose by $14 \%$ in 1991 . The retail sector was largely privatized in the first wave of reform in 1990, so shop owners had some incentive to reduce electricity costs. There was also less activity in the public sector. The increase in 1991 is likely a result of the rising activity in the private service sector (hotels, shops, restaurants, new office buildings, etc.).

The level of electricity services in most public/commercial buildings is relatively low. In most offices, lights are used sparingly. Small electric heaters are used in rooms where the heat is insufficient. With the explosion of the private retail sector has come much-increased use of lighting for signs and 
displays.

Electricity use for street lighting rose gradually between 1970 and the mid-1980s. It declined in 1990 as some municipal governments cut back to save money. While mercury-vapor lamps are more common in the stock, new installations use more efficient sodium-vapor lamps.

\subsection{Other Subsectors}

\subsubsection{Private farms}

Agriculture was not collectivized in communist Poland, and the number of small farms remained high over the years. (The 1988 Housing Survey found 2.35 million occupied dwellings on private farms, a number barely larger than that of a decade earlier.) About $80 \%$ of the farm land is privately owned. In the 1970s, there was increase in relatively large private farms (mostly for livestock raising). Although farming techniques on small farms are primitive relative to practice in the West, the number of private tractors rose greatly from 0.3 million in 1980 to 0.9 million in 1990 . Such tractors are used for transport as well as for field work.

Estimated electricity use by private farms experienced rapid growth in the 1970s (an average of $21 \% /$ year), reflecting rising ownership of home appliances and also farm equipment. ${ }^{10}$ Growth slowed in the 1980 s, but still averaged $8 \% / y e a r$. Nearly all of the increase was due to growth in average electricity use per farm, which rose from only $190 \mathrm{kWh}$ in 1970 to $2300 \mathrm{kWh}$ in 1989 . The latter figure was $10 \%$ higher than average consumption by non-farm households. The saturation of automatic washers is lower in farm than in non-farm households, but that of freezers is higher (and ownership of refrigerators is about the same). There is relatively little use of electric pumps for water. Thus, it appears that most of the electricity use by private farms is for household purposes rather than farm equipment.

In the 1970s, there was much construction of greenhouses for vegetables and flowers. These greenhouses (and also buildings for growing mushrooms) are heated with coal or coke. A small part of the huge decline in total coal/coke use by "other consumers" is attributable to efforts by growers to conserve coal.

\subsubsection{Other}

Large numbers of private enterprises engaged in small-scale industrial operations (various plastic goods are one popular product) have sprung up in Poland since 1989. They mainly electrical equipment; the consumption is likely counted in either the residential or commercial categories in Polish statistics.

Energy use by the military is reportedly included under "other consumers." Reduced heating of barracks (due to reduction in personnel) may be one factor behind the drop in coal use by "other consumers" in 1990.

\subsection{Conclusion}

Energy use by "other consumers" is dominated by households. Public and commercial buildings account for most of the remaining energy consumption. The sector's energy use rose somewhat in the latter half of the 1980s (partly due to colder weather), but then fell sharply in 1990 as households and other consumers cut back on coal use in response to higher prices. There was a small rebound in 1991.

\footnotetext{
10 We estimated electricity use by private farms by subtracting electricity use in state agriculture from total agriculture electricity consumption as given in the electricity statistics.
} 
Consumption of piped gas has risen due to growth in the number of connected households and in the share of homes using gas for space heating. Use of district heat also rose in the early part of the 1980s as more apartments were connected to the network. In sharp contrast to coal, there was little change in district heat consumption in recent years, as most occupants are unable to control the heat flow.

Residential electricity use grew at an average rate of nearly $7 \%$ per year in the 1980 s as ownership of refrigerators, freezers, automatic washers, and color TVs increased. There are signs of electricity conservation in 1991 in response to higher prices. In the service sector, on the other hand, electricity consumption rose in 1991 due to increasing activity in the private sector. 


\section{Poland Other Consumers Final Energy Use, 1970-1991}

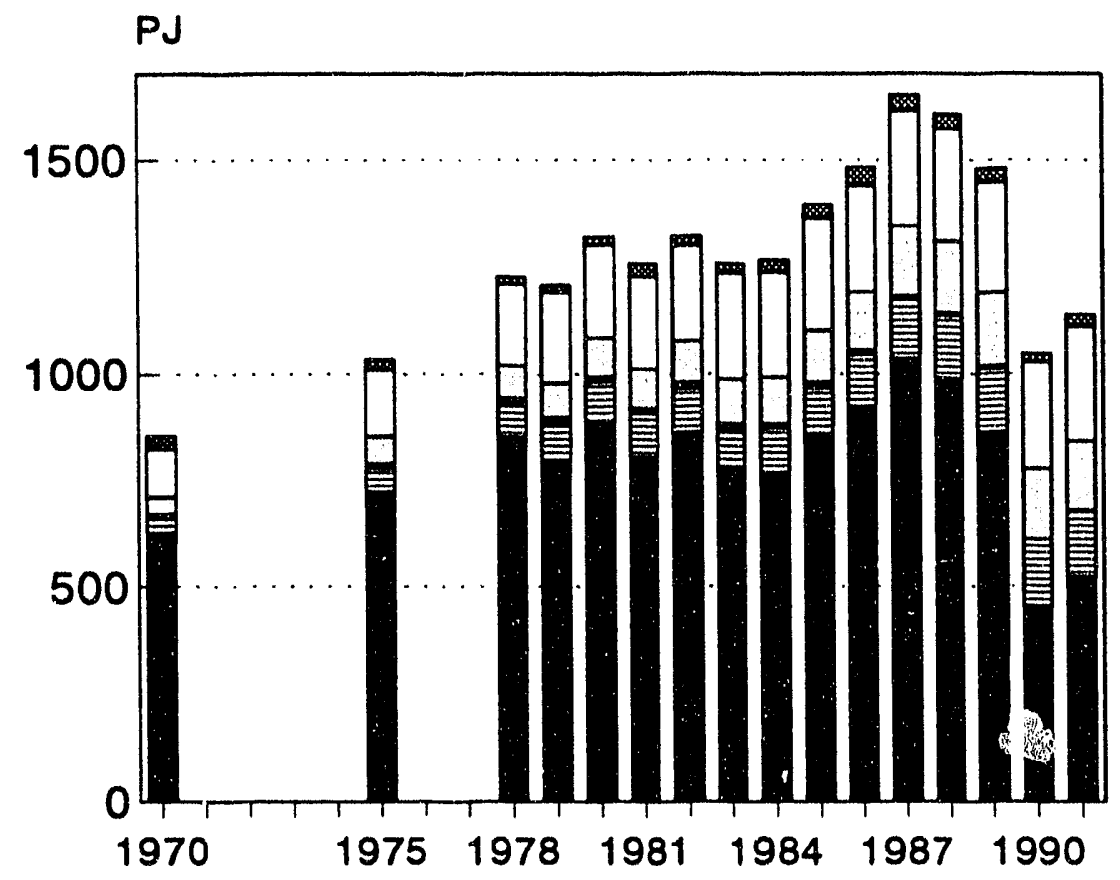

Other Solids

$\square$ Heat

$\square$ Electricity

Liquid Fuels

Gases

Coal/Coke

Figure 5-1

\section{Main Fuel Choices for Household Energy Uses, Poland 1987}

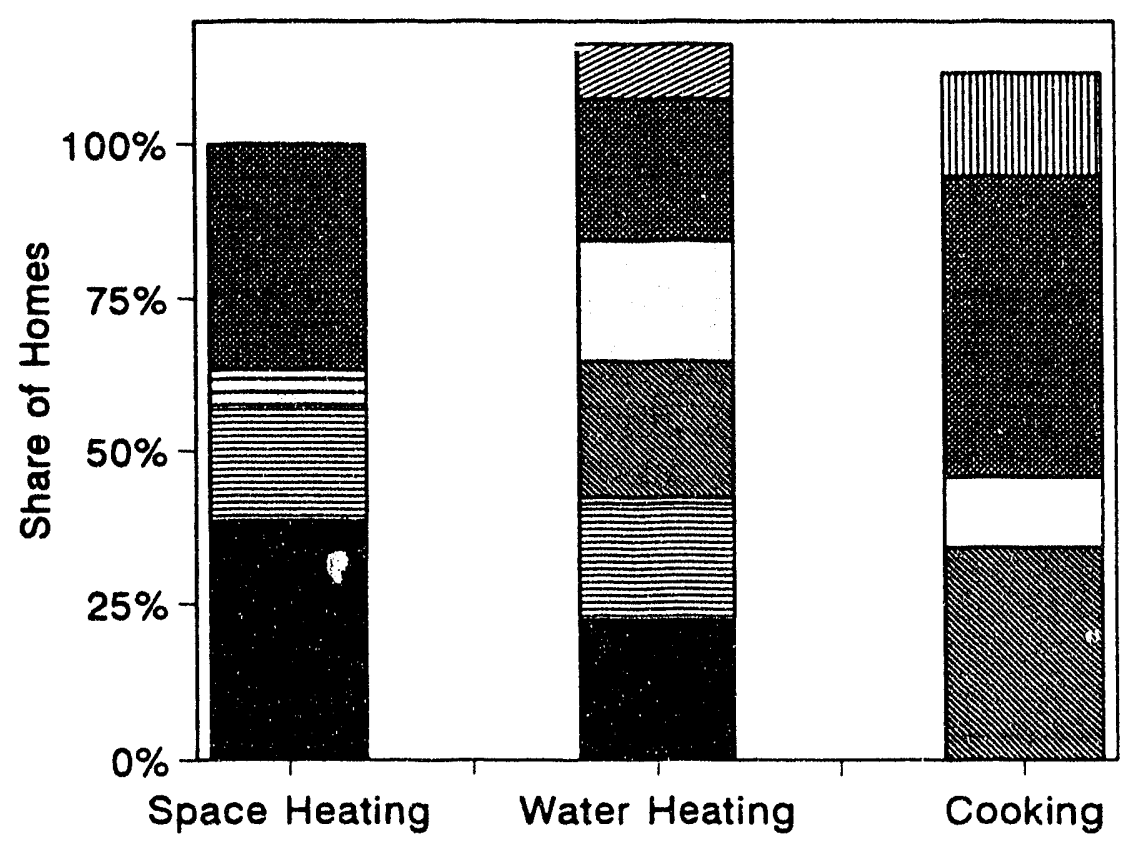

血 LPG

ROther

Coal Stove

$\square$ Electric Direct

$\square$ Electric Storage

Gas Direct

$\square$ Local: Gas

冒Local: Coal

District Heat

Source: Private household survey

Figure 5-2 


\section{Poland Appliance Ownership 1975-1991}

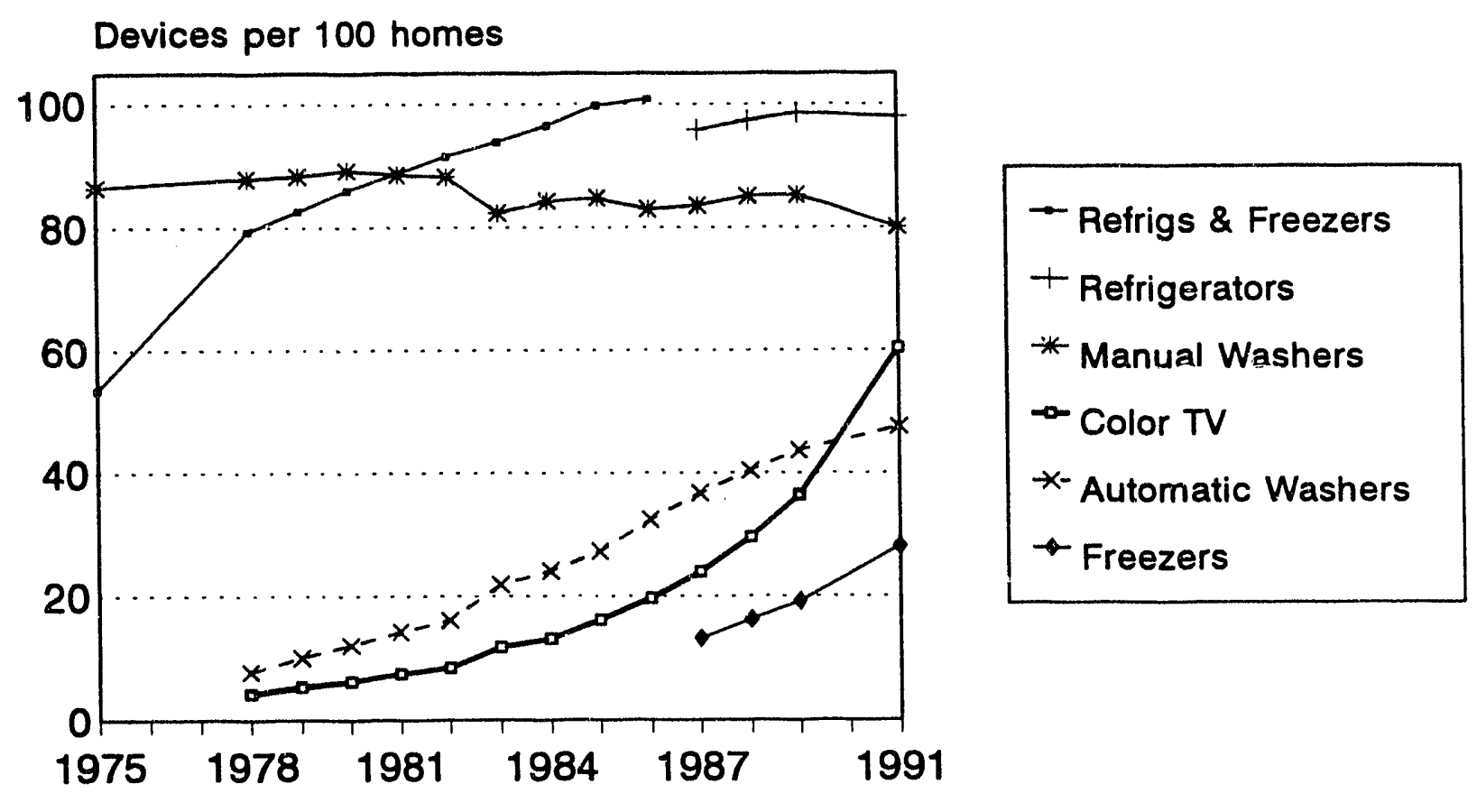

Figure 5-3 


\section{ENERGY TRANSFORMATION}

The share of total Polish energy that goes going into intermediate transformation processes has risen from two-thirds in 1970 to three-fourths in 1991. Electricity generation is the largest transformation subsector in terms of energy input, followed by heat production and oil refining. (Note that industrial selfproduction of electricity and the associated heat is considered part of the energy transformation sector.) The energy input (which includes primary and secondary energy carriers) and gross output (secondary energy carriers only) from various transformation sectors in 1990 is shown in Table 6-1. Losses in transformation amounted to $32 \%$ of the total energy input, but vary considerably (on a percentage basis) among subsectors. Losses are highest in electricity generation, although some of the apparent losses are actually utilized as heat (either in the district heat network or directly by industry). This explains why the reported efficiency of heat production is relatively high.

The amount of energy used by the plants to carry out their transformation activities ("plant use") varies among subsectors. For the sector as a whole, plant use was about $7 \%$ of the gross energy output in 1990. Plant use may be either energy produced in the plant or energy purchased from outside. Most of the plant use is counted in the energy use of the fuels \& power industrial subsector in Polish statistics. ${ }^{1}$

\begin{tabular}{lcccc}
\hline \multicolumn{5}{c}{ Table 6-1. Polish Energy Transformation Subsectors, 1990 } \\
\hline Subsector & $\begin{array}{c}\text { Energy } \\
\text { Input (PJ) }\end{array}$ & $\begin{array}{c}\text { Gross Energy } \\
\text { Output (PJ) }\end{array}$ & $\begin{array}{c}\text { Transformation } \\
\text { Losses (\%) }\end{array}$ & $\begin{array}{c}\text { Plant Use } \\
\text { (PJ) }\end{array}$ \\
\hline Electricity (thermal)* & 1313 & 479 & 64 & 39 \\
Public & 1249 & 450 & 64 & 35 \\
Self-producers & 64 & 29 & 54 & 4 \\
Heat production* & 1075 & 815 & 24 & 29 \\
Public \& municipal & 419 & 332 & 21 & 16 \\
Self-producers** & 313 & 249 & 26 & 13 \\
Oil refining & 552 & 534 & 3 & 33 \\
Coking plants & 537 & 507 & 6 & 63 \\
Blast furnaces & 63 & 63 & 0 & 0 \\
Coal gasification & 10 & 8 & 23 & 0.6 \\
Hydro plants & 14 & 12 & 16 & 0.1 \\
Other & 56 & 48 & 14 & 6 \\
Total & 3277 & 2231 & 32 & 166 \\
\hline
\end{tabular}

* For public and industrial combined heat \& power (CHP), Polish statistics allocate fuel use between electricity and heat production.

** CHP only; not including self-producing heat plants (see p. 6-3).

The final energy consumption in the fuels $\&$ power subsector (minus coal mining), which is mostly plant use but also includes miscellaneous uses by the various enterprises, was $16 \%$ of total industrial energy use in 1991. Fuels \& power energy use did not decline as much in 1990 as did energy use in other industrial subsectors. Its real value added (including coal mining in this case) fell considerably, however,

\footnotetext{
1 Small amounts are counted in the metallurgical industrial subsector (for some coking plants) and the municipal sector (for municipal heat plants).
} 
in part because the prices of inputs rose more than did the prices of its final energy products, which were decontrolled at a slower pace. Thus, its energy intensity (including coal mining) rose by nearly $50 \%$ in 1990. The rise was less in 1991 (though still considerable at around 25\%), as the prices of final energy products caught up somewhat with those of the subsector's inputs.

In addition to the energy losses in transformation, there are also losses of certain secondary energy carriers in transmission and distribution. These amount to around $10-12 \%$ for electricity and $15 \%$ (estimated) for district heat. ${ }^{2}$

\subsection{Electricity Generation ${ }^{3}$}

Most electricity in Poland (92\% in 1991) is generated by public thermal plants. Around $6 \%$ of the total is industrial self-production, a small part of which is sold to the grid. Another $2 \%$ comes from hydroelectric plants (run-of-river and pumped storage).

The total installed capacity of Polish power plants at the end of 1991 was $32 \mathrm{GW}$, of which public plants accounted for $28.8 \mathrm{GW}$ and industrial self-producers for $3.2 \mathrm{GW}$. Thermal power stations provide $30 \mathrm{GW}$ and hydro power $2 \mathrm{GW}$ (of which $1.3 \mathrm{GW}$ is pumped storage). Almost $70 \%$ of the total capacity is provided by 15 thermal power stations having a capacity over $500 \mathrm{MW}$. The average age of thermal units is about 18 years and more than $7 \mathrm{GW}$ of capacity has been in operation for more than 20 years. The share of CHP plants in total installed thermal power capacity (including self-producers) was $21 \%$ in $1989 .{ }^{4}$

In 1991 thermal power plants (public and self-producers) accounted for $97.5 \%$ of gross electric production in Poland. More than $98 \%$ of their fuel use is hard coal or lignite (Figure $6-1$ ). ${ }^{5}$ The share of coal has increased slightly since 1970 when it was $94 \%$. The heavy reliance on coal reflects earlier governments efforts to avoid imported fuels for power production. Plans to develop nuclear power were shelved in 1990 after construction on Poland's first nuclear plant at Zarnowiec near Gdansk had suffered repeated delays and cost increases in the 1980s.

Poland was a net exporter of electricity in 1970-1986. It had an annual net import of 1-4 TWh in the end of 1980s, but a net export of 1-3 TWh in 1990 and 1991.

The generation efficiency of thermal power plants has improved from an average of $31.6 \%$ in 1970 to $36.7 \%$ in 1991 . Losses in transmission and distribution, about $10-12 \%$, are higher than in Western Europe (5-6\%). The main reason is old equipment and lower voltages in distribution systems.

Until July of 1990 the power and lignite industries were supervised and coordinated by the Union of Power and Brown Coal, a state-controlled association of 108 state enterprises. With the liquidation of the Union these enterprises are now directly responsible to the Ministry of Industry and Trade. ${ }^{6}$ In May 1992 the government proposed a restructuring program for the power industry with the aim of improving efficiency of the total power system and introducing competition within the system. The program

2 L. Lipka, "District heating systems in Poland," Seminar on Energy in East and West: The Polish Case, Proceedings, International Energy Agency, 1991.

${ }^{3}$ Data are from the publications of the Energy Information Centre, Polish Power Grid Company, and International Energy Agency, Energy Policies: Poland 1990 Survey, Paris, 1991.

4 J. Popczyk, "Poland: Power generation and transmission," Polish Power Grid Company, 1992.

$556 \%$ of their fuel use was hard coal and $43 \%$ lignite. The share of lignite in the fuel mix rose from $32 \%$ in 1970 to $43 \%$ in 1991. The power plants fueled with lignite are located close to open-cast mines. Belchatw, Poland's largest thermal power plant (and one of the largest in Europe), with a capacity of $4320 \mathrm{MW}$, is fueled with lignite.

6 There are 28 power generation enterprises, 33 electricity distribution enterprises, 4 lignite mining enterprises, and over 40 enterprises engaged in various ancillary activities. The main transmission grid is operated by the Polish Power Grid Company. 
envisages mergers of the various state enterprises into larger companies. For example, the hard coal fueled power plants will be merged into four or five competitive generation companies, selling electricity to the Polish Power Grid Company. ${ }^{7}$ Many enterprises have serious financial problems; some investment capital can be provided through allocation within the new groups of companies.

The reliance on coal for electricity and other uses has lead to severe air pollution and acid precipita* tion in many parts of Poland. Air pollution is worst in the heavily industrialized Silesian region in the southern part of the country. Total Polish emissions of $\mathrm{SO}_{2}$ were estimated at 4.3 million tons per year in the mid-1980s. ${ }^{8}$ After the former Eastern Germany, Poland had the highest emissions of $\mathrm{SO}_{2}$ in Europe (excluding the former USSR). Because of reduced industrial and energy production air pollution has decreased in the past few years. According to one Polish estimate the power industry (including selfproducers) accounted for almost $65 \%$ of all $\mathrm{SO}_{2}$ emissions in the country in 1990-91. ${ }^{9}$ Its share of total of carbon dioxode emissions was $50-60 \%$ in the same period.

Before 1990, fees and fines for air pollution were generally too low to provide strong incentives to enterprises to invest in abatement technology. ${ }^{10}$ The Ministry of Environmental Protection introduced higher fees and fines in 1992, but later the same year the Ministry decided to lower them again. In February 1993 the government announced that it again would raise these payments, albeit to a level below that in 1992. Most enterprises lack adequate financial resources to buy the technology needed for pollution abatement, which sometimes must be imported from Western countries. ${ }^{11}$

\subsection{District Heat Production}

Heat for district heat networks comes from three main sources: public power plants (which contain CHP units and heat-only boilers), industrial CHP plants, and municipal heat plants. The latter are a much smaller source than the power plants. The role of these three sources in total district heat production for the network over the 1970-91 period is shown in Figure 6-2. A smaller amount comes from industrial heat-only boilers, but we do not count these as part of the district heat "network." 12 Coal dominates fuel use for district heat production (Figure 6-3). Small amounts of oil and other fuels are also used.

\footnotetext{
7 Popczyk, op cit.

8 M. Amann, L. Hordijk, G. Klasses, W. Schupp and . Sorenson. "Economic restructuring in Eastern Europe and acid rain abatement strategies", Energy Policy, December 1992, p. 1190.

S J. Kapala and P. Kaleta, "Main Sources of Atmospheric Pollutants in Poland: Branches and Regions Overview," Institute of Environmental Engineering, Zabrze, Poland, 1993.

10 Polluters pay fees for their emissions up to a certain limit (for instance, $\mathrm{x}$ zloty per $\mathrm{kg}$ of $\mathrm{SO}_{2}$ emitted within a emission limit of $\mathrm{y} \mathrm{kg} \mathrm{SO}$ ), and additional fines if this limit is exceeded.

11 The environmental payments collected from enterprises go into a special bank from which funds are supposed to be used for investments in pollution control. The amounts are often inadequate to purchase equipment that may need to be imported, however.

12 As opposed to the industrial CHP plants, it appears that much of the heat from these "self-producing heat plants" is used on-site.
} 


\section{Poland Electric Power 1970-91 Fuel Use For Electricity Generation}

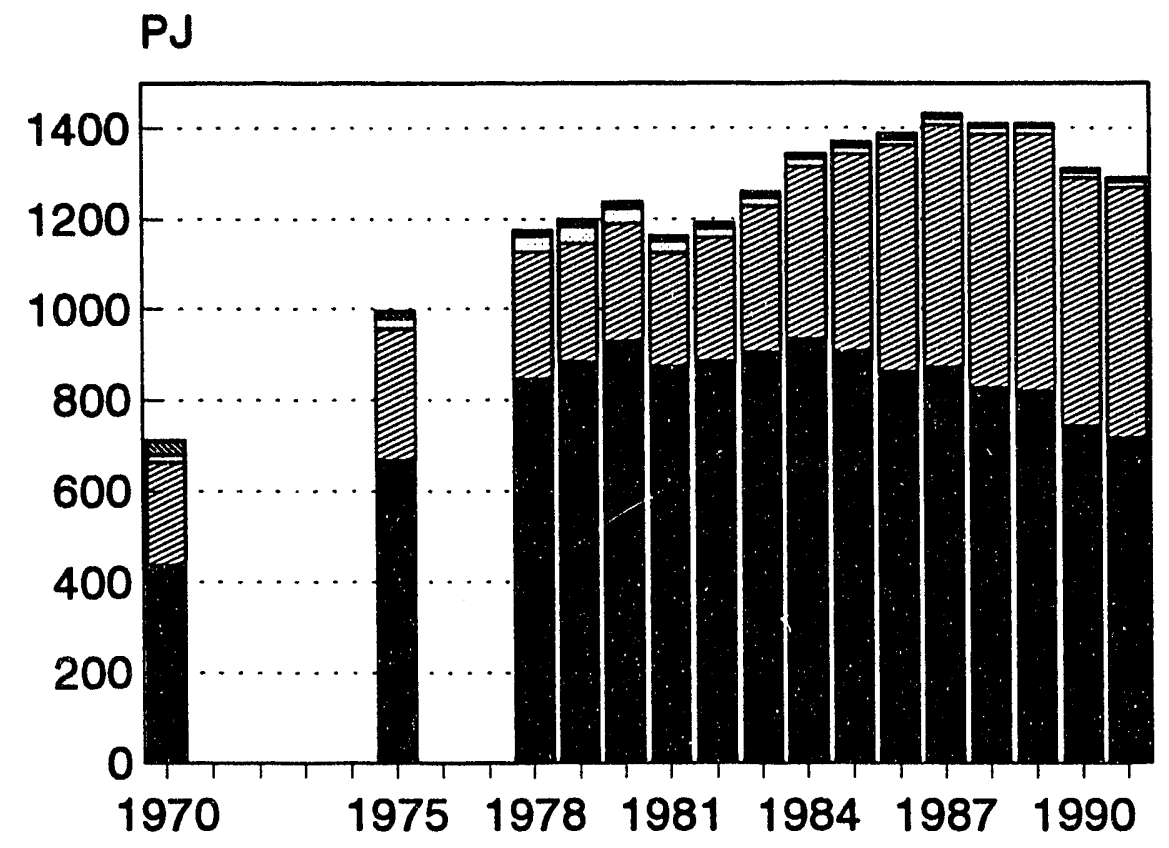

Other

$\square$ Oil

Lignite Hard Coal

Figure 6-1 


\section{Poland District Heat Production By Plant Type 1970-1991}

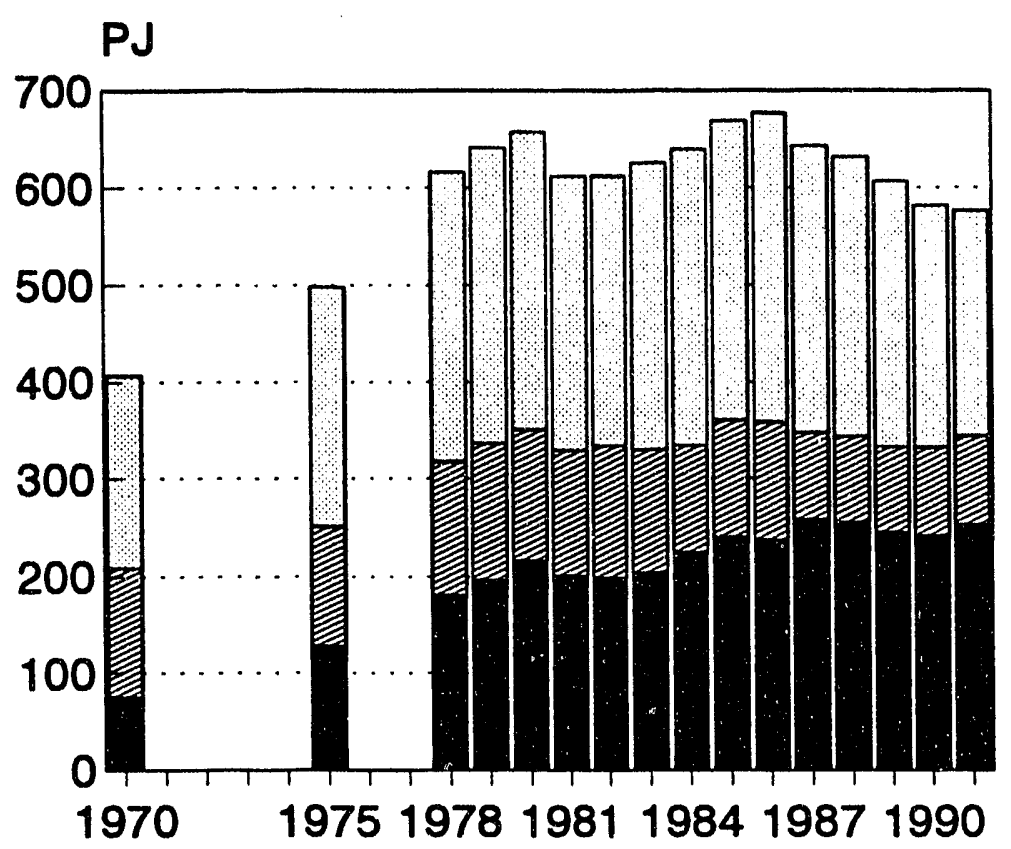

\section{$\square$ Industry CHP Plants}

Municipal Heat Plants Dublic CHP Plants*

* Includes heat-only boilers

Note: Not including "industry heat plants".

Figure 6-2

\section{Poland District Heat 1970-91 Fuel Use For Heat Production}

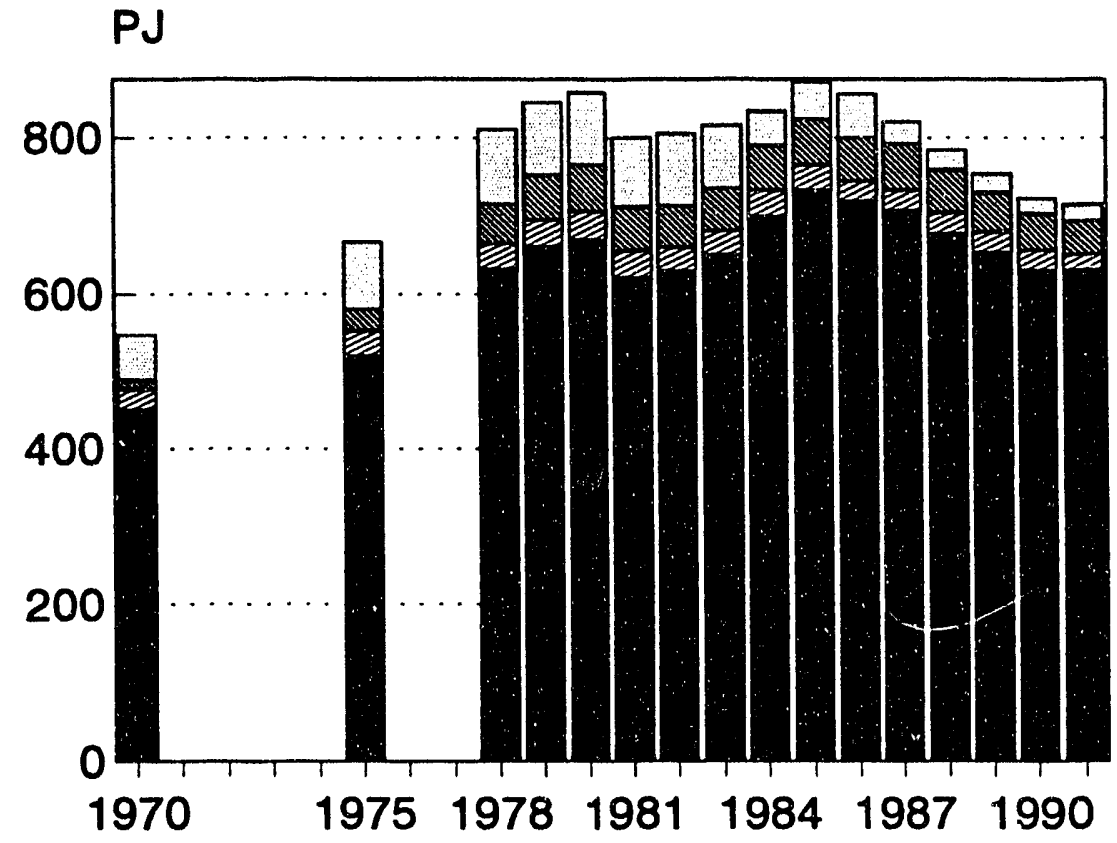

$\square$ Other Solids
Oil
Natural Gas
Coal




\section{INTERNATIONAL COMPARISON}

Understanding of energy use in any given country is always enhanced by placing that country's patterns in an international context. Careful comparisons shed light on why patterns differ and how they may evolve in the future in particular countries. In the case of Poland and other former centrally-planned economies (CPEs) that are moving toward market economies, comparison with current and historic patterns in the West can inform projections of future energy requirements.

International comparisons can also be helpful in formulation of energy policy. Certain energy use patterns in one country may resemble those that form the goals for energy policy in another country. Understanding how the first country arrived at a particular pattern may provide insights on how to stimulate change in the second country. International comparison sheds light on technologies that save energy as well as key policies that promote energy efficiency. It helps to identify the reasons why specific energy uses are very efficient in certain countries, and to understand the role of particular policies.

Comparisons of energy use at an aggregate level between Western and former centrally-planned economies are very problematic. Unfortunately, it is not uncommon to find comparisons of energy/GDP ratios between these countries, despite the fact that dollar estimates of GDP in the former CPEs are subject to considerable uncertainty. Obtaining GDP estimates in national currency units is one problem, although for most former CPEs the error margins for national-currency GDP are considered to be within 10-20 percent. ${ }^{1}$ Problems are much greater, however, in converting GDP in national currency to dollars. Exchange rates in the former CPEs were characterized by large deviations between official rates and the actual rates for various transactions. Although official exchange rates have become more meaningful in most of the countries, including Poland, which introduced a unified zloty-dollar rate in 1990, they are still poor measures of the domestic purchasing power of the currencies. Considerable effort has gone into developing so-called purchasing power parities (PPP), but the measures that have been calculated for the former CPEs suffer from various problems that tend to lead to overvaluation of GDP.

Since there is considerable difference between dollar GDP values calculated using exchange rates vs. using the PPP method for the former CPEs, the range of values for primary energy use per dollar of GDP is also great. ${ }^{2}$ Poland's energy/GDP ratio in 1989 was seven times higher than that of W. Germany using exchange rates, but only three times higher using PPP values (Figure 7-1). ${ }^{3}$ While the PPP-based value is probably too low (since the GDP is overvalued), the exchange-rate value is probably biased upward.

1 P. Marer, et al., Historically Planned Economies: A Guide to the Data. The World Bank, Washington D.C., 1992. The Material Product System traditionally used in the former CPEs excluded so-called nonproductive services (such as administration, the military, education, and health) and depreciation. Prices did not reflect the relative resource costs of production and services, but were set by central planning authorities according to certain political and economic objectives (e.g., cheap housing, low prices of raw materials and energy, high prices on luxury goods).

2 The difference between the two methods for Western countries is much smaller, but not trivial. For example, GDP calculated with exchange rates is higher than PPP-based values for W. Germany and especially for Japan because of the premium placed on these countries' currencies in the intemational trading system.

3 The source for the exchange-rate based values is the World Bank, which uses a three-year adjusted average of a country's exchange rate to smooth fluctuations in prices and exchange rates. The sources for the PPP-based values are the OECD national accounts and Marer, et al. (1992) for the former CPEs. 
Even if the problems of expressing economic output in a common unit could be overcome, the fact remains that comparison of energy/GDP ratios reveals little useful information. ${ }^{4}$ Rather, it is necessary to look carefully at energy use and the factors that shape it in each sector. The analytical framework that we present here, which we have applied in other international comparisons, involves an assessment of three key elements in each sector: (1) a measure of aggregate activity, (2) the structure (composition) of activity, and (3) the energy intensities of key activities.

In the sections below, we show how these elements differ between Poland and several Western countries, and also compare Poland to the Soviet Union, where LBL conducted a study similar to this one in 1991. We generally use 1988 or 1989 as years of comparison for reasons of OECD data availability and because these were the last years before the transformation in Poland took full force. While our comparison focuses on final demand, we note (where important) how the fuel mix influences the results.

Data sources and issues. The data for the U.S., Japan, and W. Europe are from ongoing research by the authors and their colleagues at Lawrence Berkeley Laboratory. The data for the Soviet Union are from a study by Schipper and Cooper. A list of key references is found at the end of this section.

The data on Polish energy use reflect the LBL revisions discussed in earlier sections. In some cases (e.g., the residential sector), we have made further estimates of energy end-use in Poland in order to make a rough comparison with other countries. These estimates, which are subject to some uncertainty, are discussed in the Appendix of the report.

We generally avoid comparisons that involve GDP because of the uncertainty in expressing Polish (or Soviet) GDP in dollar values. In those few cases where we make use of GDP, we utilize PPP-based estimates of GDP for Poland and the OECD countries. Note that the PPP-based estimate of Polish GDP is over twice as high as the GDP converted with the official exchange rate.

\subsection{Manufacturing}

Manufacturing final energy use per capita in 1988 was about the same in Poland as in W. Germany and somewhat higher than in the U.K. Poland's consumption was far below that of the Soviet Union, however. Five energy-intensive subsectors accounted for about $70 \%$ of total energy use in Poland, a similar share as in W. Germany and the U.S. (Figure 7-2).

The apparent similiarity between Poland and W. Germany is misleading, of course, as the manufacturing sectors in each country are vastly different. Comparing manufacturing output (value added) per capita is difficult due to the currency conversion problems discussed above, but it is obvious that W. Germany and the other high-income OECD countries had much more output per capita than Poland. (The role of manufacturing in the overall economy was lower in the West than in Poland, however.) There are also differences in the structure of the manufacturing sector and in energy intensities, as we discuss below.

\subsubsection{Structure}

Although the Polish measures of value added are not entirely comparable with similar measures in the West, they are adequate to give an approximate picture of sectoral structure. According to official value added statistics, nearly 30\% of manufacturing output in Poland (including non-coal mining) in 1990 was in the energy-intensive subsectors of ferrous and non-ferrous metals, paper and pulp, chemicals, and building materials; this share fell to $26 \%$ in 1991 . The alternate series of value added that goes back to

4 For discussion of this point, see: L. Schipper and S. Meyers, with R. Howarth and R. Steiner, Energy Efficiency and Human Activity: Past Trends, Future Prospects, Cambridge, UK: Cambridge University Press, 1992. 
1987 (by Kumanowski) indicates that $29 \%$ of the total output was in these five subsectors in 1988 . By contrast, in 1988 these same subsectors accounted for $22 \%$ of manufacturing value added in W. Germany, $24 \%$ in France, $32 \%$ in Norway, $24 \%$ in Sweden, $23 \%$ in Japan, and $21 \%$ in the U.S. Even after the shift following the introduction of radical economic reforms; Poland's energy-intensive industries still held a share of output sxceeded only by Norway.

Another way of illustrating the large role played by heavy industries in Poland is to compare its per capita physical production of important basic materials with that in other countries. As Figure 7-3 shows, Fland's per capita steel production in 1988 was around $75 \%$ of that of Sweden or W. Germany, in spite of a GDP per capita that was only 25-30\% that of those two nations in PPP terms, and much less than that in exchange-rate terms. ${ }^{5}$ Cement production per capita in Poland was close to that in Sweden and W. Germany, so the implicit GDP intensity of this material is even higher. By contrast, per capita production of paper and pulp is well below that of $G^{\prime}$.many and Japan, two countries with modest forest industries, and even farther below that of the U.S. or Sweden. Per capita production of these materials in the Soviet Union was close to that in Poland.

\subsubsection{Energy intensities}

Because of the difficulties of comparing output in monetary units, one cannot easily compare the energy intensities of key industrial subsectors in Poland with those in other countries. Nor would such a comparison be very revealing, since there are differences in the composition of subsectors among countries. One can compare the physical energy intensities (energy use per ton) of certain products, but one must exercise caution to ensure comparability. For example, it is not always clear whether the energy used to make intermediate products is included in the values given for final products. In addition, recent data are not easily available for many countries. Below we focus on two very energy-intensive products, steel and cement.

Steel. Differences in aggregate data on energy use per ton of crude steel are due to variation in the mixture of producti on processes, local circumstances, and the energy carriers used. A careful comparison of steel industry ene.gy use was undertaken for the 1986 World Energy Conference. Using data from particular integrated steel plants in a number of countries, the authors calculated the energy intensity at each stage in terms of energy consumption for producing one ton of steel (hot rolled coil), ${ }^{6}$ including energy use for inputs like coke and sinter, as of 1984. The total energy intensity in Poland was $25-50 \%$ higher than in Western Europe and the U.S., and 10-20\% higher than in Brazil and India (Table 7-1). Relative to most Western plants, the (presumably typical) Polish plant was more energy-intensive at each stage. Relative to the U.S. plant, the Polish plant was not much more energy-intensive in steelmaking and rolling, but was much more energy-intensive in iron-making.

\footnotetext{
5 While we have not subtracted the exports of steel products to estimate domestic consumption, we note that both Germany and Sweden are leading exporters of steel products and steel-using equipment like machines, cars, and trucks.

6 Final steel products are fabricated from hot coils.
} 


\begin{tabular}{lcccc}
\hline \multicolumn{5}{c}{ Table 7-1. Comparing Energy Intensity of Steel Production, 1984* } \\
(GJ/ton of hot rolled coil) \\
\hline Country & $\begin{array}{c}\text { Coke \& } \\
\text { sinter }\end{array}$ & Pig iron & $\begin{array}{c}\text { Other } \\
\text { steps** }\end{array}$ & Total \\
\hline Japan & $5.5-5.6$ & $13.1-14.3$ & $2.2-2.7$ & $20.8-22.6$ \\
France & 5.7 & 13.3 & 3.6 & 22.6 \\
Taiwan & 5.8 & 13.9 & 3.5 & 23.3 \\
U.S. & $>>$ & 16.6 & 7.1 & 23.7 \\
U.K. & $5.8-7.7$ & $12.2-13.0$ & $5.2-5.7$ & $23.7-25.9$ \\
Brazil & 8.9 & 12.8 & 5.7 & 27.2 \\
India & 8.4 & 14.7 & 7.3 & 30.5 \\
Poland & 9.0 & 17.2 & 6.7 & 33.0 \\
Mexico & 7.5 & 19.4 & 8.8 & 35.6 \\
\hline
\end{tabular}

Source: Energy Consumption in Industrial Processes: Steel World Energy Conference Monograph, 1986

* The data refer to a particular site(s) in each country. The U.S. entry under "pig iron" includes the "coke \& sinter" stage. ** Crude steel, slabs and hot strip mill.

In terms of the role of different steel-making processes, the Polish industry is comparable to that in Western Europe and the U.S. in the 1970s. Despite a considerable decline in the share of open hearth furnaces in Polish steel production in recent years, its level of 25\% in 1991 is much higher than that of Western Europe and the U.S. in the early 1980 s (2\% and $8 \%$ respectively). ${ }^{7}$ The Polish steel industry was less reliant on open-hearth technology in 1982 (43\%) than was that of the Soviet Union (59\%), however.

Cement. Data from the 1970s are available for a number of countries on fuel use per ton of clinker (which accounts for most of the energy use in cement production). The average fuel intensity of Polish clinker production in 1980 was $20-40 \%$ higher than the comparable values in 1973-74 in France and W. Germany, but lower than in the U.K. (T. America, where the cement industry had received little investment relative to $W$. Europe and Japan.

The fuel intensity of clinker production tends to be lower in countries where the more energyefficient dry process is dominant. The share of the wet process in total Polish clinker production in 1980-63\%-was comparable to that in the U.K. in 1974. The lower fuel intensity in Poland may indicate that Poland had more efficient wet-process plants than the U.K. Uniike in many OECD countries in the past, there was relatively little movement in Poland toward the dry process in the 1980 s. There was a shift in that direction in 1990-91, but the average clinker fuel intensity was higher in 1990 than in 1980 (perhaps due to low cap :ity utilization).

Whereas in Poland there vas only a slight decline in overall cement energy intensity in the 1970s and 1980 s (from $6.0 \mathrm{GJ} /$ ton in 1970 to 5.7 in 1980 to 5.2 in 1989), in W. Germany there was continuous decline (from $4.14 \mathrm{GJ} /$ ton in 1970 to 3.79 in 1980 to 3.42 in 1988). ${ }^{8}$ In W. Germany there was an increase

7 OECD data are from: M. Meunier and O. Ce Bruyn KJps, Energy Efficiency in the Steel Industry with Emphasis on Developing Countries. World Bank, 1984.

8 A. Scheuer and S. Sprung, "Energy outlook in West Germany's cement industry," Energy Efficiency in the Cement Industry, J. Sirchis (ed.), Elsevier Applied Science, London, 1990. 
in the electricity intensity due to increased automation and measures for environmental protection, but in Poland the the electricity intensity declined in the 1980 s.

\begin{tabular}{lcccc}
\hline \multicolumn{5}{c}{ Table 7-2. Cement Energy Intensity in Poland and Other Countries } \\
\hline & Year & $\begin{array}{c}\text { Fuel/ton of } \\
\text { clinker (GJ) }\end{array}$ & $\begin{array}{c}\text { Electricity/ton } \\
\text { of cement (GJ) }\end{array}$ & $\begin{array}{c}\text { \% share by } \\
\text { wet process }\end{array}$ \\
\hline Germany (W) & 1974 & 3.77 & 0.36 & 5 \\
France & 1973 & 4.40 & 0.33 & 30 \\
Turkey & 1978 & 4.52 & n.a. & 10 \\
Poland & 1980 & 5.36 & 0.42 & 63 \\
& 1990 & 5.71 & 0.33 & 61 \\
Portugal & 1977 & 5.53 & 0.47 & 30 \\
U.K. & 1974 & 6.15 & 0.36 & 69 \\
India & 1977 & 6.82 & 0.44 & 65 \\
W. Europe & 1979 & 4.18 & - & - \\
N. America & 1979 & 6.20 & - & - \\
Pacific & 1979 & 3.60 & - & - \\
\hline
\end{tabular}

Non-Polish country-specific data are from: M.H. Fog and K.L. Nadkarni, Energy Efficiency and Fuel Substitution in the Cement Industry with Emphasis on Developing Countries, World Bank, 1983.

Regional averages are from: Energy Consumption in Industrial Processes: Aluminium, Cement, Glass, Pulp, Paper, Steel, Sugar, World Energy Conference, 1986.

\subsection{Passenger Transportation (Travel)}

Total energy use for travel in Poland in 1989 was around $4 \mathrm{GJ} /$ capita, below that in Japan and far below the level in W. Europe or the U.S. (Figure 7-4)..$^{9}$ It was also less than in the Soviet Union, mainly due to the higher use of air travel (which is very energy-intensive) in the latter. The very high figure for the U.S. results from its greater car ownership, use, and fuel consumption per $\mathrm{km}$. For all of the countries except the Soviet Union, the automobile dominates travel energy use, in part because it is more energy intensive (in MJ/pass-km) than either rail or bus. ${ }^{10}$ The automobile share of travel energy use is largest in Poland even though fuel use per capita for cars is only one-fifth of the value for the European countries. Energy use per capita for buses and rail in Poland lies within the relatively narrow range of values for the other countries.

\subsubsection{Activity and structure}

In terms of total p-km per capita (excluding walking and cycling), Poland is well below W. Europe and even Japan (Figure 7-5). ${ }^{11}$ Poles traveled about the same as citizens of the Soviet Union in the late

\footnotetext{
9 We estimated the passenger and freight portions of rail energy use based on the assumption given below.

10 Automobiles include personal light trucks, buses include intercity and city, rail is heavy and light rail. Air travel is domestic

11 "EU-7" in Figure 7-5 and other figures refers to the weighted average of Sweden, Norway, Denmark, former W. Germany, France, Italy, and the United Kingdom.
} only. 
1980s, however, despite the latter country's enormous size. This may reflect the better condition of roads in Poland, the proximity of Poland to the West, and the relative ease of foreign travel.

While travel in the U.S. and Western Europe is dominated by the automobile, less than one-third of travel in Poland took place in cars (Figure 7-5). Poland's automobile travel share was higher than that of the Soviet Union, however. The wide disparity in automobile ownership partly explains the differences in the structure of travel (Figure 7-6). By 1990 the ownership of cars in Poland (138 cars/1000 persons) reached the level in Japan in 1970, but this level had been reached in W. Europe in the early 1960s. By contrast, auto ownership in the Soviet Union was well below that in Poland, although ownership in the Baltic republics in the late 1980s was close to that in Poland.

Per capita travel in Poland is very close to the level of Japan in 1988, even though the ownership of cars in Poland is only half the level in Japan. This is because per capita bus and rail travel in Poland is higher than in any country or region shown.

\subsubsection{Energy intensities}

Given the data uncertainties, caution is required in comparing estimates of energy intensities of Polish vehicles with those in W. Europe or elsewhere. For automobiles, it appears that the average gasoline car in Poland in 1989 required approximately $8-9$ liters $/ 100 \mathrm{~km}(26-30 \mathrm{mpg})$. In the U.S. the comparable figure was close to 12 liters $/ 100 \mathrm{~km}$, while in W. Europe it varied from a low of around 8 in Denmark and Italy to $\mathbf{1 0 . 5}$ in W. Germany. The relatively low fuel irtensity of Polish cars reflects the dominance of small, low-power cars, which is not the case for either Denmark or Italy. The Polish intensity is much less than that estimated for Soviet cars (around 11 liters $/ 100 \mathrm{~km}$ ), but the Soviet figure is higher than that expected on the basis of the power and size of most cars in the stock due to poor maintenance, spare parts, and roads. With lower car ownership, the Soviet fleet had a greater share of large cars (owned by government and Communist Party members) than in Poland.

Polish data indicate that city buses required around $12 \mathrm{MJ} / \mathrm{v}-\mathrm{km}$ in 1991, in the range of figures for buses in Germany, Sweden, and Japan, but far lower than city buses in the U.S. Polish intercity buses required $0.27 \mathrm{MJ} / \mathrm{p}-\mathrm{km}$. This was below the levels of the other countries, probably due to high load factors.

We cannot easily estimate the energy intensity of rail travel in Poland because sources do not distinguish between energy used for freight and passenger trains. If we set the energy use for a passenger-km to half of that for a tonne-km (close to what is used in Germany), we find that Polish train travel required about $0.35 \mathrm{MJ} / \mathrm{pass}-\mathrm{km}$ in 1988 . This value is comparable to that of $\mathrm{W}$. Germany in the $1980 \mathrm{~s}$, where a roughly similar share of passenger travel was provided with electric trains. The average load factor may have been higher in Poland, however.

\subsection{Freight Transportation}

Final energy use per capita for freight transport in 1989 was very low in Poland relative to the OECD countries and the Soviet Union (Figure 7-7). The reason is not so much the level of freight shipment (tonne-km per capita), but rather the dominance of rail, which mainly relies on electricity, in freight transport.

\subsubsection{Activity and structure}

For travel, the level of activity per capita in Poland lies below the levels of W. Europe, but for freight transport the situation is different. Similar to the Soviet Union, the Polish economy relies heavily on shipment of heavy materials. Coal in particular-for domestic use and export- is important in 
Poland. The U.S. is not dissimilar in this respect. But the U.S. and Soviet Union dwarf Poland in size, which accounts for their high levels of tonne-km per capita (Figure 7-8). The level in Poland is close to levels in W. Europe, in spite of much lower GDP/capita, due to the importance of coal. ${ }^{12}$

Although the role of rail has declined in Poland, it still dominates freight transport. The U.S. and Soviet Union, with enormous movement of coal, grain, and other raw materials, also rely heavily on rail travel. By contrast, trucks have become the dominant mode in W. Europe, growing steadily in share over the last two decades. The share of truck freight in Poland began to rise after 1988, as the economic decline struck rail freight far more than truck freight, and there was much growth in private truck activity. In the long run, economic reform in Poland is likely to stimulate more truck activity as the trade in consumer goods produced by smaller, decentralized firms increases.

\subsubsection{Energy intensities}

Polish data give energy use per tonne-km for two classes of trucking enterprises, which together accounted for about $35 \%$ of the energy used by non-private trucks in $1990 .{ }^{13}$ Weighted according to the energy use in each class, these trucks used around $2 \mathrm{MJ} /$ tonne- $\mathrm{km}$ in 1988 . The overall average (for all trucks) for W. Europe was around 3.2 MJ/tonne- $\mathrm{km}$ in 1988, while the U.S. value was around $4 \mathrm{MJ}$. It is hard to compare the Polish and OECD figures, however, as the intensities depend critically on the average truck sizes, which are uncertain.

For rail, our estimate of the energy use for freight transport (using the approximation given under travel above) implies an intensity of 0.4-0.5 MJ/tonne-km, which is higher than the W. Europe and U.S. averages of around $0.35 \mathrm{MJ} /$ tonne- $\mathrm{km}$. The difference may reflect less efficient operations in Poland.

\subsection{The Residential Sector}

Comparing overall residential energy use in Poland with that in other countries is difficult because of the lack of precise data on energy use in that sector. As shown in Figure 7-9, our estimate of Polish residential final energy use per capita in 1988 (around 25 GJ) is slightly below the average for the former W. Germany, France, Italy, and the United Kingdom ("EU-4" in the figure) in 1973 (accounting for climate differences). This apparent similarity hides major differences in structural factors and end-use energy intensities, as we describe below.

\subsubsection{Structural factors}

In 1970, per capita living area in Polish homes averaged 14 sq. meters, roughly half of the average W. European level at that time. ${ }^{14}$ By 1990 , area per capita in Poland was 20 sq. meters, but the levels of area in W. Europe also grew, so the gap between Poland and W. Europe remained (Figure 7-10). These differences in per capita area exist because the average home in Poland is considerably smaller than in W. Europe (60 sq. meters vs $85-100$ sq. meters) and household size (people per dwelling) is higher in Poland (3.5 vs. only 2.5 in Scandinavia and 2.6-2.8 elsewhere in W. Europe). Conversely, household size in the Soviet Union was larger than in Poland, but dwelling size was about the same, giving less area per capita.

12 Foreign shipping is excluded from these comparisons, but we do not believe this alters our conclusion, since all of $W$. Europe relies heavily on shipping. Inclusion of this shipping would make up some of the difference between the U.S. or Soviet Union and $W$. Europe.

13 The two classes are the state trucking enterprise (PKS) and enterprises operated by large industrial groups. Data for trucks operated by individual enterprises are given only in MJ per vehicle-km.

14 We multiplied the Polish data on "useful" area by 1.15 to approximate "living" area, which is the measure most commonly used in the West. 
About $62 \%$ of Polish households had either central heating from a system in the building (or nearby) or district heating in 1988 . The corresponding figures for W. Europe are $75-80 \%$ for W. Germany, France, and the U.K., and over 95\% for Sweden and Denmark. An estimated 65-75\% of homes in the Soviet Union had central heat in 1988.

In terms of heating equipment, one is struck by the similarity between patterns in Poland and those in W. Germany in the 1960 s or the U.K. in the early 1970s. In both cases, coal was the dominant fuel for both central heating and room stoves, although individual boilers were far more common in those countries than in Poland today. In both cases, a cleaner fuel-gas in the U.K., oil (and later gas) in W. Germany-drove coal from its dominant position. In the case of the U.K. in particular, this shift meant a decline in per capita final energy intensity because of the greater efficiency of burning gas.

Polish homes have fewer and smaller appliances than those in W. Europe. The combined ownership of refrigerators and freezers is slightly over 100 per 100 households, compared to 140-150 in W. Europe or the U.S. Automatic washing machines are less widespread in Poland than in the West, and clothesdryers or dishwashers are almost unknown. The ownership of major appliances in Poland is also similar to W. Europe in the 1960s. But unlike Germany or Britain then, there is little use of electricity for water heating, cooking, or space heating.

\subsubsection{Energy intensities}

Space heating. We estimate that Poles used an average of 75-85 GJ of final energy per dwelling for space heating in 1988 , which amounts to $1.1-1.3 \mathrm{GJ}$ per sq. meter of living area. The comparable value in Denmark, which also relies heavily on district heating and has a roughly similar climate, was only $0.5 \mathrm{GJ}$ per sq. meter. While this comparison strongly suggests that space heating in Poland is inefficient relative to that in Denmark, there are problems with using final energy in such a comparison, since there is more reliance on electricity in Denmark than in Poland.

If we adjust final energy to reflect the losses in combustion of fuels (assumed to be $33 \%$ for oil and gas, $\mathbf{4 5 \%}$ for solids), we obtain a rough measure of useful heat entering living spaces. The likely range of useful heat per square meter per degree-day in Poland in the late $1980 \mathrm{~s}-220-260 \mathrm{~kJ}$-is far above the comparable values in W. Europe and the U.S. in the same period $(110-150 \mathrm{~kJ})$, but not much above where many of the Western countries stood in the early 1970s (when the type of equipment used for heating was more similar to that in Poland today). ${ }^{15}$ The Polish intensity is somewhat higher than that estimated for the Soviet Union (200-220 kJ), perhaps due in part to the greater proportion of apartments in the Soviet housing stock.

The difference between indoor temperatures in Poland and W. Europe is uncertain, as we found no reliable data on indoor temperatures in Poland (such data are also not common in W. Europe). For Polish dwellings with district heat (around $40 \%$ of the stock), overheating has been common (leading occupants to open windows, since they have no control over the heat flow from the system). On the other hand, it is likely that homes heated with stoves have relatively lower average indoor temperatures. On balance, it seems that the higher energy intensity of space heating in Poland is mainly due to the much lower thermal integrity of building envelopes. Investigations of construction practices in Poland confirm that this is indeed the case.

15 Polish sources did not have weighted-average national degree-day values as are used in the West. Weighting average monthly temperatures from ten cities by the approximate shares of the population their regions represent, we estimated that Poland has approximately 3600 heating degree-days (using a base of $18 \mathrm{C}$ ) outside of the three summer months. In this system, Sweden and Norway have slightly over 4000 degree-days, Denmark 3300 , W. Germany 3000 , the U.K. 2800 , the U.S. 2700 , and France about 2400. 
Further evidence of the low thermal integrity of Polish apartment buildings can be found by examining district heating. Polish sources estimate that homes (mostly apartments) used close to $1200 \mathrm{MJ} / \mathrm{sq}$ $\mathrm{m}$ in 1988 (330 kJ per degree-day). In comparison, Swedish apartments used only $700 \mathrm{MJ} / \mathrm{sq} \mathrm{m}(175 \mathrm{~kJ}$ per degree-day), and there is more delivery of domestic hot water in Sweden. Less insulation in walls (k-values of around 0.6 W/sq. meter/degree C in Poland vs. 0.3-0.4 in Sweden) partly explains the difference. Swedish apartments are on average the most energy-efficient in Europe, but the Polish intensity is also well above the values for district heating in other Western countries.

It is difficult to make reliable estimates of energy intensity for other end uses in Poland. Water heating energy use per capita may be lower in Poland than in W. Europe since there is less central provision of hot water. Conversations with Polar, the largest maker of appliances in Poland, suggest that Polish refrigerators use some $25-33 \%$ more electricity than comparable models in the West. Polish automatic washers are probably more energy-intensive as well.

\subsection{The Service Sector and Other Sectors}

As discussed in Section 5, it is difficult to estimate energy use in Poland's service sector, and we found no estimates of intal floor area. In fact, there are also measurement problems in OECD countries, but not as severe as with Poland. Our rough estimate of service sector energy use in 1988 in Poland250-350 PJ-gives a per capita use of 6-9 GJ. This is well below the level of $18 \mathrm{GJ}$ in W. Germany, which has a somewhat warmer climate than Poland. (The German average in 1970 was around $15 \mathrm{GJ}$.) In terms of energy use per dollar of total GDP (PPP basis), Poland's 1.4-2.0 MJ was higher than the W. German average of $1.0 \mathrm{MJ}$, despite the fact that the share of the service sector in GDP in Poland is much less than in Germany. This comparison, while rough, suggests that the buildings, equipment, and practices are less efficient in Poland.

For electricity, a more precise comparison is possible (values for some Western countries are inflated by use of electricity for heating and air conditioning). Polish electricity use per capita in the service sector (including transport-related buildings) was around $320 \mathrm{kWh}$ in 1988 , and slightly higher than that in 1991. In W. Germany, where there is relatively little use of electricity for space heating in commercial buildings, the comparable value was $1360 \mathrm{kWh}$ in 1988 . Even in 1970, the German value was nearly twice as high as the current Polish level. Relative to GDP (PPP), on the other hand, the recent German and Polish values are quite close, indicating that the level of electricity use per dollar of services GDP would be higher in Poland. Since German buildings have much more electricity-using equipment than Polish ones, the comparison suggests that the level of end-use efficiency and the quality of electricity management are lower in Poland.

As for other sectors, comparison between Poland and other countries is difficult since total energy use in Poland (state and private) for agriculture and forestry, construction, and mining is uncertain. Most private farms in Poland are smaller and less mechanized than farms in W. Europe.

\subsection{Energy Prices}

Apart from petroleum products, energy prices in Poland were subsidized by the state. The degree of subsidy was especially large for households. In contrast to Western practices, which are based more closely on cost of service, in Poland household prices were much lower than industrial prices. The legacy of low energy prices was certainly a factor in shaping Polish energy use patterns, and partially explains the differences between Poland and the West.

Judging how much lower Polish energy prices were compared to $W$. Europe is difficult due to the problems of currency conversion discussed earlier. Table 7-3 presents the average Polish price for 
various energy carriers in U.S. dollars based on the official exchange rate and based on PPP values. The comparison with average $W$. European prices shows considerable variation among energy products. For coal, the most important fuel in Poland, the price in 1989 was only 8-20\% of the W. Europe average. (The lower price is based on exchange rates, the higher one on PPP values.) Even after the price increases, the Polish average for 1991 was still only $23-57 \%$ of the W. Europe average.

In contrast to coal, Poland's industrial gas price in 1989 was much closer to the W. Europe average. The household gas price was far lower than in W. Europe in 1989, however, and was still much lower in 1989. The situation was somewhat similar for electricity. The Polish industrial price in 1989 was $25-$ $67 \%$ of the W. Europe average, while the household price was only $6-14 \%$ of the W. Europe average. By 1991 Poland's industrial price was closer to the W. Europe average, while the residential price was still much lower.

Poland's gasoline and diesel prices in 1989 were closer to W. European levels (and exceeded them on a PPP basis). The increase in Poland was much more modest than for other energy products.

While useful, comparing the levels of energy prices tells only part of the story, since the role of energy costs in overall production or household costs also differs. To argue that low energy prices were the major determining factor in shaping technology choices and equipment-use practices in Poland is to misunderstand the workings and outcomes of the central planning system, as well as the choices that were available given the barriers between the Communist Bloc and the Western world. On the other hand, the combination of higher energy prices, the demise of central planning, and the openness to the West will certainly contribute to the choice of more energy-efficient technologies and practices. 
Table 7-3. Energy Prices in Poland and Western Europe

(average current prices in US\$)

\begin{tabular}{|c|c|c|c|c|c|c|}
\hline \multirow{3}{*}{$\begin{array}{l}\text { Energy } \\
\text { carrier }\end{array}$} & \multicolumn{4}{|c|}{ Poland } & \multicolumn{2}{|c|}{ W. Europe ${ }^{a}$} \\
\hline & \multicolumn{2}{|c|}{1989} & \multicolumn{2}{|c|}{1991} & 1989 & 1991 \\
\hline & Exch & PPP & Exch & PPP & Exche & e rates \\
\hline Steam coal (\$/ton) ${ }^{\mathbf{b}}$ & 5.8 & 14.7 & 18.0 & 45.5 & 74.4 & 80.0 \\
\hline \multicolumn{7}{|l|}{ Natural gas $(\$ / \mathrm{m} 3)^{c}$} \\
\hline Industry & 68.0 & 172 & 145 & 367 & 150 & $180^{d}$ \\
\hline Households & 11.3 & 28.6 & 73.0 & 185 & 384 & $480^{d}$ \\
\hline \multicolumn{7}{|l|}{ Electricity $(\$ / \mathbf{k W h})$} \\
\hline Industry & 0.016 & 0.041 & 0.032 & 0.081 & 0.061 & 0.077 \\
\hline Households & 0.006 & 0.015 & 0.029 & 0.073 & 0.110 & 0.135 \\
\hline Gasoline (\$/liter) ${ }^{\mathbf{e}}$ & 0.31 & 0.78 & 0.43 & 1.09 & 0.73 & 0.93 \\
\hline Diesel (\$/liter) & 0.22 & 0.56 & 0.29 & 0.73 & 0.45 & 0.61 \\
\hline \multicolumn{7}{|l|}{ Heavy fuel oil (\$/ton) } \\
\hline Industry & 39.4 & 99.7 & 111 & 281 & 136 & 158 \\
\hline
\end{tabular}

Source: For values based on exchange rates: Energy Prices and Taxes, 3rd quarter 1992, International Energy Agency, Paris.

We derived PPP values from exchange-rate values using the ratio of GNP (PPP basis) to GNP (exchange rate basis) given in Marer, et al, 1992 (see p. 7-1).
a. OECD Europe average
b. For electricity generation
c. Net calorific value
d. 1990
e. Leaded premium

\subsection{Summary}

Total fina? energy use per capita in Poland in 1988 was around 20\% lower than in W. Germany, which has a roughly similar climate. Manufacturing plays a larger role in final energy use in Poland than in all of the OECD countries except Japan, which exports much of its output (Figure 7-11). ${ }^{16}$ The role of the residential sector is slightly smaller than in W. Germany. ${ }^{17}$ The importance of passenger travel and freight transport is much less than in the West.

In the manufacturing sector, the level of per capita activity (value added) in Poland, although hard to compare precisely, is clearly much lower than in the West (which indicates how much less productive

\footnotetext{
16 We excluded the energy transformation sector from Polish final energy use to provide a better comparison with the Western values. The Polish value given for "Services" in Figure 7-11 is the residual of "other consumers" after removing estimated residential use. The category "Other" includes state agriculture, construction, and mining.

17 The values for residential energy use in the figure were not adjusted to a common climate, as was the case for Figure 7-9. The climate in 1988 was close to normal in most of the countries, however.
} 
Polish manufacturing is). The structure of the sector is more heavily weighted towards energy-intensive industries, however, even after the changes of recent years. Although we were not able to compare energy intensities for more than a few industries, these cases suggest that Poland uses more energy per ton than Western countries for most (if not all) major industrial products.

The residential sector is nearly as important in Polish energy use as manufacturing. Living area per capita is much less than in the West, meaning less space to be heated and lit. Structural factors (space and water heating equipment and appliance ownership) also lead to lower energy use per capita. But the energy intensity of space heating, by far the most significant end use, is much higher than in the West. The intensities of other end uses (average use per capita or per device) appear to be closer to W. European averages, though in some cases the Polish equipment is smaller (e.g. refrigerators).

The services sector plays a relatively small role in Poland. Although its energy consumption is uncertain, it clearly uses much less energy per capita than in W. Europe-mainly because Poland has much lower floor area per capita for services. The levels of electrical equipment in Polish buildings are much lower than in the West.

In passenger travel, both per capita activity and the modal structure of travel lead to much lower energy use per capita in Poland. Energy intensities are lower than (automobiles) or comparable to those in the West (rail and bus). In freight transport, per capita activity is comparable to W. Europe, but the dominance of rail in the structure contributes to lower energy use per capita. The difference between energy intensities is hard to judge due to data limitations.

Energy use per capita in Poland is not much below W. European levels despite Poland's much lower GDP per capita. Poland's comparatively high energy intensities in manufacturing and residential space heating, along with the energy-intensive structure of manufacturing, are the key reasons for this result. They far more than outweigh the impact of the structure of passenger and freight transportation and the low energy intensity of automobiles, which contribute to lower energy use per capita in Poland than in Western Europe. Since 1988, the year of our comparison, Poland's residential heating intensity has declined greatly, but energy intensities in manufacturing have increased due to low utilization of capacity. In transport, the patterns in Poland have moved closer to those that prevail in the West. Since the capital stock in transport can turn over more rapidly than in industry, Poland's transport sector will likely move toward Western patterns at a faster rate than the industrial sector, whose transformation still requires challenging institutional changes.

\section{References for OECD and Soviet Data}

An overview of the OECD data may be found in:

L. Schipper and S. Meyers, with R. Howarth and R. Steiner, Energy Efficiency and Human Activity: Past Trends, Future Prospects, Cambridge, UK: Cambridge University Press, 1992.

L. Schipper, S. Meyers, and R. Howarth, "Energy Intensities in OECD Countries, 1970-1989," LBL33108, Lawrence Berkeley Laboratory, 1992.

For multi-country sector-specific information, see:

R. Howarth and L. Schipper, "Manufacturing Energy Use in Eight OECD Countries: Trends through 1988," The Energy Journal, vol. 12, no. 4, pp. 15-40, 1991. Also LBL-31228.

R. Howarth, L. Schipper, P. Duerr, and S. Strơm, "Manufacturing Energy Use in Eight OECD Countries: Trends through 1988; Decomposing the Impacts of Changes in Output, Industry Structure, and 
Energy Intensity," Energy Economics, vol. 13, pp. 135-142, April 1991.

L. Schipper and D. Hawk, "More Efficient Household Electricity Use: An International Perspective," Energy Policy, vol. 19, no. 3, pp. 244-263, 1991.

L. Schipper, R. Steiner, P. Duerr, F. An, and S. Strom, "Energy Use in Passenger Transport in OECD Countries: Changes between 1970 and 1987," Transportation, vol. 19, 25-42, 1992. Also LBL29831.

For more detailed country-specific information, see:

L. Schipper, R. Howarth, and H. Geller, "United States Energy Use from 1973 to 1987: The Impacts of Improved Efficiency," Annual Review of Energy, vol. 15, pp. 455-504, 1990.

L. Schipper, R. Howarth, and D. Wilson, "A Long-Term Perspective on Norwegian Energy Use," LBL27295, 1990. Lawrence Berkeley Laboratory,

L. Schipper, R. Howarth, B. Andersson, and L. Price, "Energy Use in Denmark: An International Perspective," LBL-32362, Lawrence Berkeley Laboratory, 1992.

The data for the Soviet Union are discussed in:

L. Schipper and R.C. Cooper, "Energy Use and Conservation in the USSR: Patterns, Prospects, and Problems", LBL-29830, Lawrence Berkeley Laboratory, 1991.

R.C. Cooper and L. Schipper, "The Efficiency of Energy Use in the USSR-An International Perspective," Energy-The International Journal, vol. 17, no. 1, January 1992. 


\section{Primary Energy Use per Unit GDP, 1989}

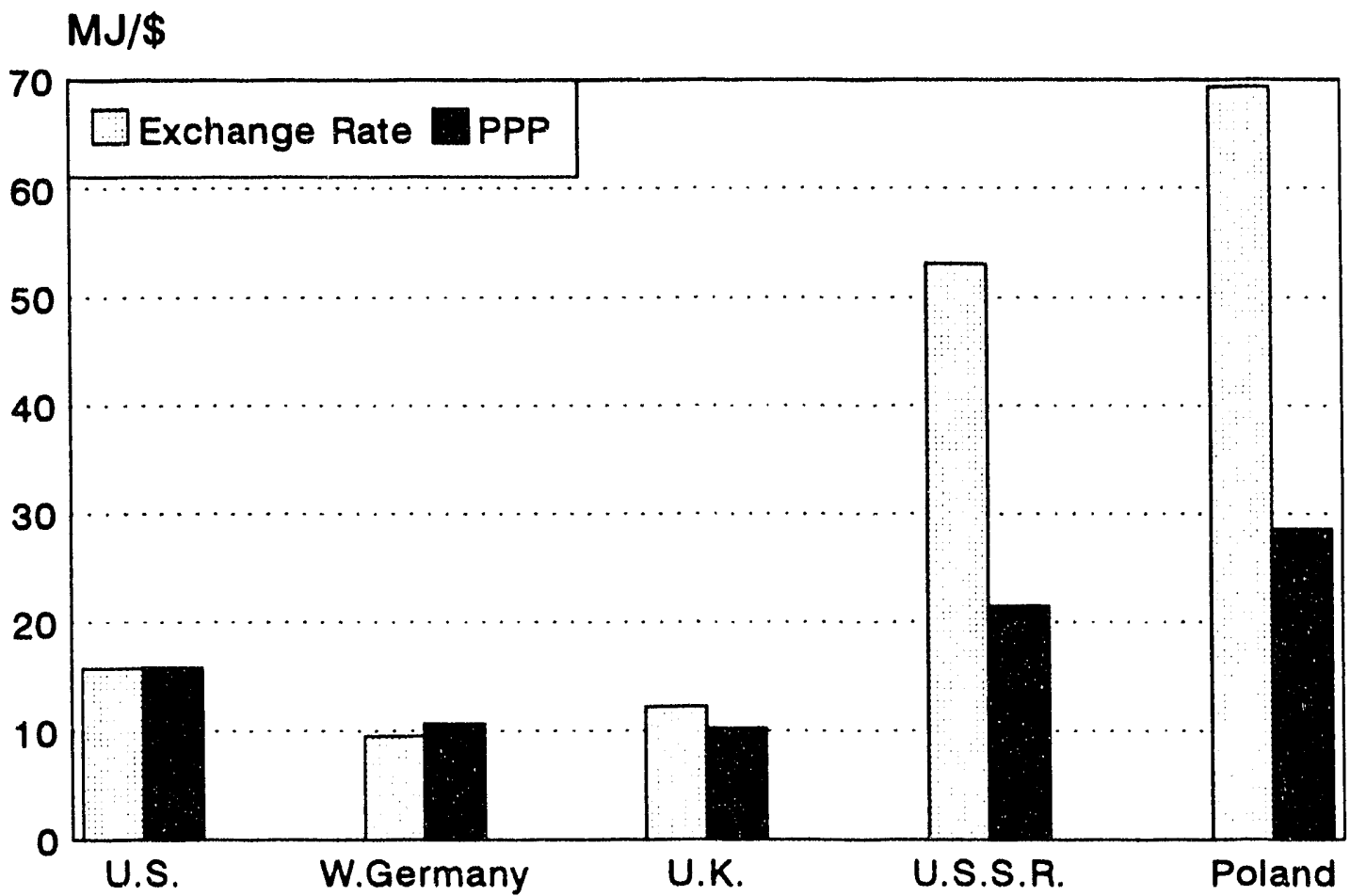

Figure 7-1

\section{Manufacturing Energy Use per Capita, 1988}

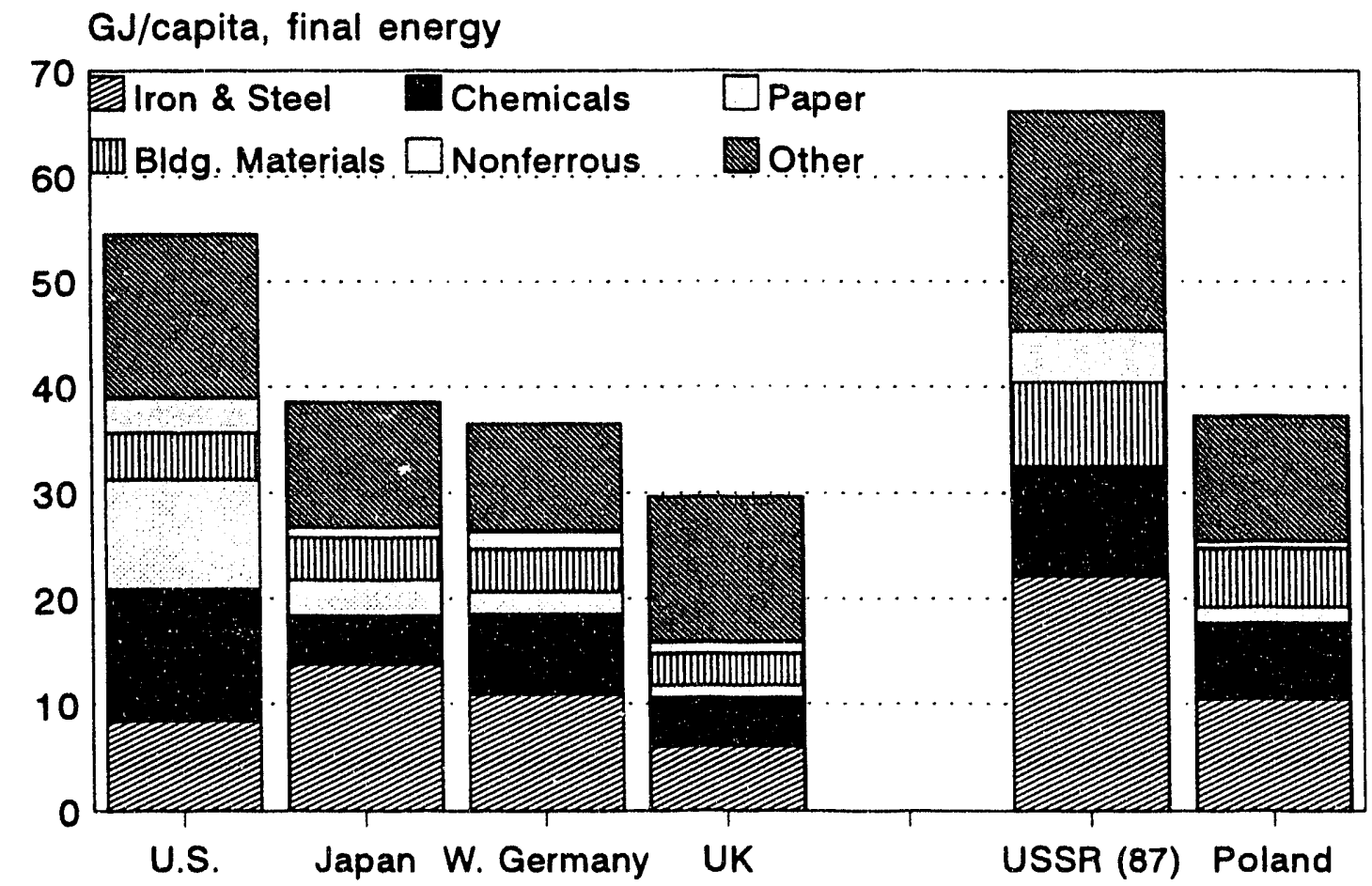




\section{Energy Intensive Materials Production Late 1980s}

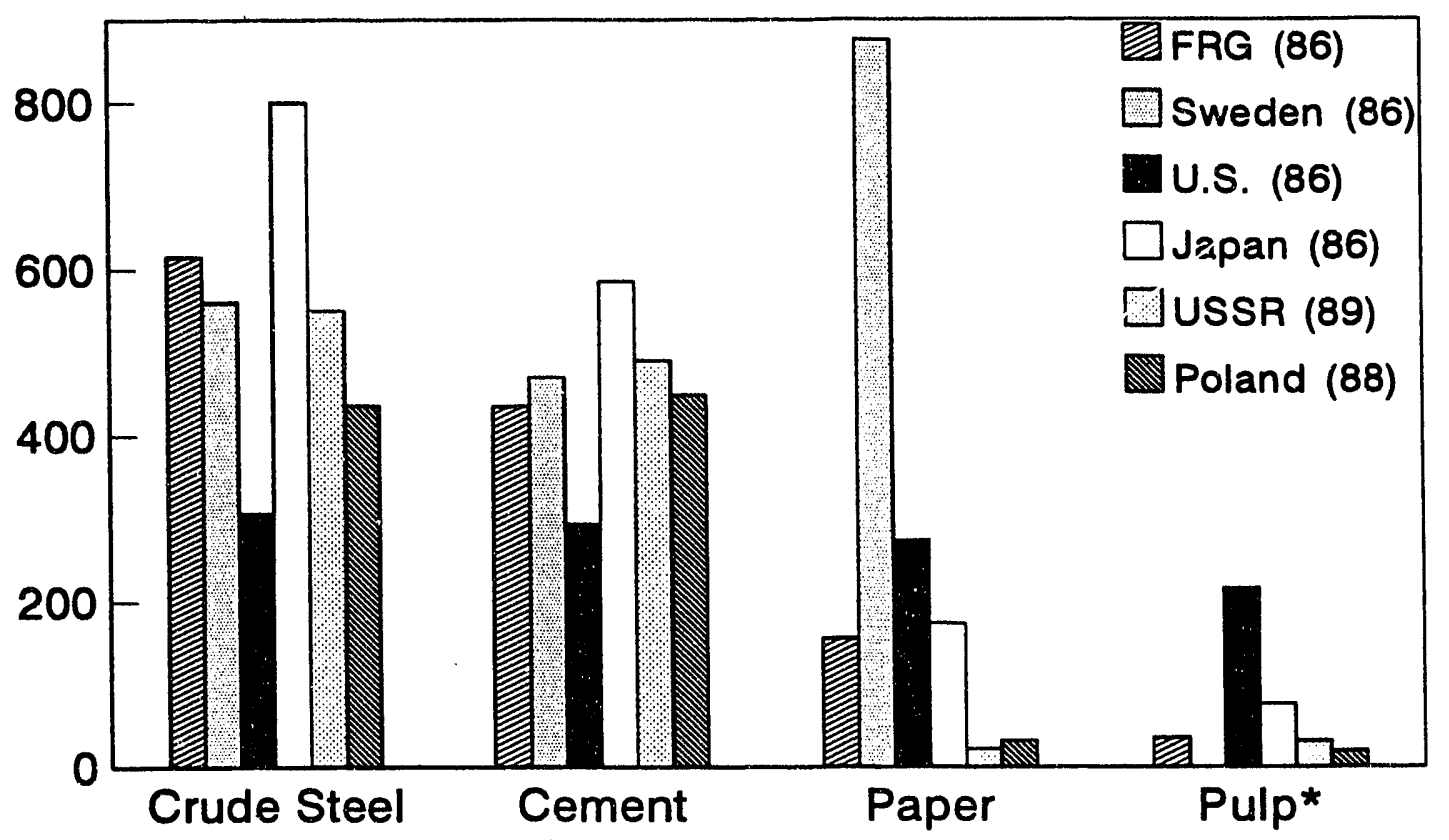

* Sweden pulp production $=1000 \mathrm{~kg} / \mathrm{cap}$.

Figure 7-3

Per Capita Energy Use for Travel

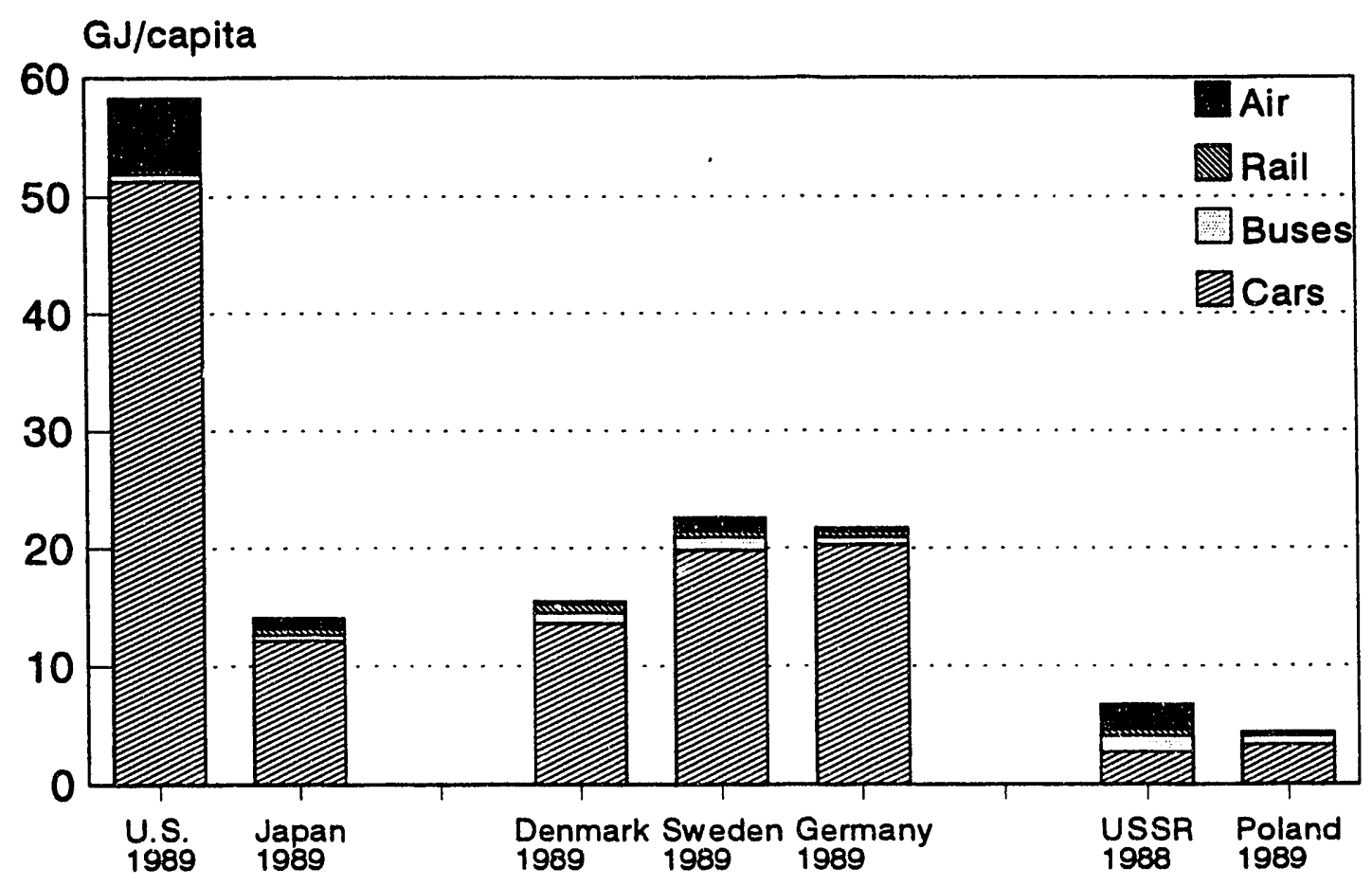

Figure 7-4 
Passenger Travel per Capita

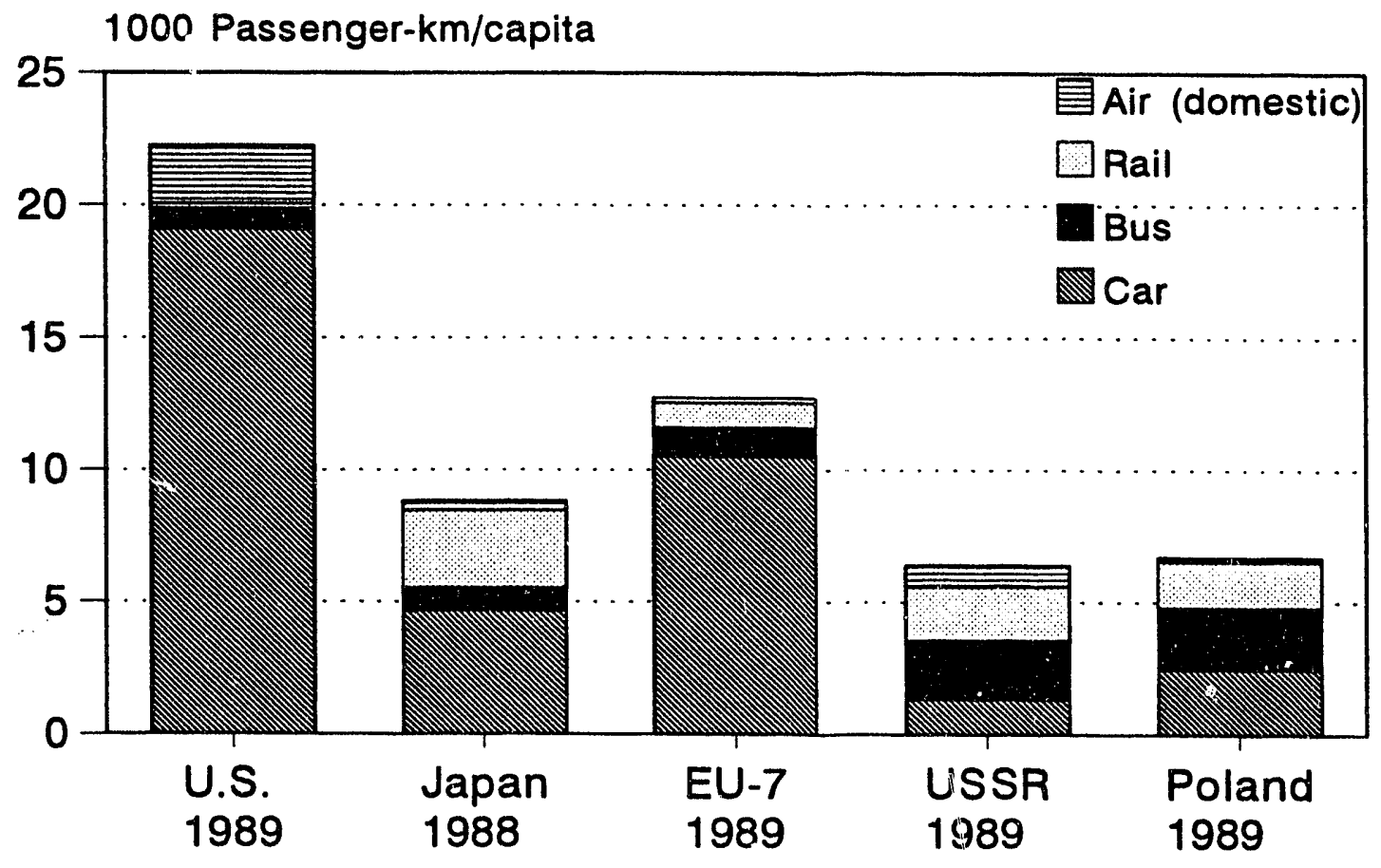

Figure 7-5

\section{Automobiles per 1000 Persons}

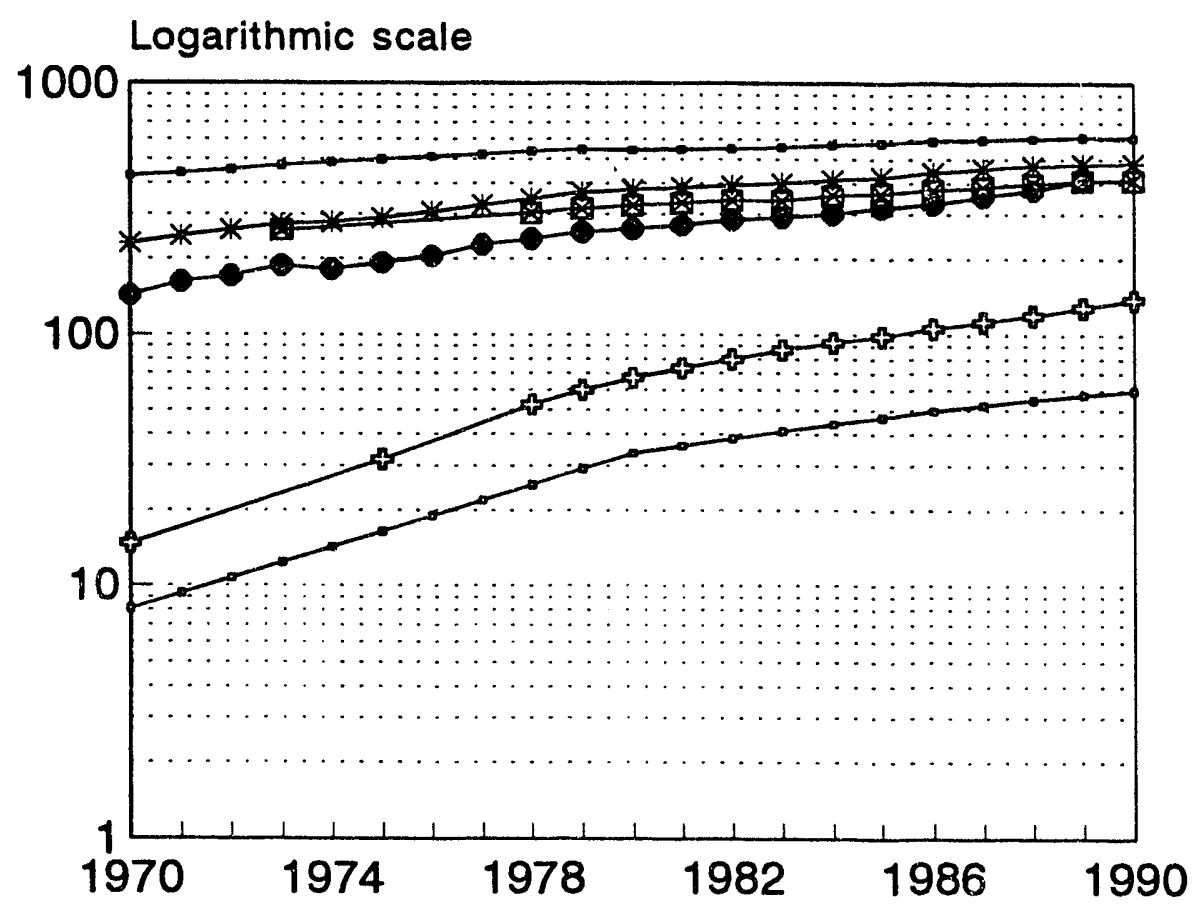

- U.S.*

*W. Germany

Japan

Europe-7

+ Poland

$\rightarrow$ USSR

* U.S. includes personal light trucks.

Figure 7-6 


\section{Domestic Freight Transport Per Capita Energy Use, 1989}

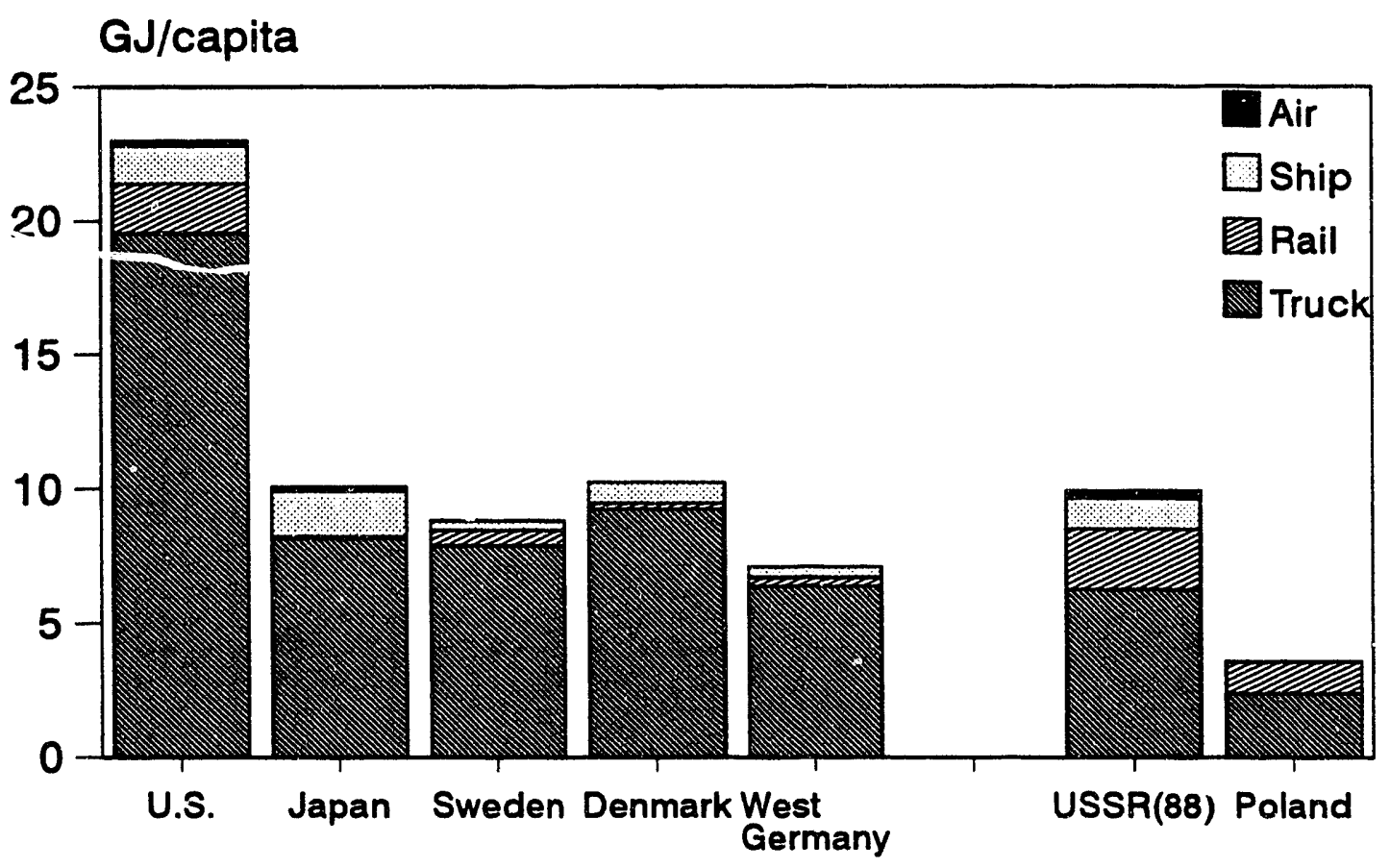

Figure 7-7

\section{Domestic Freight Per Capita By Mode}

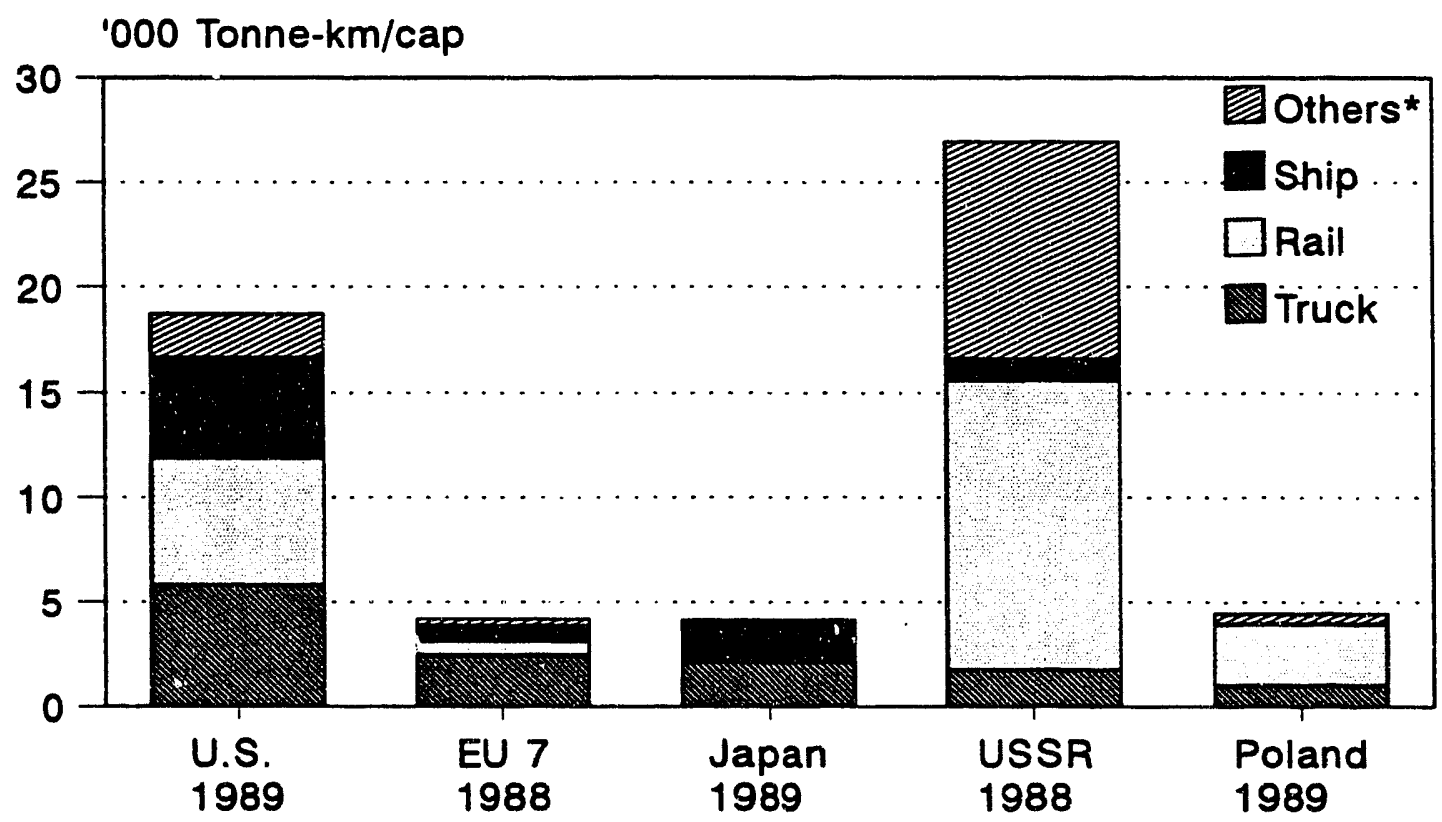

* Primarily pipeline (est for U.S. EU-7).

Figure $7-\overline{8}$ 


\section{Residential Energy Use Per Capita* By End Use}

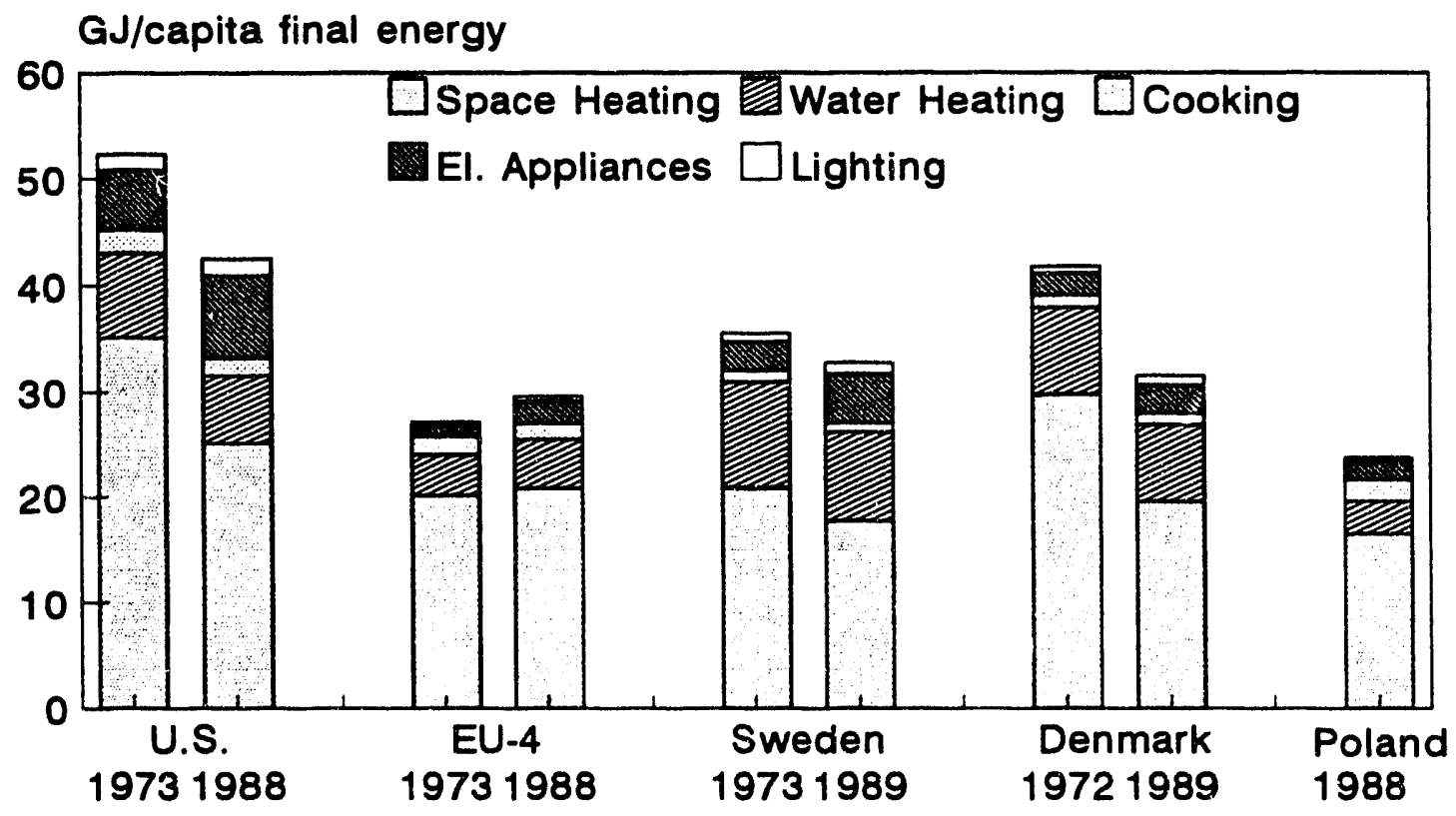

- Heating adjusted to 2700 deg-days C

Poland values are rough estimates. EU-4: France, Germany, Haly, UK

Figure 7-9

\section{Per Capita Living Area in Homes}

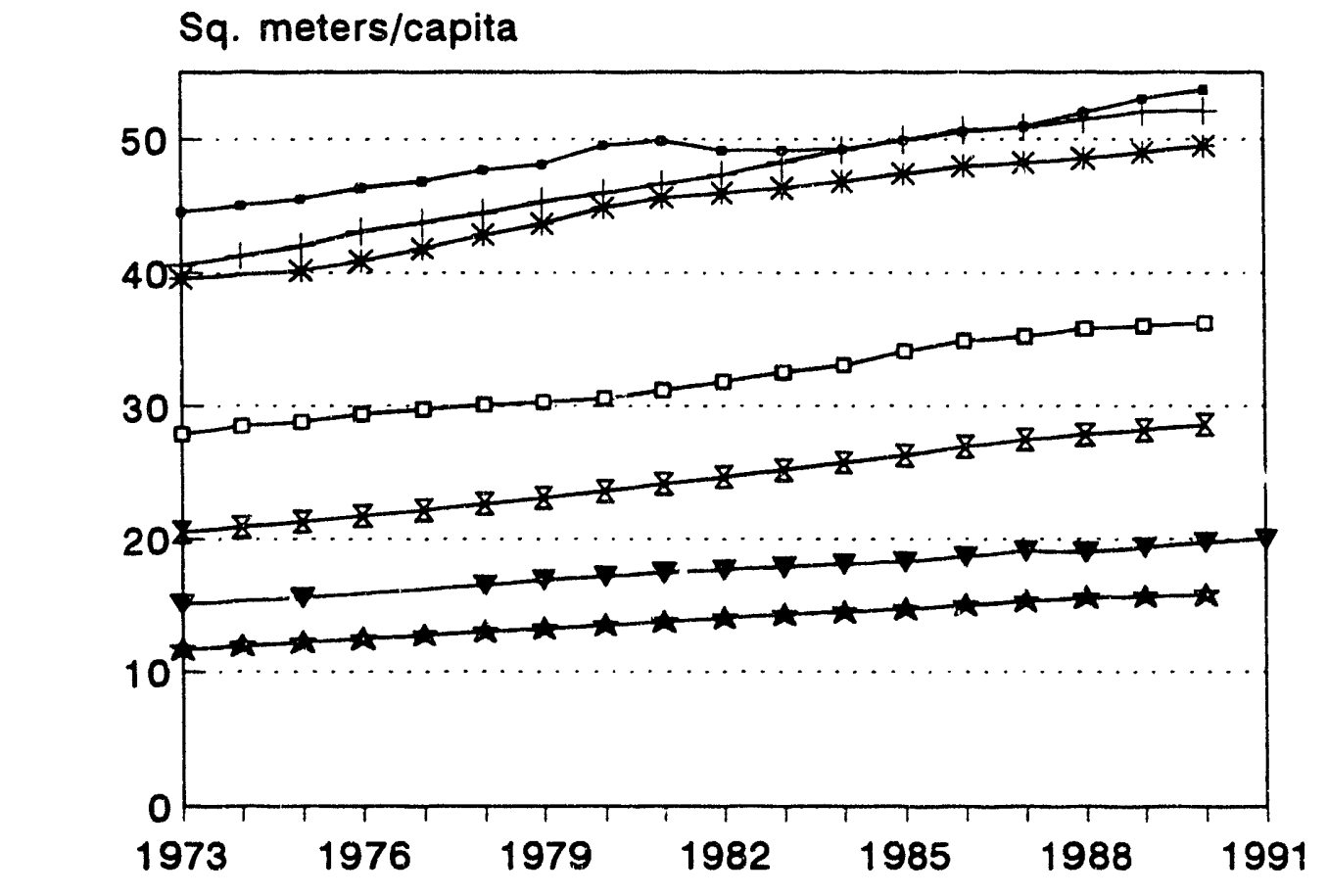

$\rightarrow$ U.S.

+ Sweden

* Denmark

ㅁ. W. Germany

\& Japan

F Poland*

$\star$ USSR

$* 1.15 \times$ usetul area

Figure $7-10$ 


\section{Final Energy Use Per Capita 1988 By Sector*}

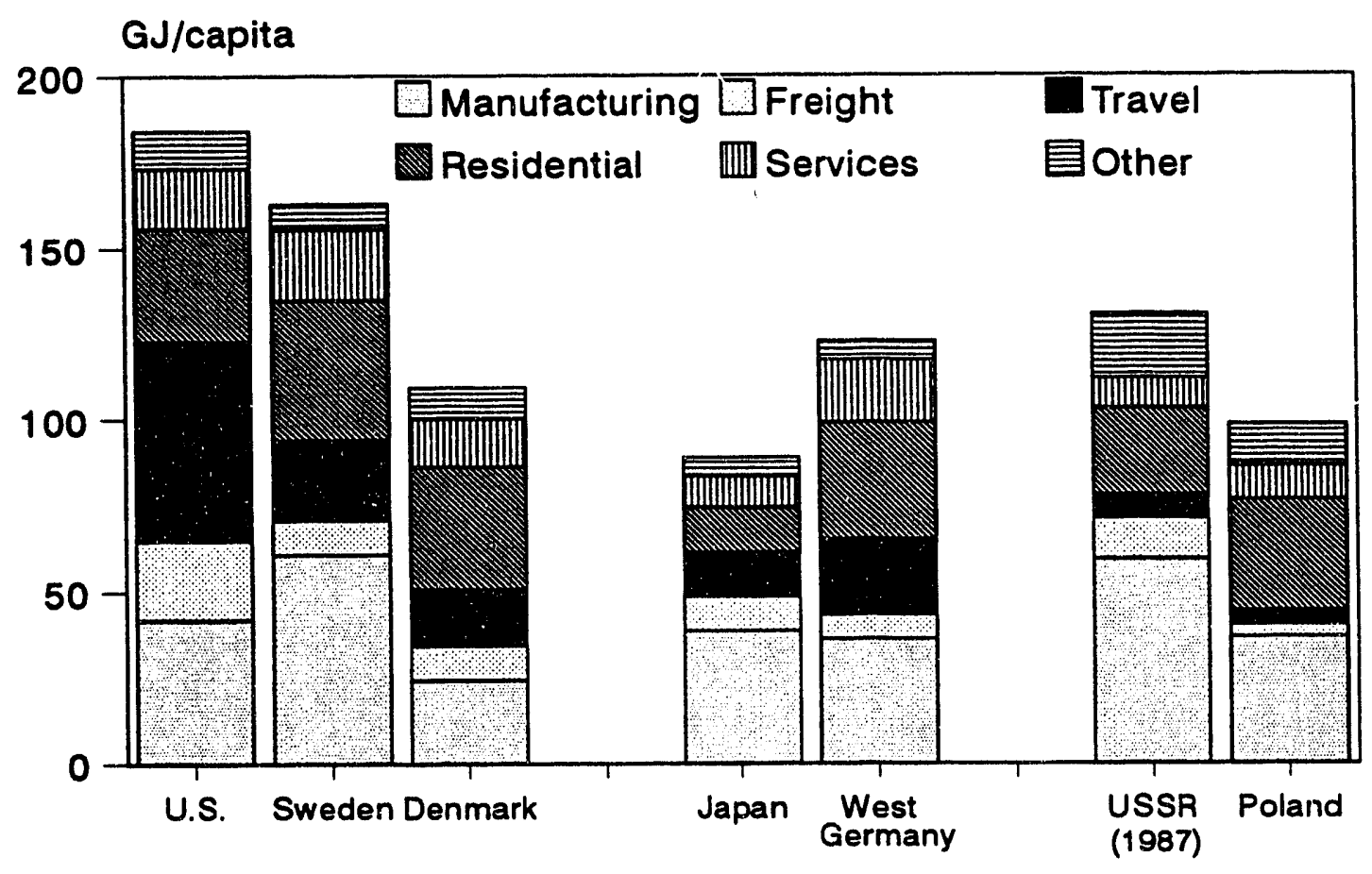

- Poland \& USSR disaggregations are approximate.

Figure 7-11 


\section{Appendix: A Portrait of Energy Use in Poland}

Our analysis of final energy-demand patterns in Poland is carried out in two stages. The first stage transforms original data from the Polish Central Statistical Office (GUS) to match sectoral definitions more consistent with those in use in the West. The second stage uses certain key assumptions to disaggregate the data further into six final demand sectors and many subsectors or end uses. The data come from three main GUS sources. First, the energy balances covering the years 1970-1989; second, more detailed analyses of the years 1986 through 1991; and finally, various editions of statistical yearbooks, transportation yearbooks or data publications, and housing data from GUS, including an unpublished 1987 marketing survey of household equipment. The analyses from 1986 present energy balances in greater detail than the 1970-1989 series, particularly for transportation, where use of transportation fuels in industry and for city buses is presented.

\section{The First Transformation}

In the first step, original energy consumption data by sector, as defined by GUS, were gathered from original Polish sources for the years 1970,1975 , and 1978-1991, and then several modifications were made.

In Polish statistics, the energy input to large, non-power-producing boilers is not counted as final energy; rather, final energy refers to the heat output of the boiler. These so-called "autoproducing heat plants" are treated as an energy transformation sector, in part because some of the heat from these boilers goes into the district heat network. ${ }^{1}$ It appears that much of the heat produced by these autoproducing heat plants is used on-site. (In the statistics, the heat retained by industry is aggregated with that purchased from the network.) Thus, we included the fuel input to the autoproducing heat plants under final energy, and subtracted their beat production from the values given under industry heat consumption in the Polish statistics (so as not to double-count).

We knew the total input of fuels to industrial autoproducing heat plants, but not the amount for each subsector in industry. We assumed that for each subsector, its share of total industrial self-producer heat is the same as its share of total heat consumption. We then assumed the same share of the fuels used for heat auto-production. By counting the losses arising in producing this heat, this transformation makes final consumption in Polish industry more consistent with its usual definition in the West.

The data for the fuel and power subsector in industry were separated, leaving an approximation of manufacturing energy use as defined in the West. Unfortunately, it was not possible to separate figures for certain mining activites (in non-ferrous metals, non-metallic minerals, and chemicals) from manufacturing. ${ }^{2}$ The mining share of manufacturing energy use is particularly important for non-ferrous metals (copper mining) and for chemicals (sulfur mining). Also, we could not accurately separate transportation fuel use (gasoline and diesel) for each manufacturing branch, although the total amounts of these two fuels consumed by each branch (for all purposes, not just transportation) are known. In all, about 60 PJ of road fuels, mostly diesel, appear to have been consumed by vehicles owned by ministries or state enterprises in the late 1980s. This figure, while a significant fraction of all liquid fuels used in industry, is less than $6 \%$ of industrial consumption in most years.

1 The same is true of autoproducing power plants. In principle (if not always in practice), autoproducing power plants are treated as an energy transformation sector in Westem statistics also.

2 The Polish energy balances produced for the IEA and their original version in Polish (which are disaggregated to the equivalent of 4 ISIC digits) do show these for a limited number of years (1988-1991). 
The data on transportation were transformed as follows. To the official data on (state) transport, we added data for the municipal sector (trams, trolley, and diesel buses) from "other consumers"; gasoline from "other consumers" (which probably contains some military as well as private use), and diesel fuel used for private cars, trucks, tractors, and military vehicles. The energy use for transportation-sector buildings (district heat, gas, and a small amount of electricity not counted as "traction energy" in the Polish data) was moved to "other consumers". Overseas marine fuels were excluded from our analysis.

We treated the "other consumers" sector in a complementary fashion, removing gasoline and energy use for municipal transportation and adding the energy used in transportation-sector buildings. Unfortunately, we were not able to estimate the use of diesel fuel in private agriculture or private trucking (which are included in "other consumers"). We removed all of the diesel fuel from "other consumers" to transport, however, since trucking probably dominates diesel use. Some of this diesel fuel was probably used by the military.

Figure A-1 shows (for 1988 and 1991) the original GUS data and our first transformation. Since the LBL transformation includes a significant quantity of fuel consumed for industrial heat generation, the total is greater than that shown for GUS. The small "residual" shows the energy we were not able to allocate by sector, which includes principally liquid fuels used for miscellaneous transportation uses, including military.

\section{Energy Use by Subsector or End Use}

In the second stage of the analysis, we disaggregated sectoral energy use into subsectors or end uses. Many assumptions were required for this synthesis. The result is a portrait of energy use in Poland that is plausible, though not built on primary "data". Figure A-2 shows the results for 1988 and 1991 . Agriculture (private and state), construction, and coal mining are grouped as "other industry." The following describes key assumptions used in disaggregation of the "other consumers" sector and the transport sector.

\subsection{Other consumers: residential, services, private agriculture, and others}

Separating the "other consumers" sector into components is difficult. Our work is based on partial data on district heating and natural gas use, relatively good data on electricity use, information on household equipment, discussions with Polish authorities, and inferences from historical data from Germany and Great Britain, two countries whose energy consumption was once dominated by coal.

First we divided coal, LPG, and district heating consumption into that used by households (residential) and that used by others. For coal and other solids, discussions with Polish experts suggest that the household shares is in the range of $70-80 \%$ (this excludes self-gathered wood). Our share starts at $75 \%$ in 1970 , falling in the early 1980 s to $72 \%$, and then rising again to reach $77 \%$. But the data for coal count only sales, not consumption. Actual consumption depends on stock changes in individual households, which could be substantial. To account for hoarding in 1989 and the subsequent drawing down of stocks in 1990 and 1991 (as prices soared), we assumed that only 90\% of the coal purchased in 1988 and 1989 was consumed in those same years; the remainder was instead consumed in 1990 and 1991, along with the coal actually recorded as consumed in those years. This smoothes out somewhat the drastic drop in consumption shown by the official data.

For district heat, some Polish experts estimate that $80-85 \%$ of consumption is for homes, but others put this share lower. S. Pasierb of FEWE puts it as low as $75 \% .^{3}$ We adopted figures towards the higher

\footnotetext{
${ }^{3}$ Recall that the consumption of heat by the "other consumers" sector is the residual when all other major consumers have been counted. For these other consumers (mostly industry), reported use excludes transmission losses. These must lie with the
} 
end of this range for the period 1985-1991, starting with a much lower shar $\approx(70 \%)$ in 1970 , when fewer heating customers drew domestic hot water from the same system and when systems were concentrated to city centers where service-sector buildings were prominent. Electricity and gas were treated as they are reported in the Polish statistics, where residential consumption is separated from other users. Electricity use by private farms was counted $20 \%$ as agricultural (i.e., used in processes) and $80 \%$ as residential. Finally, we estimated that $80 \%$ of LPG is for homes for cooking. ${ }^{4}$ Using these estimates, we obtained the consumption of energy by type for the residential sector shown in Figure A-3.

We next estimated the final residential uses of each fuel in the period 1970-1991. Our guides are a Polish equipment survey of 1987 (J. Maron, priv. communication) and our experience with trends in other countries--West Germany, Great Britain, and Denmark--where coal, gas, or district heating is important. For this step, we assumed that:

- About $15 \%$ of coal and other solid fuels were used for cooking in the early 1970 s, falling to $8 \%$ as gas, LPG, and electricity became more important. By 1991, only $3 \%$ of residential solid fuel was used for cooking. About $8 \%$ of residential solid fuel was used for water heating in the early 1970 s, rising to $10 \%$ as more central heating based on coal was installed. The rest of the residential solid fuels was used for space heating. The 1987 survey indicated that about $10 \%$ of homes had coal water heaters, while another 9\% obtained water heat from the coal cooking stove.

- Gas was used predominantly for cooking: $69 \%$ in 1970 falling to $29 \%$ in 1991 . Thirty percent was used for water heating in $1970,40 \%$ in 1981 , rising to $50 \%$ in the mid-1980s, then falling back to by 1991 as space heating began its rapid rise. Only $1 \%$ was used for space heating in the 1970 s, when this end use was all but forbidden. In the mid 1980s however, this portion began to increase, passing $20 \%$ in 1987 (based on our estimate of $2 \%$ of homes with gas-based heating systems) to $25 \%$ in 1991.5 Increasing numbers of consumers obtained water heated by gas ( $20 \%$ with instant water heaters in 1987).

- Initially $92 \%$ of residential district heating was for space heating, and only $8 \%$ for water heating. This reflects the low penetration of district water heating in homes with district heating. By 1991, the water heating share rose to $10 \%$, reflecting a $50 \%$ penetration of this end use in homes with district space heating. This implies about $10 \mathrm{GJ} / \mathrm{dwelling}$ for water heating. (In Sweden and Denmark, where these two end uses are almost always found together, water heating accounted for about $20 \%$ of district heating use in the early 1980s, but the share rose as conservation reduced the need for space heating. This suggests our split for Poland is reasonable.)

- All LPG is used for cooking. The 1987 survey indicates that about 15\% of homes had LPG cooking. However, the total consumption of LPG in the "other consumers" sector implies a relatively low figure for LPG use per household for cooking, about $3 \mathrm{GJ} / \mathrm{household.} \mathrm{This} \mathrm{figure} \mathrm{is} \mathrm{so} \mathrm{low} \mathrm{that} \mathrm{the} \mathrm{drop} \mathrm{in} \mathrm{LPG}$ consumption in 1990 either means that most stopped using it for cooking due to the higher price, or that the consumption figures for those years are completely wrong.

- Electricity is difficult to allocate. In 1987 about $4 \%$ of homes in Poland had either direct electricity heating or night-time storage heating, and $20 \%$ of homes had electric instant water heaters. $11 \%$ had electric cooking. Using West German estimates for unit consumption for these three end uses, scaled to larger

residual, i.e., in the "other consumers" sector. In consultation with Polish experts, we have removed 15\% of all district heat consumed from this residual to represent total transmission losses.

4 Unfortunately, LPG counted in the "other consumers" sector appears to be a pure residual. The rapid decline in 1990 and 1991 appears to be caused by a change in this residual, not a change in actual use in the "other consumers" sector.

5 This nicely accounts for the clear upward trend in gas use per customer. 
households but smaller homes, we could attribute $5000 \mathrm{kWh} /$ year to heating, $1200 \mathrm{kWh}$ /year to water heating, and $1000 \mathrm{kWh} / \mathrm{year}$ to cooking. If these unit consumptions are multiplied by the number of homes with each end use, about $25 \%$ of residential electricity is accounted for; the rest is for lights and appliances. The number of houses with electricity heating has probably not changed much over the period, but the number using electricity for cooking and water heating appears to be increasing. Together the three uses accounted for $15 \%$ of residential electricity use in 1970.

Using these assumptions, we assembled residential energy uses to form a reasonable portrait of final demand in 1970-1991. The results are shown in Figure A-4.

\subsection{Transportation: travel, freight, and other vehicle uses}

As noted above, Polish data do not track fuels for private transportation. Furthermore, the liquid fuel data that are available do not explicitly separate modes of road travel from each other, or fuel and electricity use for rail travel from rail freight. Using a series of assumptions and the available data, however, we can assemble a plausible picture of the structure of energy use in travel and freight. This picture is constructed from actual, but limited, data on Poland, using our experience with more detailed data from a dozen other industrialized countries in the OECD and the former Soviet Union. Figure A-5 shows the results for the main land-based modes.

We constructed this picture using a bottom-up approach. That approach estimates the activity and structural components of each energy demand togetier with the energy intensity. Often two of these three quantities are known, rarely are all three known. This approach requires us to estimate activity measures as well as allocate energy uses.

For example, Polish data for 1987-1991 indicate the vehicle intensity (energy use per vehicle-km traveled) of certain kinds of bus travel, and give total energy use for that travel. From these two quantities we obtain total distance traveled for the kind of bus in question. Estimating this trio of parameters for a variety of buses, we can find total distance traveled by all buses. For inter-city buses, total travel in passenger-km is also known, from which we can estimate the modal intensity of inter-city bus travel, in energy/passenger-km.

Combining data on the numbers of urban buses, trolleys, and trams, seats available, and distances driven, with an estimate that $40 \%$ of all seats were occupied (on average) for each mode, we calculated passenger-km traveled. Energy consumption for this urban transport is known for 1987-1991, while total road fuel and electricity use for these modes (and likely city cars or utility vehicles) back to 1986 is published in Polish statistics. Passenger-km for inter-city bus are published. These are split into "state", "branch", and "professional" vehicles, i.e., state-owned by transport enterprises ("common carriers"), state-owned by ministries, and state-owned by other state enterprises. Fuel use for each of these modes is known from 1987.6 Thus the picture for 1987-1991 is essentially complete for bus travel. From these data we can estimate fuel use for buses backward in time assuming a constant ratio of energy use to total passenger-km traveled.

For automobiles we have far less data. We know the number of private and state-owned cars registered, and we know something about their characteristics (motor size, for example). We also have data on the total use of gasoline and diesel for private and military (and excluding other state-owned) vehicles, but not how this fuel is allocated. Using our international experience, we estimate a plausible figure for the distance each car travels in a year and its fuel use per $\mathrm{km}$. When these two are multiplied

6 In the energy balances, this consumption is counted under industry enterprises, not under transport. Figures are important for transport but small compared to industrial energy use. 
together and the result multiplied by the number of cars, the resulting total gasoline should be less than the figure for gasoline use derived from the Polish data. The residual represents small trucks and buses and other miscellaneous uses of gasoline, including military.

This procedure is fraught with dangers. Yet by carrying out the procedure over as many years for which there are estimates of total gasoline use and total number of cars, we rapidly converge on likely values. This is because other information or trends indicate how one or more of these hidden variables changes. For example, Table 4-2 showed that the number of cars in Poland with engine displacement under $1000 \mathrm{cc}$ grew between 1970 and 1980. As a result, average engine size declined. Accordingly, we slowly reduced the vehicle intensity of cars through the late 1980 s. After the fall of the old regime in 1989, the number of cars in Poland shot up with the wave of imports of used cars from Western Europe. These cars were latger than the small cars made in Poland, suggesting a small increase in average vehicle intensity.

Distance traveled varies, too. Typically, a state-owned car is used a great deal by those with privilege, while a private car in a country with few private cars is also driven a great deal. As the number of cars rises, distance driven per car falls, all else being equal. There were, however, significant variations in Polish car travel in the 1980s. Martial law and the near collapse of the economy in 1981 in Poland cut into activity sharply. The decrease in gasoline sales the following years indicates a fall in driving, since the vehicle intensity of the fleet is fixed in the short run. Gasoline rationing also limited driving in the 1980s, but this was ended in 1988. The spurt of private activity that followed the transition in 1989 released economic activity (that was based in part on using cars to transport goods and people around as never before), although the economic difficulties that soon followed may have limited this increase in driving.

Using these ideas, we shaped distance driven consistent with our assumptions about vehicle intensity to estimate fuel use. ${ }^{7}$ Assuming 2.25 persons per car--a not unreasonable assumption from international experience--we calculated passenger- $\mathrm{km}$ traveled in cars. This permits us to compare travel in cars with that of collective modes. We also assumed each motorcycle travels $5000 \mathrm{~km} / \mathrm{year}$, with 1.2 persons. We ignore mopeds, although one source (Skowronski, priv. communication) suggests that mopeds consume almost as much fuel as motorcycles.

Passenger-km data for intercity rail are published by GUS. The energy data published under "rail" in the detailed energy balances after 1986 include electricity for stations and fuel for heating and motor vehicles, as well as district heating and gas for buildings and even some manufacturing activity of the state railroad company. For 1987-1991, these data cover traction by fuel and track gauge. However, these energy consumption data are not split into energy for freight and for passenger trains. Polish statistics aggregate freight and passenger traffic into gross tonne-km. This aggregation is a common practice. Using the equivalency of 1 passenger- $\mathrm{km}=0.5$ tonne- $\mathrm{km}$, we split energy consumption for traction from the 1987-1991 statistics into these two modes. Using the ratio of diesel (or coal or electricity) for traction to total diesel (or total coal or electricity) consumed by the railroads, we estimated traction energy back to 1978 and split the results by the same passenger/freight breakdown, using each year's actual ratio of passenger- $\mathrm{km}$ to tonne- $\mathrm{km}$. By this method we obtained reasonable first-order estimates for energy use of

7 For private cars, we assumed $10000 \mathrm{~km} /$ year in the early $1970 \mathrm{~s}$, falling to $8500 \mathrm{~km} / \mathrm{year}$ in 1981 , and to $7000 \mathrm{~km} / \mathrm{year}$ in 1985 , then rising to $8500 \mathrm{~km} /$ year in 1989 (when gasoline became readily avalible), and finally falling back slightly as economic activity decreased (and fuel prices increased temporarily) in the following years. Combined with our assumption of a fuel intensity of $91 / 100 \mathrm{~km}$ in 1991 and $9.4 \mathrm{l} / 100 \mathrm{~km}$ in the $1970 \mathrm{~s}$ and 1980s, these calculations yield the automobile share of gasoline. We carried out this calculation for state cars using gasoline, for private cars using gasoline, and for private cars using diesel, for which the most recent years show an increase in their numbers (we assumed there were no government diesel cars). 
this important mode of travel.

For air travel (total energy use for air travel includes heating and lighting of air terminals), we used the data in the 1987-1991 statistics, noting that the 1987 value for energy use/passenger-km was unrealistically low. Unfortunately, fuels for air travel are counted under gasoline in the older statistics, so tracing energy for air travel before 1986 is not possible. Also, the fuel (and passenger-km) reported appears to cover all operations, both domestic and international, of the national carrier LOT. How the passenger-km data are divided (i.e., those of Poles or those of all passengers traveling) is not clear. Since the schedules of LOT were dominated by foreign travel and total consumption never exceeded $12 \mathrm{PJ}$, the domestic portion of air activity is probably very small. We ignore a small amount of domestic water-born travel.

\subsection{Freight}

Procedures for estimating energy use for trucks were similar to those for buses. For 1987-1991, we estimated energy use for trucking (again, state transport enterprises, ministries, and other state enterprises). From the total figures we obtained energy use per tonne-km for all public truck freight, which we used to extrapolate back to 1978 . To this we added the small residual of gasoline from private activity not counted in our estimate for automobiles. 8

We estimated energy use for the small amount of domestic shipping by calculating the ratio of fuel to tonne-km for foreign shipping and multiplying the result by tonne-km of domestic shipping.

\footnotetext{
8 Data received recently indicate that private freight hauling represented as much as $15 \%$ of total freight in $1989-91$. We do keep track of the residual of diesel fuel consumed by private vehicles (trucks and military) we obtained after estimating the use of diesel for city buses and private cars. We assumed private truckes used beteen 30 and $40 \mathrm{GJ} /$ year of fuel, estimating the share of diesel and gasoline trucks to obtain very rough measures of diesel and gasoline use for private trucking. From the vary small levels in the 1970s, these surpass a total of $10 \mathrm{PJ}$ by the late 1980s, and reach $20 \mathrm{PJ}$ in 1991.
} 


\section{Polish Final Energy Use LBL Initial Transformation}

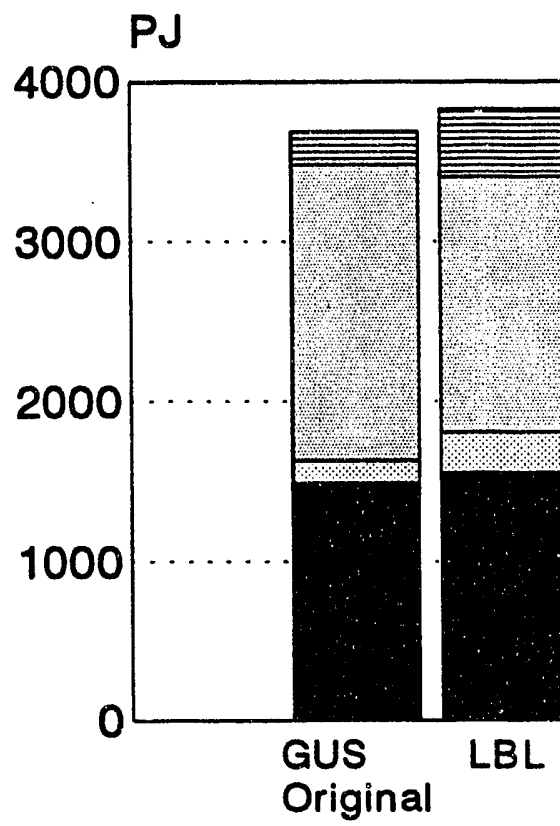

1988

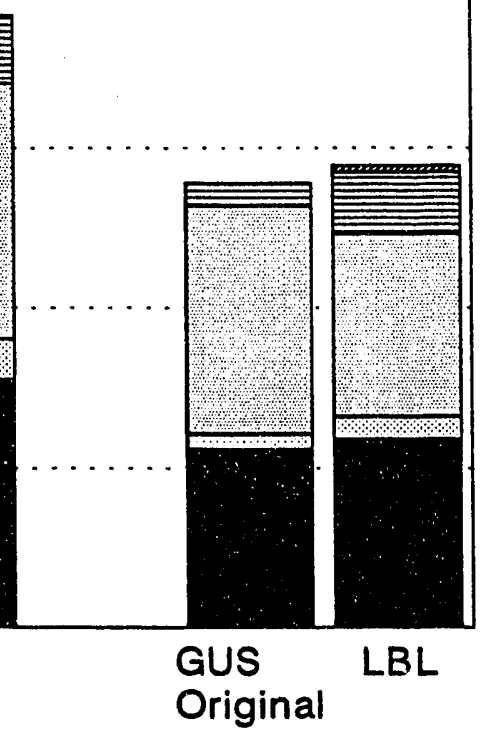

1991

Figure A-1

\section{Final Energy Uses In Poland LBL Sector Definitions}

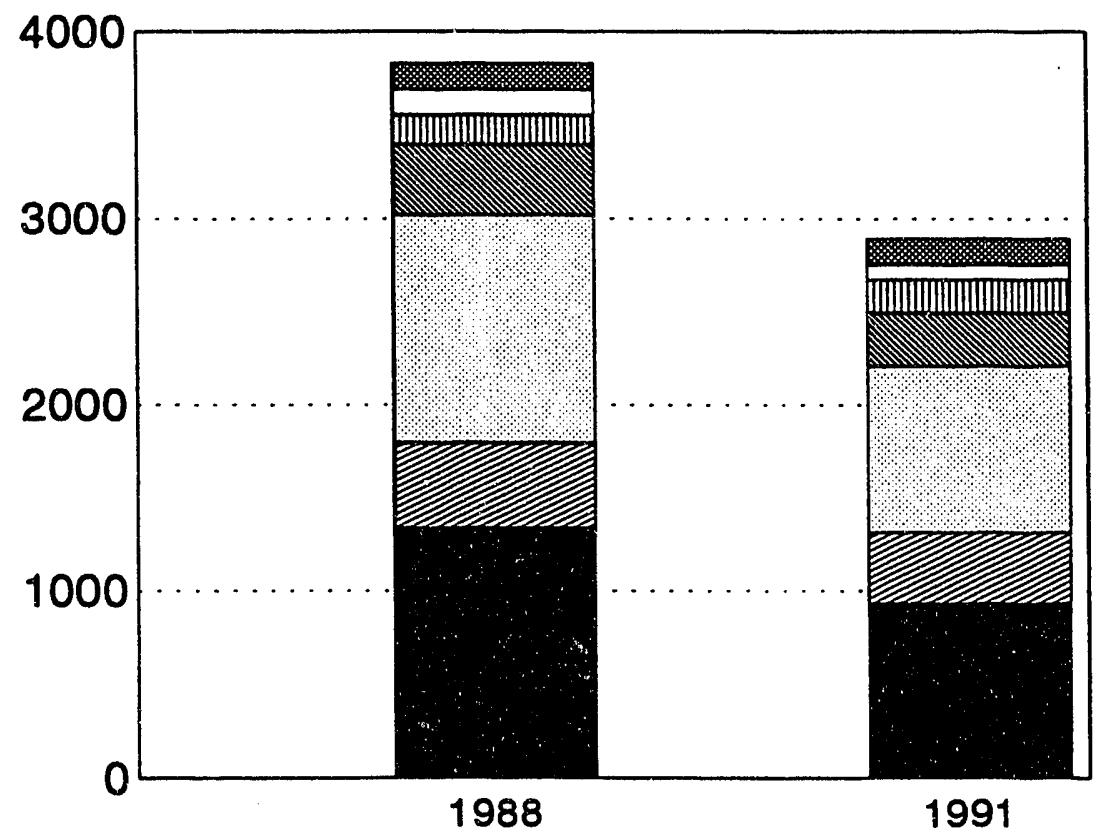

Residual

冒Transport

Other Consumers

Agric. \& Construct.

- Industry 


\section{Residential Energy Use in Poland By Fuel}

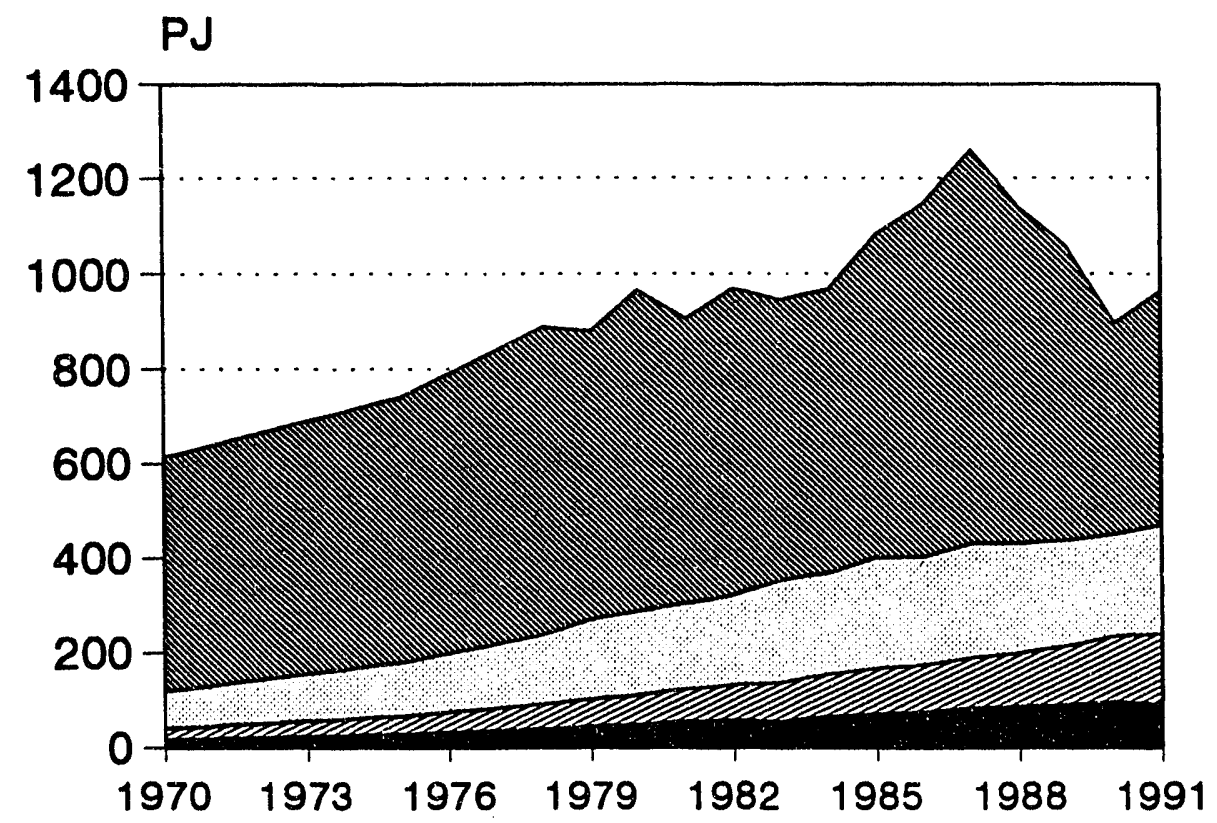

$\mathbb{N}$ Solids

$\square$ Dist Heat

Gases

Electricity

Figures not corrected for yearly variations in climate Excludes 20-40 PJ of gathered wood

Figure A-3

\section{Residential Energy Use in Poland By End Use (Estimated)}

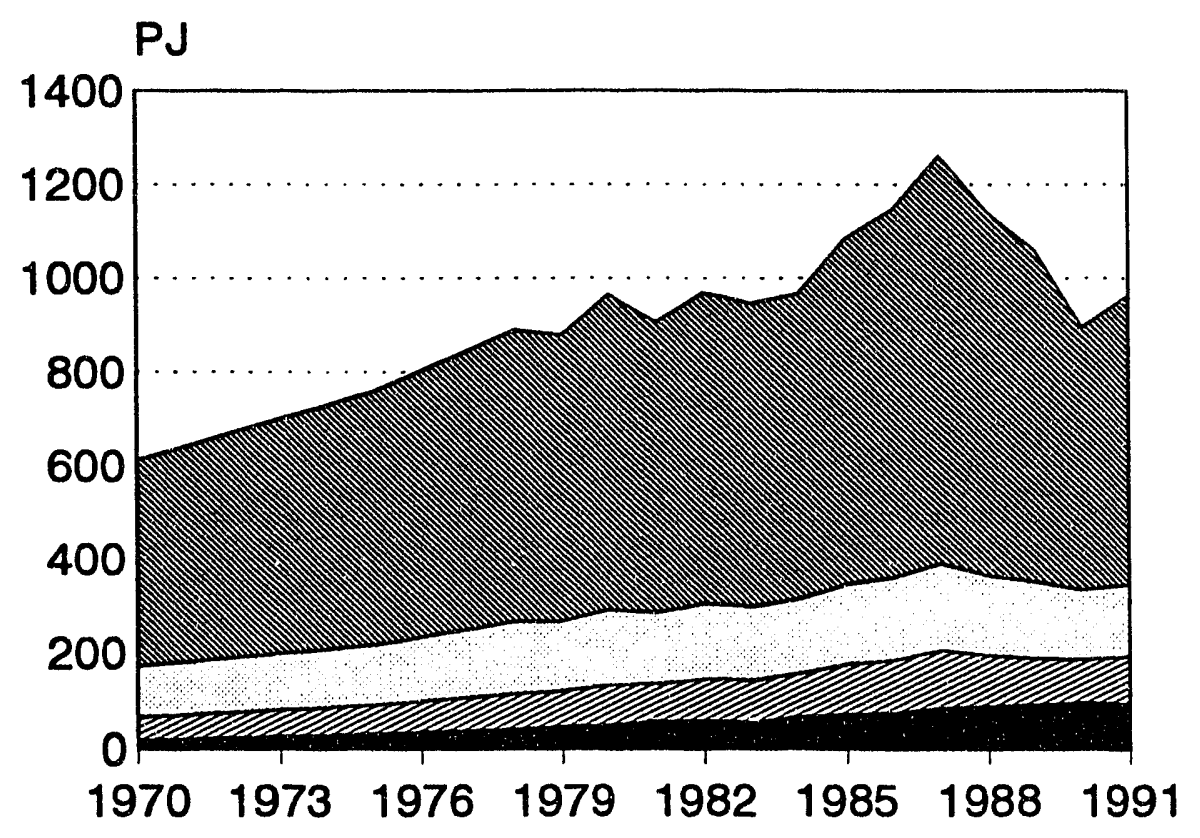

Space Heat

Cooking

Water Heat

All Electricity

Figures not corrected for yearly variations in climate

Figure A-4 


\section{Energy Use for Transportation in Poland Main Land Modes}

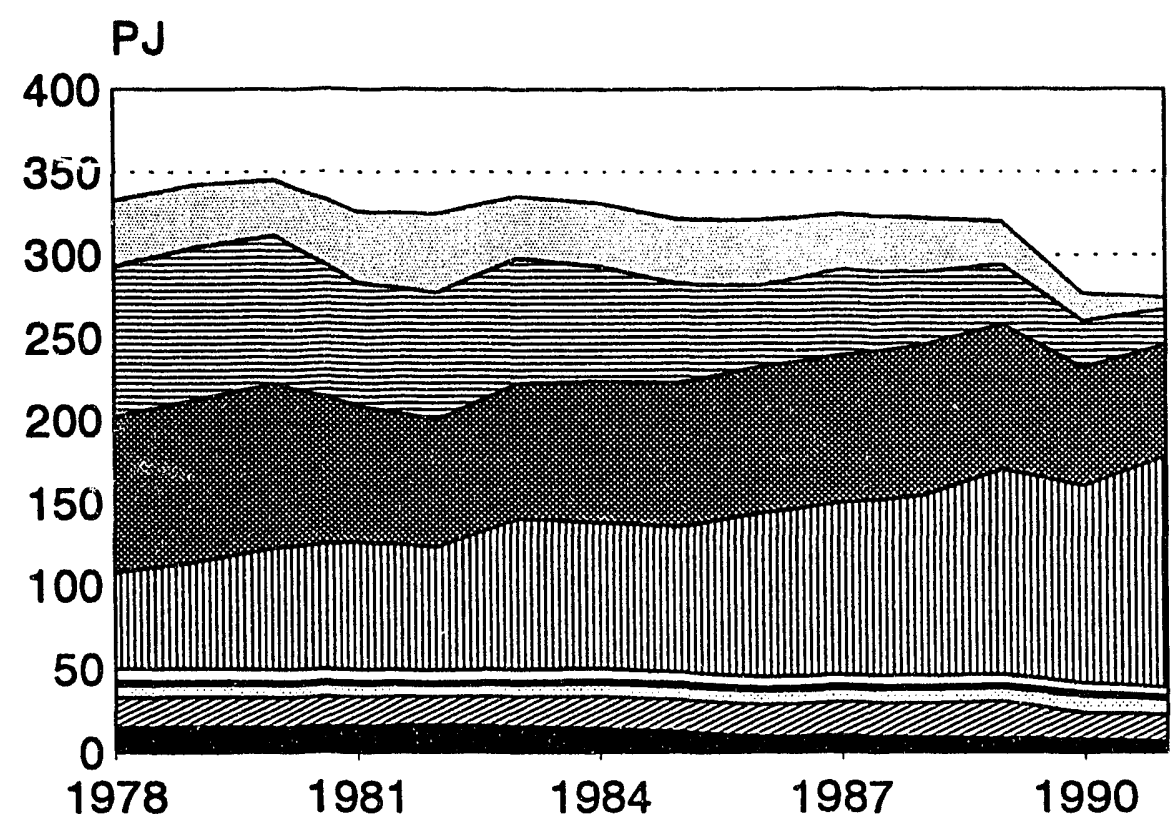

$\square$ Residual

員Rail Freight

Truck Freight

血Car

$\square$ M'Cycle

$\mathbb{N}$ Tram, Trolley

City Bus

Intercity Bus

Intercity Rail

Residual includes military, ship bunkers, int'l air, other

Figure A-5 

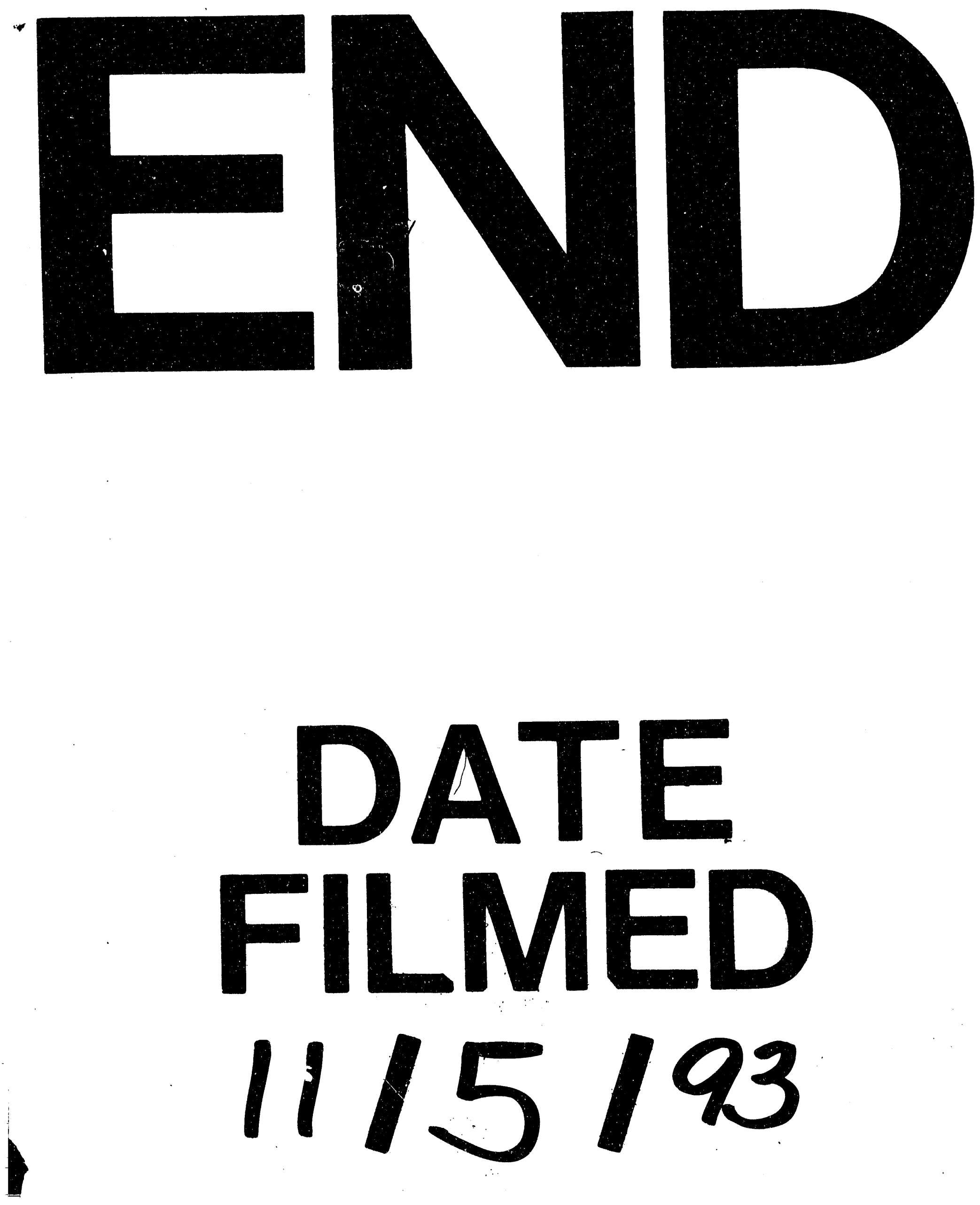
